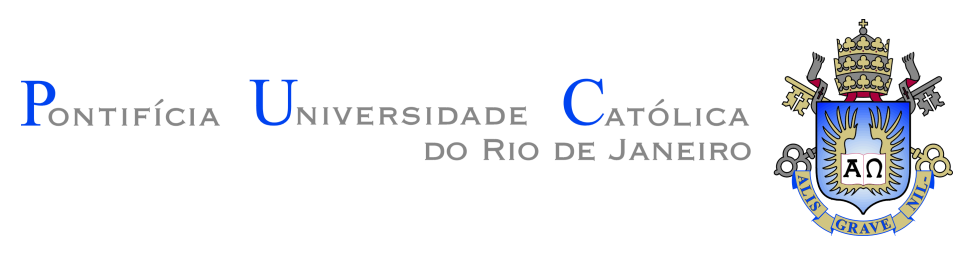

Sara Brolhato de Oliveira

Firm dynamics in Brazil: trade shocks, resource misallocation and life cycle growth

Tese de Doutorado

Thesis presented to the Programa de Pós-graduação em Economia of PUC-Rio in partial fulfillment of the requirements for the degree of Doutor em Economia.

Advisor : Prof. Juliano Junqueira Assunção

Co-advisor: Prof. Gabriel Lopes de Ulyssea 


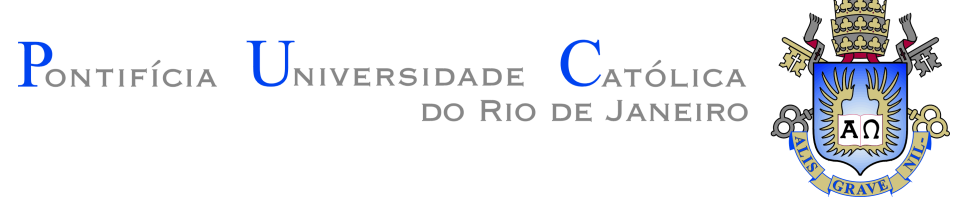

Sara Brolhato de Oliveira

\section{Firm dynamics in Brazil: trade shocks, resource misallocation and life cycle growth}

Thesis presented to the Programa de Pós-graduação em Economia of PUC-Rio in partial fulfillment of the requirements for the degree of Doutor em Economia. Approved by the undersigned Examination Committee.

Prof. Juliano Junqueira Assunção

Advisor

Departamento de Economia - PUC-Rio

Prof. Gabriel Lopes de Ulyssea

Co-advisor

Departamento de Economia - PUC-Rio

Prof. Claudio Abramovay Ferraz do Amaral

Departamento de Economia - PUC-Rio

Prof. Fábio Miessi Sanches

Departamento de Economia - PUC-Rio

Prof. Naercio Aquino Menezes Filho Instituto de Ensino e Pesquisa - Insper

Prof. Francisco Junqueira Moreira da Costa Escola Brasileira de Economia e Finanças - FGV-EPGE

Prof. Augusto Cesar Pinheiro da Silva

Vice Dean of the Centro de Ciências Sociais - PUC-Rio

Rio de Janeiro, September the 17th, 2018 
All rights reserved.

\section{Sara Brolhato de Oliveira}

Graduated in Economics from Insper in 2012.

Bibliographic data

Oliveira, Sara Brolhato de

Firm dynamics in Brazil: trade shocks, resource misallocation and life cycle growth / Sara Brolhato de Oliveira; advisor: Juliano Junqueira Assunção; co-advisor: Gabriel Lopes de Ulyssea. - Rio de janeiro: PUC-Rio, Departamento de Economia, 2018.

v., 126 f: il. color. ; $30 \mathrm{~cm}$

Tese (doutorado) - Pontifícia Universidade Católica do Rio de Janeiro, Departamento de Economia.

Inclui bibliografia

1. Economia - Teses. 2. Dinâmica de firmas;. 3. Comércio;. 4. Má alocação;. 5. Produtividade;. 6. Serviços;. I. Junqueira Assunção, Juliano. II. Lopes de Ulyssea, Gabriel. III. Pontifícia Universidade Católica do Rio de Janeiro. Departamento de Economia. IV. Título.

CDD: 330 


\section{Acknowledgments}

I would like to thank my advisors, Prof. Juliano Assunção and Prof. Gabriel Ulyssea, for their guidance, support and patience during these years. I would also like to thank my committee members, Prof. Claudio Ferraz, Prof. Fabio Miessi, Prof. Naercio Menezes and Prof. Francisco Costa, for their participation and valuable comments.

I am grateful for my family, for their unconditional love and support. I am also grateful for Guilherme, for always being by my side. This work would also not have been possible without the support and inspiration from my friends and colleagues from PUC-Rio and the Sala de Sigilo at IBGE. Finally, I thank the professors and administrative staff at PUC-Rio.

This study was financed in part by the Coordenação de Aperfeiçoamento de Pessoal de Nível Superior - Brasil (CAPES) - Finance Code 001. Financial support from CNPq and FAPERJ is also gratefully acknowledged. 


\section{Abstract}

Oliveira, Sara Brolhato de; Junqueira Assunção, Juliano (Advisor); Lopes de Ulyssea, Gabriel (Co-Advisor). Firm dynamics in Brazil: trade shocks, resource misallocation and life cycle growth. Rio de Janeiro, 2018. 126p. Tese de doutorado - Departamento de Economia, Pontifícia Universidade Católica do Rio de Janeiro.

This thesis consists of three essays on firm dynamics. The first essay evaluates the effects of supply and demand shocks on firm dynamics and selection in Brazil. We explore the fact that China's recent growth has led not only to an increase in import competition, but also to higher export demand for commodities, which is especially relevant in developing countries. We find that firms facing greater competition from Chinese imports suffer from an increase in exit probability, while firms in industries benefiting from increased export demand have lower probability of exit. In both cases, these effects are concentrated among smaller firms. In the second article, we describe the relationship between energy misallocation and resource misallocation across manufacturing industries in Brazil, and quantify the extent to which distortions affecting energy use result in output losses at the aggregate level. We find that these two measures of misallocation are positively related across industries, which suggests that energy is an important component of resource allocation efficiency. We show that reallocating resources between firms would result in substantial aggregate output gains. However, capital distortions account for most of the potential gains in manufacturing from reallocating resources between firms. The third essay compares firm life cycle dynamics in manufacturing and services, and finds that life-cycle growth is slower for service firms, even when controlling for initial size. We show that this result arises because of the selection pattern and weaker relationship between productivity and size in service industries. Finally, we assess the role of two potential explanations for these results: age-related distortions and monitoring costs.

\section{Keywords}

Firm dynamics; Trade; Misallocation; Productivity; Services; 


\section{Resumo}

Oliveira, Sara Brolhato de; Junqueira Assunção, Juliano; Lopes de Ulyssea, Gabriel. Dinâmica de firmas no Brasil: choques de comércio, má alocação de recursos e crescimento no ciclo de vida. Rio de Janeiro, 2018. 126p. Tese de Doutorado Departamento de Economia, Pontifícia Universidade Católica do Rio de Janeiro.

Esta tese contém três ensaios sobre dinâmica de firmas. O primeiro ensaio avalia os efeitos de choques de oferta e demanda sobre a dinâmica de firmas e seleção no Brasil. Exploramos o fato de que o crescimento recente da China não apenas aumentou o nível de competição via importações, mas também aumentou a demanda por exportações de bens primários, um fator especialmente relevante para países em desenvolvimento. Nossos resultados mostram que firmas afetadas pelo aumento de competição proveniente de importações chinesas apresentam um aumento na probabilidade de sair do mercado, enquanto firmas em indústrias beneficiadas pela demanda por exportações para a China têm uma menor probabilidade de saída. Em ambos os casos, esses efeitos estão concentrados em firmas com um menor número de trabalhadores. O segundo ensaio descreve a relação entre a má alocação de energia e a má alocação de recursos no setor de manufaturas brasileiro, e quantifica em que medida distorções que afetam o uso eficiente de energia resultam em perdas de produto agregado. Nós encontramos que as duas medidas de má alocação são positivamente relacionadas nos setores, sugerindo que a energia é um importante componente da eficiência alocativa de recursos. Nós mostramos que a realocação de recursos entre firmas de um mesmo setor levaria a ganhos agregados significativos. Entretanto, distorções de capital são responsáveis pela maior parte dos ganhos potenciais pela realocação de recursos. O terceiro ensaio compara a dinâmica do ciclo de vida em manufaturas e serviços e encontra que o crescimento ao longo do ciclo de vida é menor para firmas do setor de serviços, mesmo controlando pelo seu tamanho inicial. Nós mostramos que esse menor crescimento ocorre devido ao padrão de seleção e à fraca relação existente entre produtividade e tamanho das firmas em serviços. Finalmente, nós investigamos o papel de duas possíveis explicações para os resultados encontrados: distorções relacionadas ao ciclo de vida e custos de monitoramento.

\section{Palavras-chave}

Dinâmica de firmas; Comércio; Má alocação; Produtividade; Serviços; 


\section{Table of contents}

1 Trade shocks and firm dynamics: the role of demand 11

1.1 Introduction 11

$\begin{array}{ll}1.2 & \text { Empirical Strategy }\end{array}$

$\begin{array}{lll}1.3 & \text { Data and descriptive statistics } & 19\end{array}$

$\begin{array}{lll}1.3 .1 & \text { Data } & 19\end{array}$

$\begin{array}{ll}\text { 1.3.2 Descriptive statistics } & 22\end{array}$

$\begin{array}{lll}1.4 & \text { Results } & 27\end{array}$

$\begin{array}{lll}1.4 .1 & \text { Exit } & 27\end{array}$

$\begin{array}{lll}1.4 .2 & \text { Entry } & 38\end{array}$

1.4.3 Employment 44

$\begin{array}{ll}1.5 \text { Conclusions } & 46\end{array}$

2 Energy and Misallocation: Evidence from Brazil $\quad 49$

2.1 Introduction 49

2.2 Data $\quad 52$

2.3 Energy misallocation 54

$\begin{array}{lll}2.4 & \text { Theoretical framework } & 62\end{array}$

$\begin{array}{lll}2.5 & \text { Potential gains } & 66\end{array}$

$\begin{array}{lll}2.6 & \text { Robustness checks } & 73\end{array}$

$\begin{array}{lll}2.7 & \text { Conclusions } & 74\end{array}$

3 Firm life cycle and the service sector $\quad 76$

$\begin{array}{ll}3.1 & \text { Introduction } \\ 3.2 & 76\end{array}$

$\begin{array}{lll}3.2 & \text { Firm life cycle dynamics } & 78\end{array}$

$\begin{array}{ll}\text { 3.2.1 Firm life cycle determinants } & 80\end{array}$

3.3 Data 83

$\begin{array}{lll}3.4 & \text { Employment over life cycle } & 85\end{array}$

$\begin{array}{ll}3.5 \text { Selection } & 93\end{array}$

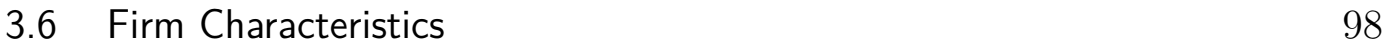

3.6.1 Productivity and employment 98

$\begin{array}{ll}\text { 3.6.2 Monitoring costs } & 105\end{array}$

$\begin{array}{lll}3.7 & \text { Conclusions } & 108\end{array}$

$\begin{array}{lll}\text { A } & \text { Chapter } 1 \text { - Additional results } & 118\end{array}$

B Chapter 2 - Additional results 121

$\begin{array}{ll}\text { C Chapter 3 - Additional results } & 125\end{array}$ 


\section{List of figures}

$\begin{array}{lll}\text { Figure 1.1 Shares of Chinese imports and exports. } & 12\end{array}$

Figure 1.2 Histogram of import and export shares. 22

$\begin{array}{lll}\text { Figure } 1.3 & \text { Import and export shares. } & 23\end{array}$

Figure 1.4 Exposure to trade and instrumental variables. 24

Figure 2.1 Aggregate energy efficiency and aggregate productivity 55

$\begin{array}{lll}\text { Figure 2.2 Aggregate misallocation } & 58\end{array}$

Figure 2.3 Resource and energy misallocation at the industry level $\quad 59$

$\begin{array}{lll}\text { Figure 2.4 Distribution of TFPQ } & 68\end{array}$

$\begin{array}{lll}\text { Figure 2.5 Distribution of TFPR } & 69\end{array}$

$\begin{array}{lll}\text { Figure 3.1 } & \text { Employment over the life cycle } & 87\end{array}$

$\begin{array}{lll}\text { Figure 3.2 } & \text { Employment growth of surviving firms } & 92\end{array}$

$\begin{array}{lll}\text { Figure 3.3 } & \text { Entry and exit rates by year } & 93\end{array}$

$\begin{array}{lll}\text { Figure 3.4 Exit rates by age } & 95\end{array}$

$\begin{array}{lll}\text { Figure 3.5 } & \text { Average productivity by employment groups } & 102\end{array}$

Figure 3.6 Average productivity by employment groups (Emp>1) 102

$\begin{array}{lll}\text { Figure A.1 Value of Chinese imports and exports. } & 118\end{array}$

$\begin{array}{lll}\text { Figure B.1 Resource and energy misallocation (TFP) } & 123\end{array}$

$\begin{array}{lll}\text { Figure B.2 Resource and energy misallocation (TFPQ) } & 124\end{array}$

Figure B.3 Resource and energy misallocation (2015) 124

$\begin{array}{lll}\text { Figure C.1 Employment over the life cycle } & 126\end{array}$ 


\section{List of tables}

$\begin{array}{lll}\text { Table } 1.1 & \text { Middle-Income countries. } & 19\end{array}$

Table 1.2 Descriptive statistics. 25

Table 1.3 Exposure to Chinese trade. 26

Table 1.4 Industries most affected by Chinese imports and exports. $\quad 26$

Table 1.5 First stage estimation $\quad 31$

Table 1.6 Plant exit. $\quad 32$

Table 1.7 Plant exit - additional controls. 33

Table 1.8 Plant exit - size groups. 36

Table 1.9 Plant exit - skill and exporting status. $\quad 37$

Table 1.10 Plant entry. $\quad 40$

Table 1.11 Plant entry - additional controls. 41

Table 1.12 Plant entry - size groups. 42

Table 1.13 Plant entry - skill and exporting status. 43

Table 1.14 First stage - employment. 44

Table 1.15 Employment. $\quad 46$

Table 1.16 Employment - size groups. 48

Table 2.1 Number of observations in PIA 54

$\begin{array}{lll}\text { Table 2.2 Energy efficiency and productivity decomposition } & 57\end{array}$

$\begin{array}{lll}\text { Table 2.3 Energy efficiency } & 60\end{array}$

Table 2.4 Productivity 61

Table 2.5 Dispersion of TFPQ $\quad 69$

Table 2.6 Dispersion of TFPR $\quad 70$

Table 2.7 $\quad$ Potential TFP gains (\%) 71

Table 2.8 Highest and lowest gains from equalizing TFPR (\%) 72

Table 2.9 TFP gains from equalizing TFPR within industries (\%) 73

Table 2.10 TFP gains from equalizing TFPR within industries (\%) 74

Table 3.1 Tertiary sector shares of employment and GDP (2010) 79

Table 3.2 Brazilian sector employment share in $2012(\%) \quad 79$

Table 3.3 Average firm size by year $\quad 86$

Table 3.4 Regressions of size by age $\quad 91$

$\begin{array}{lll}\text { Table 3.5 } & \text { Exit probability } & 97\end{array}$

Table 3.6 Descriptive Statistics $\quad 99$

$\begin{array}{lll}\text { Table 3.7 } & \text { Productivity and firm size } & 101\end{array}$

Table 3.8 Productivity, firm size and age 104

$\begin{array}{lll}\text { Table } 3.9 & \text { Fraction of family members } & 107\end{array}$

Table 3.10 Employment and family members 108

Table A.1 Employment - OLS. 119

Table A.2 Employment - size groups OLS. 120

$\begin{array}{lll}\text { Table B.1 Three-digit CNAE industries } & 121\end{array}$

Table C.1 Number of observations (RAIS) 125

$\begin{array}{lll}\text { Table C.2 Service sector composition } & 125\end{array}$ 
Table C.3 Number of observations (PIA and PAS) 


\section{Trade shocks and firm dynamics: the role of demand}

\section{1 Introduction}

The main goal of this paper is to provide new estimates of the effects of demand and supply shocks on plant entry, exit and employment. I use variation in the degree of exposure to China's supply of imports and demand for exports in Brazil, while relying on an instrumental variables strategy. To provide additional insight on the mechanisms driving plant dynamics, I explore how results are heterogeneous in plant characteristics.

In the last two decades, China's fast economic growth has significantly increased international trade flows. The resulting increase in competition stemming from Chinese imports has been widely used to estimate the effects of a supply shock on various outcomes (David et al., 2013; Costa et al., 2016; Bloom et al., 2016), including firm dynamics and selection (Bernard et al., 2006a; Iacovone et al., 2013). These studies have mostly focused on countries with a unilateral increase in trade with China. However, China's growth has also led to an increase in its demand for primary products, to be used as raw materials in the production of manufactured goods. The rise in Chinese demand is especially relevant in developing countries specializing in the production of agricultural and mining products. This phenomenon characterizes a demand shock which has not yet been explored in the firm dynamics literature.

Brazil is a developing country that was significantly affected by the surge in Chinese demand for raw goods. As described in Costa et al. (2016), Figure 1.1 plots, for the period of 1997 to 2012, the evolution of Brazil's share of imports from China, relative to total imports, and the share of exports to China, relative to total exports. From this figure, we can infer that there was a dramatical rise in Brazilian exports to China, and that trade between Brazil and China increased in a bilateral way. The increase in China's share of imports by Brazil was symmetrical to the increase in Brazilian export shares to China. Moreover, the initial surge in international trade due to China's growth takes 
Figure 1.1: Shares of Chinese imports and exports.

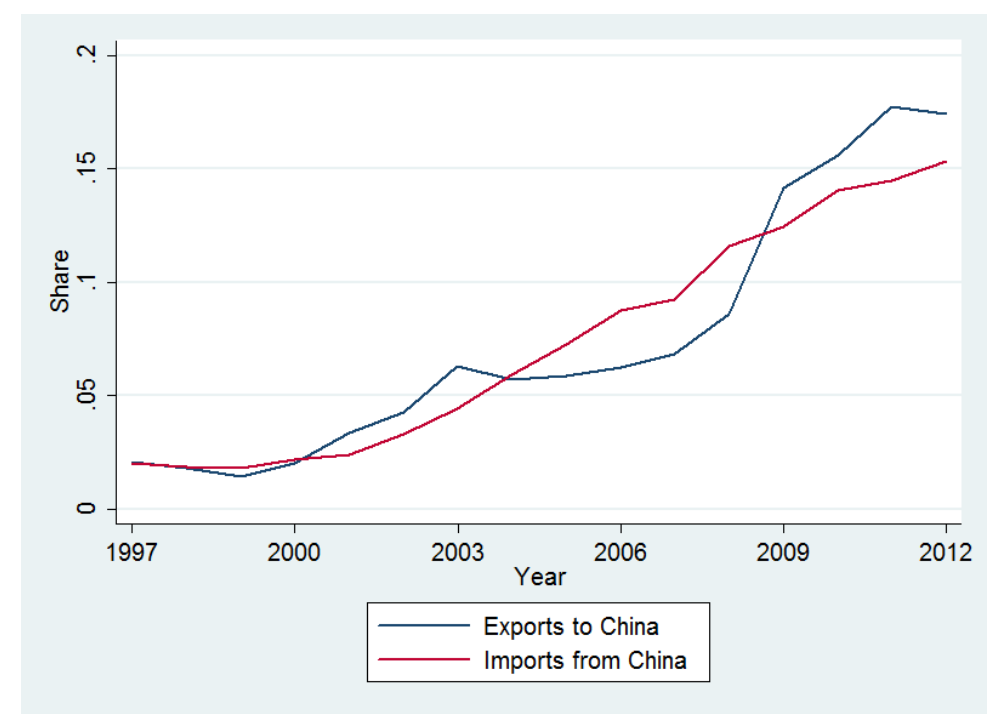

Notes: The Figure shows the evolution of the share of imports from China and the share of exports to China in Brazil, from 1997 to 2012. Trade data is from UN Comtrade.

place around the year 2000. Figure A.1 in the Appendix confirms that the increase in trade with China is not altered when I plot the evolution of traded values instead of trade shares.

The steep rise in trade between China and Brazil depicted in Figure 1.1 suggests that export demand played a relevant part in many Brazilian industries over this period. The point is that Brazilian industries are likely to provide enough variation in exposure to Chinese exports, so it is possible to estimate its effects on plant dynamics and selection.

A primary contribution of this paper is to determine not only the effect of supply shocks from China's growth on plant dynamics, but also the effect of demand shocks resulting from the rise in Chinese demand for primary products. I also test how these effects are heterogeneous in plant characteristics. I consider heterogeneity based on plant size and skill intensity, as in previous studies, and provide new evidence on how trade shocks differently affect exporting and non-exporting plants. I define industry exposure to Chinese import supply as the share of total Brazilian imports that come from China, as introduced by Bernard et al. (2006a). This measure focuses on trade partners rather than on values, and consequently captures the pattern of specialization that arises from trade based on countries' comparative advantages. I use this measure and expand its definition to compute a measure of exposure to Chinese demand for exports as well.

To estimate the effects of import and export shocks resulting from international trade, I use the instrumental variables strategy from David et al. (2013). I use exposure to Chinese trade in other middle-income countries as 
instruments, to avoid endogeneity due to unobservable factors that simultaneously affect exposure to China and plant outcomes.

I use plant-level data from Brazil covering the period from 2002 to 2012. The dataset contains self-reported plant and worker characteristics, and it includes all formal Brazilian plants. Another contribution is the estimation of trade shock effects from data including the whole size distribution of plants. To the best of my knowledge, all previous papers addressing the role of supply shocks on firm dynamics use datasets in which the sample is restricted to firms above certain employment or revenue thresholds, for example, Bernard et al. (2006a) and Iacovone et al. (2013). The inclusion of smaller plants is important in this context, first because there is empirical evidence that these plants suffer most of the negative effects from trade shocks (Head and Ries, 1999), but also because of their relevance in the economy. In the database used for this chapter, plants with up to 10 workers account for $80 \%$ of all formal plants. Additionally, the dataset encompasses not only manufacturing plants, as is usually the case, but also plants operating in agricultural and mining industries.

I find evidence that firm selection is the most relevant channel of adjustment to supply and demand shocks. Exposure to import competition from China is positively related to plant exit probability, while exposure to the demand of exports to China is negatively related to plant exit at the industry level. These results are heterogeneous in plant characteristics, and in both cases effects are concentrated among small plants. I do not find that increased demand for exports lead to higher entry in affected industries. One possible explanation for this result is that increased Chinese demand benefits industries with high entry and fixed costs of operation, such as mining, preventing the entry of new firms. Finally, I find no link between exposure to Chinese trade and plant employment.

This work is related to the literature estimating the empirical effects of trade shocks on firm performance ${ }^{1}$. Trade liberalization increases competition and selection, which results in a higher exit propability for both exporting and non-exporting firms (Muendler, 2004). However, this effects is not homogeneous across firms. Firm survival following a trade liberalization is closely related to productivity ${ }^{2}$ (Eslava et al., 2013; Bernard et al., 2006b; Pavcnik, 2002). Decreases in trade costs also facilitate access to cheaper and higher quality inputs from abroad. Higher competition, along with access to better

\footnotetext{
${ }^{1}$ For a literature review of the effects specific to international trade with China, see Autor et al. (2016)

${ }^{2}$ For a comprehensive review on the effects of trade in the context of heterogeneous firms, see Bernard et al. (2012).
} 
inputs, lead to higher productivity growth in surviving firms (Eslava et al., 2013; Bernard et al., 2006b; Muendler, 2004) and encourages technology upgrading (Bustos, 2011).

The goal of this chapter is similar to that of Bernard et al. (2006a) and Iacovone et al. (2013), which measure the impact of an increase in competition due to import penetration on the reallocation of resources across plants and industries in the United States and Mexico, respectively. Both papers find that exposure to imports in manufacturing industries is positively related to plant exit and negatively related to growth, measured by either employment or sales. Within industries, resources are reallocated towards more capital intensive, skill intensive, and productive plants. They also present evidence that plants adjust their product mix in response to competition shocks. I contribute to this literature by addressing simultaneously the effects of supply and demand shocks from China on plant outcomes. Furthermore, I use data including the whole size distribution of firms. This is an important contribution, since small firms are more likely to exit following increased competition from trade (Head and Ries, 1999).

The first paper to consider export demand shocks resulting from Chinese growth is Costa et al. (2016). They exploit the rise in bilateral trade between Brazil and China to estimate the effects of supply and demand shocks from trade in local labor markets in Brazil. Their results indicate that wage growth was low in labor markets most exposed to import competition, while it was high in markets benefiting from demand of exports to China. I explore the duality of demand and supply shocks, but focus instead on industry-level exposure and its effects on plant outcomes.

Bernard et al. (2007) provides theoretical predictions of firm dynamics following trade liberalization in the presence of comparative advantages. They develop a model with heterogeneous firms and industries differing in factor intensities. Countries are different in their initial relative endowments, which results in distinct comparative advantages between countries. Following trade liberalization, increased export opportunities result in higher entry, competition and selection in all industries, but these effects are stronger in comparative advantage industries. The main difference between this model and the context of my analysis is that the model assumes instant transition from autarky to costly trade, so that export opportunities increase both in comparative advantage and disadvantage industries. In the context of this chapter, China's increased supply of manufacturing goods and demand for commodities results in higher export opportunities in comparative advantage industries in Brazil, but lower in comparative disadvantage industries. The 
model's predictions concerning increased export opportunities are used as a benchmark to interpret my results.

The remainder of the chapter is organized as follows. In Section 1.2, I explain the empirical strategy guiding the analysis, along with what results can be expected from previous empirical and theoretical evidence. Section 1.3 describes the data sources and reports descriptive statistics. The empirical results are presented in Section 1.4. Section 1.5 concludes.

\section{2}

\section{Empirical Strategy}

In this section, I describe the measures of import supply and export demand used in this chapter and explain the empirical strategy used to estimate the effects of exposure to trade with China on plant selection, entry and employment.

I define the industry measure of import competition from Chinese trade as the share of Chinese imports relative to total imports in Brazil. This measure was first introduced by Bernard et al. (2006a), but later adopted by a number of studies such as Broda and Romalis (2009); Bloom et al. (2016); Iacovone et al. (2013). The intuition for using this measure comes from the HeckscherOhlin model, and it reflects the pattern of specialization that arises from trade, given countries' comparative advantages. I use an analogous definition for the measure of export demand, equal to the share of exports to China relative to total Brazilian exports. In the context of Brazil and China, we would expect that an increase in trade levels between the two countries would reallocate resources away from Brazilian industries facing intense Chinese competition (manufacturing), and towards industries where Chinese demand has played an important role (agriculture and mining industries).

Amiti and Freund (2008) shows that the increase in Chinese products exported to other countries is driven mainly by high export growth of existing products, instead of an increase in the variety of products exported by China. Additionally, Iacovone et al. (2013) presents evidence that the increased participation of China in international trade performed by developing countries do not simply reflect a change in the composition of trade with other countries. Rather, increases in the share of trade with China seem to capture most of the increase in trade observed in these countries, taking into consideration countries' comparative advantages.

Exposure to Chinese imports in industry $s$ and year $t, \mathrm{IS}_{\mathrm{st}}$, is thus given by the value of Brazilian imports from China divided by the overall value of 
Brazilian imports in that particular industry and year, which I refer to as import shares from China:

$$
I S_{s t}=\left(\frac{\text { Imports from China }_{\text {st }}}{\text { Total Imports }}\right)
$$

Symmetrically, the exposure to Chinese exports in industry $s$ and year $t, \mathrm{XS}_{\mathrm{st}}$, or export shares to China, is given by:

$$
X S_{s t}=\left(\frac{\text { Exports to } \text { China }_{s t}}{\text { Total Exports }}\right)
$$

The main outcomes of interest in this chapter are plant exit, entry and employment. Exit for plant $i$ operating in industry $s$ in year $t+1$ is defined as:

$$
\text { Exit }_{i s, t+1}= \begin{cases}1, & \text { if plant } i \text { exits the market in year } t+1 \\ 0, & \text { in all years prior to exit. }\end{cases}
$$

To infer the effect of supply and demand shocks originating in China on the probability of plant exit, I estimate the following regression:

$$
\operatorname{Pr}\left(E_{x i t} i_{i s, t+1}\right)=\Phi\left(\beta_{1} I S_{s, t-1}+\beta_{2} X S_{s, t-1}+\alpha V_{i s t}+\gamma X_{i s t}+\delta_{s}+\delta_{t}+\delta_{s} \cdot t+\epsilon_{i s=t}\right)
$$

I assume that exit probability for plant $i$ in industry $s$ and year $t+1$ is a function of the measures of exposure to Chinese trade in the previous year, $\mathrm{IS}_{\mathrm{s}, \mathrm{t}-1}$ and $\mathrm{XS}_{\mathrm{s}, \mathrm{t}-1}$, a set of plant and industry characteristics, $\mathrm{X}_{\mathrm{ist}}$, and interactions between each of the measures of exposure to China with a subset of plant characteristics, $\mathrm{V}_{\text {ist }}$. These interactions reveal how exposure to trade heterogeneously affect plants within industries. I consider how effects vary with plant size, skill intensity and exporting status. The set of plant characteristics considered in the regression are plant size, age, skill intensity and exporting status. Industry specific control variables include the Herfindahl index of market concentration and entry rates in year $t$.

I include year fixed effects, $\delta_{t}$, to control for macroeconomic events affecting selection in all industries simultaneously, and industry fixed effects, $\delta_{s}$, to control for unobserved industry fixed characteristics that affect exit rates, such as entry costs and fixed costs of operation. The presence of industry fixed effects implies that the effect of trade shocks on plant selection is identified 
from variation over time in industry exposure to Chinese trade. I also introduce industry specific time trends, $\delta_{s} \cdot t$, to allow for the possibility that factors other than exposure to China linearly affect exit rates. These trends would capture, for example, global supply or demand changes at the industry level.

$\mathrm{X}_{\text {ist }}$ is a set of plant and industry characteristics that are believed to affect plant exit. It is important to control for plant characteristics in the analysis, since there is vast theoretical and empirical evidence that exit rates are negatively correlated with plant characteristics such as age and size (Dunne et al., 1988; Evans, 1987; Hopenhayn, 1992). Moreover, entry and exit rates are known to be contemporaneously related (Dunne et al., 1988, 1989). One concern, however, is that plant and industry characteristics included in the regression are themselves affected by industry exposure to China. For example, Bernard et al. (2006a) shows that import competition stemming from Chinese imports affects plant employment, while Bas (2012) presents evidence that the probability of becoming an exporter increases following trade liberalization. This situation is known as the "bad controls" problem, described by Angrist and Pischke (2009), in which the inclusion of control variables is undesirable even if they help to predict the outcome of interest. For that reason, the baseline specification only includes age as a control variable. Later, I also include other plant and industry characteristics to the regression to test if results are robust to these additional controls.

An estimated $\beta_{1}>0$ implies that increased import competition leads to higher selection. Theoretical predictions in Bernard et al. (2007) imply that increased export opportunities would boost entry and result in higher competition and selection. This prediction would be reflected in an estimated $\beta_{2}>0$. As to the heterogeneity of results, coefficients for the interactions between IS or XS and plant characteristics inform how selection affects different plants within industries, according to their size, skill intensity and exporting status.

Next, I run similar regressions with entry as the dependent variable, to understand how industry exposure to China affects entry rates and newborn plant characteristics:

$$
\operatorname{Pr}\left(\text { Entry }_{i s, t}\right)=\Phi\left(\beta_{1} I S_{s, t-1}+\beta_{2} X S_{s, t-1}+\alpha V_{i s t}+\gamma X_{i s t}+\delta_{s}+\delta_{t}+\delta_{s} \cdot t+\epsilon_{i s t}\right)
$$

This regression includes the same set of controls as described in the regression for plant exit. In the case of plant entry, we also control for industry exit rates. 
In the context of plant entry, Bernard et al. (2007) predicts that a raise in competition resulting from Chinese imports would decrease expected profits and, consequently, lower entry. This prediction is equivalent to $\beta_{1}<0$ in the regression. Symmetrically, a raise in export demand would increase expected profits and result in higher entry rates, $\beta_{2}>0$.

Lastly, I assess the effects of increased exposure to Chinese trade on the employment of surviving plants.

$$
\log \left(\text { Employment }_{i, t+1}\right)=\beta_{1} I S_{s, t-1}+\beta_{2} X S_{s, t-1}+\alpha V_{i s t}+\gamma X_{i s t}+\delta_{i}+\delta_{t}+\delta_{s} \cdot t+\epsilon_{i s t}
$$

Again, this regression includes the set of plant characteristics, and the Herfindahl index of market concentration is included as an industry level control variable. When analyzing employment, I include plant fixed effects to control for constant individual unobserved characteristics that influence the level of employment. Consequently, the identification of the effect of supply and demand shocks in this case comes from variation in employment within plants, as their exposure to trade varies over the years.

The predictions in Iacovone et al. (2013) point to a decrease in firm size, measured by sales, following increased competition from Chinese imported products in Mexico. This effect would be reflected in an estimated $\beta_{1}<0$. They also report that negative effects from Chinese competition are less felt by larger firms.

One issue with this estimation strategy is that the measure of import and export shares do not exogenously reflect Chinese supply and demand. There might be factors originating in Brazil that affect plant outcomes and are simultaneously related with the intensity of trade performed with China. For example, there might be supply shocks in Brazil, due to technological innovations or government policies, or changes in the pattern of demand, due to aggregate income or a change in preferences, that are correlated with exposure to Chinese trade. If that is the case, then the error term $\epsilon_{i s t}$ will be correlated with the shares of Chinese imports and exports, and I will not be able to correctly identify the causal effect of supply and demand shocks on plant outcomes.

To deal with this issue, I instrument the share of imports from China and the share of exports to China with the corresponding exposure to Chinese trade from middle-income countries other than Brazil. The intuition from using exposure to China in countries similar to Brazil as instruments is that I expect it to reflect the general trend in trade levels that is due to increased Chinese 
supply and demand for goods. At the same time, the exclusion restriction for these instruments requires that neither the share of imports from China or the share of exports to China from middle-income countries are related to Brazilian plant outcomes. Table 1.1 reports the 54 middle-income countries considered in the construction of instrumental variables.

The instrumental variables strategy of using other countries' exposure to trade is first introduced by David et al. (2013), but is widely adopted in studies regarding the growth of China in international trade, such as Iacovone et al. (2013) and Costa et al. (2016). Denoting middle-income countries by $j$, the instruments ivIS $\mathrm{st}_{\text {st }}$ and iv $\mathrm{XS}_{\mathrm{st}}$ are defined as:

$$
\begin{aligned}
& i v I S_{s t}=\left(\frac{\sum_{j} \text { Imports from China }_{s j t}}{\sum_{j} \text { Total Imports } \text { Imjt }}\right) \\
& i v X S_{s t}=\left(\frac{\sum_{j} \text { Exports to China }}{s j t}\right)
\end{aligned}
$$

Table 1.1: Middle-Income countries.

\begin{tabular}{llll}
\hline Albania & Cuba & Lybia & Samoa \\
Algeria & Dominica & Macedonia & Serbia \\
American Samoa & Dominican Rep. & Malaysia & South Africa \\
Argentina & Equatorial Guinea & Maldives & St. Lucia \\
Azerbaijan & Ecuador & Marshall Islands & St. Vincent \\
Belarus & Fiji & Mauritius & Suriname \\
Belize & Gabon & Mexico & Thailand \\
Bosnia-Herzegovina & Grenada & Montenegro & Tonga \\
Botswana & Guyana & Namibia & Turkey \\
Bulgaria & Iran & Panama & Turkmenistan \\
China & Iraq & Paraguay & Tuvalu \\
Colombia & Jamaica & Peru & Venezuela \\
Costa Rica & Kazakhstan & Romania & \\
Croatia & Lebanon & Russia & \\
\hline
\end{tabular}

Notes: Countries defined as middle-income countries according to the World Bank for the year of 2016. This definition includes countries whose Gross National Income (GNI) ranges from US\$3,956 to US\$12,235.

\section{3}

\section{Data and descriptive statistics}

\subsection{1}

Data

The primary source of data for this study is the Relação Anual de Informações Sociais (RAIS), an annual panel at the plant level collected by the Brazilian Ministry of Labor. I use data from 2002 to 2012. This dataset 
contains plant-level characteristics, but also individual information on all its registered workers. RAIS is a census of all Brazilian formal firms, which means my analysis includes the whole size-distribution of plants. Including plants of all sizes is especially important when studying the effects of trade on firm selection, because exit rates are decreasing in firm size, and smaller firms are likely to be more affected by an increase in competition from foreign trade (Head and Ries, 1999).

The variables I use from RAIS are plant size, industry at the three-digit CNAE 95 level, workers' educational attainment, and workers' hiring year. I measure plant size as the number of workers on December $31^{\text {st }}$. Plants' skill intensity is defined as the percentage of workers with at least a high school level degree. The Herfindahl index of industry concentration is defined as the sum of squared market shares in an industry. However, since RAIS does not provide any information on plants' sales or added value, I compute market shares based on employment.

To understand how supply and demand shocks differently affect plants, I define three groups based on plants' size that will be included in the regressions. Small plants are defined as employing up to 9 workers. Medium plants employ between 10 and 49 workers, and large plants employ 50 or more workers.

Although there is no reported entry year in the database, I take advantage of the data's census sample and panel structure to infer plant entry from workers' hiring year. I assume that entry year for each plant is given by the oldest hiring year reported, considering all its workers during the sample period. Plant age is computed based on its entry year, considering that newborn plants are one year old. This strategy is also adopted by Cabral and Mata (2003).

This entry year proxy has an advantage over the common practice of inferring entry by registering when plants first appear on the database. It allows me to estimate entry year for all establishments in the data, not only those whose entry occur after 2002. However, the disadvantage of introducing this entry proxy is that it inevitably introduces measurement error, since worker turnover will imply that the proxy underestimates plants' true age.

I define that plant $i$ exits the market in period $t+1$ if it is contained in RAIS with positive employment up to period $t$, but is not included in any subsequent years. Due to either measurement error of firms failing to report information to the Labor Ministry, some plants go missing from the data, but are still present in RAIS in later years. In these cases, I do not consider plants as exiting the market. This happens to about $12 \%$ of plants in the database, and in most cases plants go missing for a single year before being included 
back in the data.

I define industry exit rates as the ratio of exiting plants from period $t$ to $t+1$ to the total number of operating plants in period $t$. However, I do not consider exit rates for 2011, since measurement error for the exit variable in increased in the last year of the sample. Entry rates in period $t$ are computed as the ratio of newborn plants in period $t$ to market size, which is given by the maximum number of plants operating in a single year, during the period covered by the sample.

One limitation from using the RAIS dataset is that it does not include informal firms, as well as information on informal workers employed by formal firms. For that reason, our results might not perfectly represent the population of Brazilian firms, as both the extensive and intensive margins of informality are relevant in developing countries (La Porta et al., 2008; De Paula and Scheinkman, 2010; Ulyssea, 2018). Ulyssea (2018) describes that, in Brazil, nearly two thirds of firms are informal, and that informality accounts for $40 \%$ of GDP and 35\% of employment. This limitation is likely to disproportionately affect data for the agricultural sector, since it presents a high fraction of informal and self-employed workers (Blanchflower, 2000).

Trade data are obtained from the United Nations Commodity Trade Statistics database (UN Comtrade), gathered by the DESA/UNSD, which contains detailed annual information on bilateral trade at the product level for over 160 countries or areas. I use data from 2002 to 2012.

To obtain trade data attributable to each industry in RAIS, I create a concordance between products at the six-digit Harmonized System product classification and CNAE 95 activities at the four-digit level. Whenever it is not possible to associate products to a single four-digit activity in CNAE, I use three-digit industry levels. The final trade dataset comprises 231 industries, 207 at the CNAE four-digit level, and 24 at the three-digit level.

To identify middle-income countries in the trade data, I use the definition of income groups provided by the World Bank for 2016. According to this definition, there are 54 middle income countries which are listed in Table 1.1, with Gross National Income (GNI) ranging from US\$3,956 to US\$12,235.

I use publicly available data from Secretaria de Comércio Exterior (SECEX) to identify the exporting status of Brazilian plants from 2002 to 2012. I define an exporting dummy variable equal to one for all plants reporting positive exports in a given year ${ }^{3}$. The dummy is equal to zero for all nonexporters.

${ }^{3}$ The exact value exported by each plant is not reported in the data due to confidentiality. 
I drop plants that switch between industries at least once during the sample period. These plants account for $16 \%$ of observations in the data. The resulting dataset contains 1,025,411 unique plants and 4,328,725 observations throughout the sample period.

\subsection{2 \\ Descriptive statistics}

First, Figure 1.2 describes the distribution of exposure to trade by presenting a histogram of import shares from China, on the left side, and of export shares to China, on the right, pooling all industries and years in the sample ${ }^{4}$. We can see that there is variation in the degree of exposure to Chinese trade across industries for both measures. Even though there are industries that heavily rely on either Chinese imports or exports, the majority of industries are little or not exposed at all.

Figure 1.2: Histogram of import and export shares.

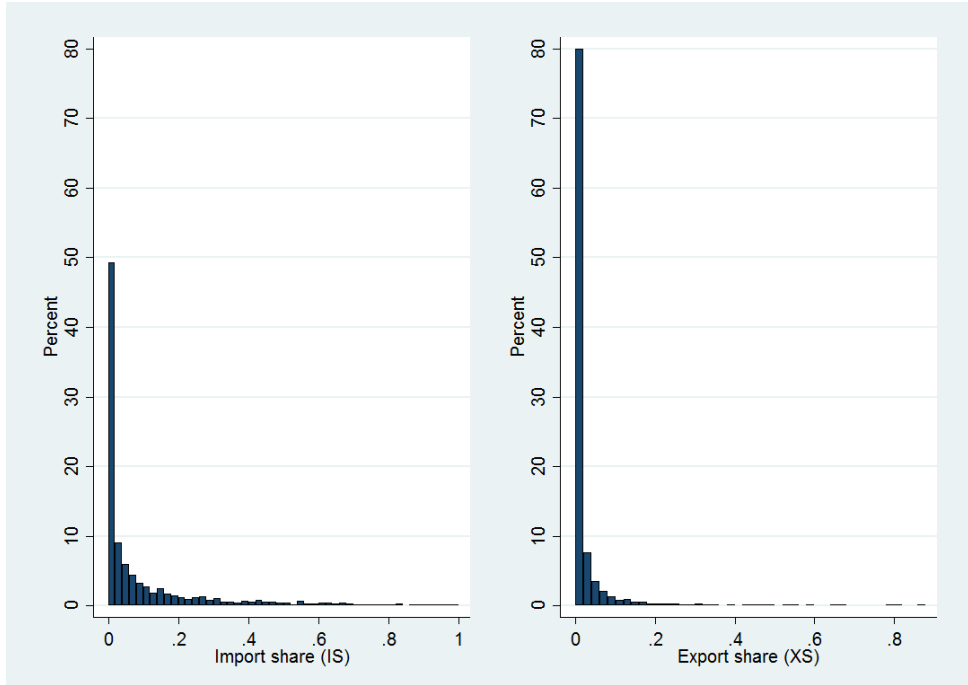

Notes: Histogram of the measures of import shares from China (left panel), and of export shares to China (right panel). Data from UN Comtrade.

We now explore the relationship between exposure to Chinese imports and exports, which is plotted in Figure 1.3 at the industry level. Industries with a high share of imports from China usually have a low share of exports to China, and vice versa. This negative relationship is consistent with a specific trade pattern arising due to countries' comparative advantages. We expect Brazil to produce and export land intensive products, such as agricultural and mineral goods, while China specializes in labor intensive manufacturing

\footnotetext{
${ }^{4}$ The shape of the distributions are unchanged when plotted separately for each year.
} 
goods. One interesting conclusion from this figure is that there is more variation in import shares from China than in export shares to China. This difference suggests that Chinese import penetration is more generalized across industries, while Chinese demand for Brazilian exports is more concentrated in a few specific products.

Figure 1.3: Import and export shares.

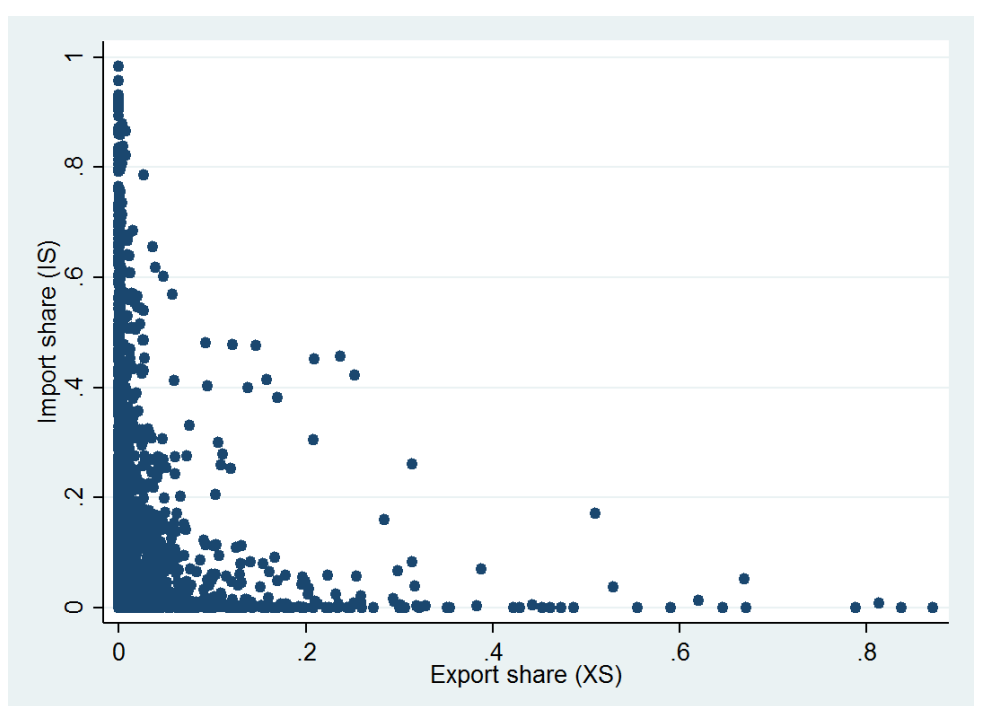

Notes: Scatter plot of measures of import shares from China and exports shares to China at the industry level. Data is from UN Comtrade.

Figure 1.4 plots the relationship between each measure of exposure to Chinese trade, $\mathrm{IS}_{\mathrm{st}}$ and $\mathrm{XS}_{\mathrm{st}}$, and their respective instrumental variables, ivIS $_{\text {st }}$ and ivXS $\mathrm{st}_{\text {st }}$, along with a linear fit. The correlation between $\mathrm{IS}_{\mathrm{st}}$ and its instrument is 0.79 , while for $\mathrm{XS}_{\mathrm{st}}$ it is 0.59 . There is a positive relationship between both measures of exposure to trade and their instruments. However, from the scatter plot, we see that this relationship is stronger for $\mathrm{IS}_{\mathrm{st}}$ and iviS $S_{\text {st }}$, and observations are more concentrated along the trend, while for $\mathrm{XS}_{\mathrm{st}}$ and ivXS $\mathrm{Xt}_{\mathrm{st}}$, observations are more dispersed and the positive relationship is less clear.

The reason why export shares in middle-income countries are not so strongly related to Brazilian levels could be that, while imports from China tend to be similar in all countries, products exported to China are more dependent on each countries' relative endowments. So even if middle-income countries' exports consist basically of primary products, Brazil's exports will be concentrated on soy and iron, for example, while other countries will specialize in other specific goods. Since the instrument is an average of shares from all countries, it will still be a good approximation for the increase in Chinese demand for Brazilian products. 
Another possibility is that export shares to China are less related to instruments specifically because of supply or demand shocks that lead to the endogeneity of $\mathrm{XS}_{\mathrm{st}}$. This could happen, for example, if the government provides benefits and incentives specific to exporting industries. In this case, the differences between $\mathrm{XS}_{\mathrm{st}}$ and ivXS $\mathrm{S}_{\mathrm{st}}$ reflect these unobserved factors.

Figure 1.4: Exposure to trade and instrumental variables.

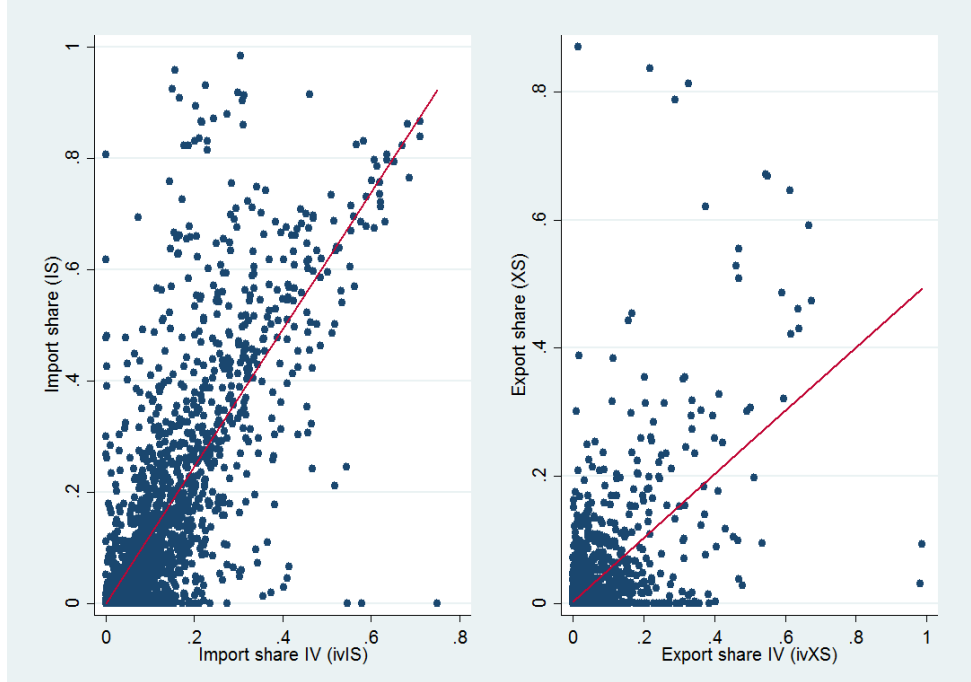

Notes: Dispersion between imports shares from China and instrumental variables (right panel), and export shares to China and instrumental variables (left panel). Data from UN Comtrade.

Table 1.2 provides descriptive statistics for the treatment variables, instruments, outcomes and control variables. I compute means and standard deviations for all the sample and also separately for the agricultural, mining and manufacturing sectors, to provide an intuition on how exposure to China and plant outcomes are distributed across activities.

The overall exposure to Chinese imports is higher in magnitude than the exposure to Chinese exports, 0.11 on average versus 0.02 , and its values are also more dispersed across the distribution. This fact is consistent with the distribution of exposure to trade presented in Figures 1.2 and 1.3, which we implies that $\mathrm{XS}_{\mathrm{st}}$ is concentrated in zero and very low levels of exposure. However, by looking at the nature of trade with China across sectors, we realize that imports to China are concentrated in the manufacturing and mining sectors, while exports to China affect mainly mining sectors, but are also relevant in agriculture. Once more, these facts illustrate how the trade pattern between China and Brazil reflect countries' comparative advantages. As for the instruments adopted in this study, ivIS $\mathrm{s}_{\mathrm{s}, \mathrm{t}-1}$ and $\mathrm{ivXS}_{\mathrm{s}, \mathrm{t}-1}$, their average magnitudes seem to adequately capture the exposure to Chinese trade, both at the aggregate and sectoral levels. 
Entry rates, exit rates, and age distribution seems very similar across sectors. One important difference between sectors is the scale of operation. In agriculture, average plant employment is equal to 7.96 , while it is 20.62 in mining and 24.17 in manufacturing. Higher average sizes along with higher industry concentration, as measured by the Herfindahl index, suggests higher entry and fixed costs in mining and manufacturing relative to agriculture.

Only $2 \%$ of Brazilian plants export part of their production to other countries. However, in agriculture, exporters represent less than $1 \%$ of operating plants. This number is higher in manufacturing, where exporting plants represent $4 \%$ of the total. Manufacturing is also the most skilled sector, and plants employ on average $40 \%$ of workers with at least a high school degree. This statistic is equal to $26 \%$ in mining and $12 \%$ in agriculture.

We can think of Brazilian plants in the sample as belonging to one of three groups: one consisting of plants exposed only to either imports or exports, another of plants exposed simultaneously to both Chinese imports and exports, and the last one, of plants with zero imports and exports to China. Table 1.3 presents the average and standard deviation of exposure to trade, $\mathrm{IS}_{\mathrm{s}, \mathrm{t}-1}$ and $\mathrm{XS}_{\mathrm{s}, \mathrm{t}-1}$ separately for the two first groups.

Industries exposed to either imports or exports can be considered core activities of Chinese or Brazilian comparative advantages. We see that, overall, the magnitude of exposure to China is higher in these industries, even when we split the sample into agriculture, mining and manufacturing.

Table 1.2: Descriptive statistics.

\begin{tabular}{|c|c|c|c|c|c|c|c|c|}
\hline & \multicolumn{2}{|c|}{ Total } & \multicolumn{2}{|c|}{ Agriculture } & \multicolumn{2}{|c|}{ Mining } & \multicolumn{2}{|c|}{ Manufacturing } \\
\hline & Mean & S.D. & Mean & S.D. & Mean & S.D. & Mean & S.D. \\
\hline $\mathrm{IS}_{\mathrm{s}, \mathrm{t}-1}$ & 0.11 & 0.18 & 0.02 & 0.06 & 0.09 & 0.24 & 0.12 & 0.18 \\
\hline $\mathrm{XS}_{\mathrm{s}, \mathrm{t}-1}$ & 0.02 & 0.06 & 0.04 & 0.13 & 0.10 & 0.15 & 0.01 & 0.05 \\
\hline $\operatorname{ivIS}_{\mathrm{s}, \mathrm{t}-1}$ & 0.09 & 0.11 & 0.04 & 0.05 & 0.04 & 0.08 & 0.10 & 0.12 \\
\hline $\operatorname{ivXS}_{\mathrm{s}, \mathrm{t}-1}$ & 0.03 & 0.08 & 0.07 & 0.15 & 0.14 & 0.20 & 0.02 & 0.05 \\
\hline Exit $_{i t}$ & 0.13 & 0.34 & 0.15 & 0.36 & 0.12 & 0.32 & 0.13 & 0.33 \\
\hline Entry $_{i t}$ & 0.12 & 0.33 & 0.12 & 0.33 & 0.11 & 0.31 & 0.12 & 0.33 \\
\hline Employment $_{i t}$ & 15.39 & 106.73 & 7.96 & 52.79 & 20.62 & 175.67 & 24.17 & 140.29 \\
\hline Herfindahl $_{\text {st }}$ & 0.05 & 0.09 & 0.005 & 0.004 & 0.12 & 0.12 & 0.06 & 0.10 \\
\hline Age $_{i t}$ & 7.75 & 7.05 & 7.99 & 7.58 & 8.89 & 7.88 & 8.02 & 7.33 \\
\hline Skill $_{\text {it }}$ & 0.26 & 0.35 & 0.12 & 0.28 & 0.26 & 0.33 & 0.40 & 0.36 \\
\hline Exporting status $_{i t}$ & 0.02 & 0.15 & 0.002 & 0.05 & 0.02 & 0.15 & 0.04 & 0.21 \\
\hline Small $_{\text {it }}$ & 0.78 & 0.41 & 0.87 & 0.32 & 0.67 & 0.46 & 0.66 & 0.47 \\
\hline Medium $_{\text {it }}$ & 0.17 & 0.37 & 0.10 & 0.30 & 0.27 & 0.44 & 0.26 & 0.43 \\
\hline Large $_{i t}$ & 0.04 & 0.20 & 0.01 & 0.13 & 0.05 & 0.22 & 0.07 & 0.26 \\
\hline
\end{tabular}

Notes: This table presents descriptive statistics for the main variables used in the analysis from 2002 to 2012. Statistics for import and export shares and instruments are calculated at the industry level. Statistics for plant characteristics are calculated at the plant level. Means and standard deviations are calculated for the whole sample and separately for agriculture, mining and manufacturing sectors. Data is from UN Comtrade and RAIS. 
Table 1.3: Exposure to Chinese trade.

\begin{tabular}{|c|c|c|c|c|c|c|c|c|}
\hline \multicolumn{9}{|c|}{ Panel A: Industries affected by either IS or XS } \\
\hline & \multicolumn{2}{|c|}{ Total } & \multicolumn{2}{|c|}{ Agriculture } & \multicolumn{2}{|c|}{ Mining } & \multicolumn{2}{|c|}{ Manufacturing } \\
\hline & Mean & S.D. & Mean & S.D. & Mean & S.D. & Mean & S.D. \\
\hline $\mathrm{IS}_{\mathrm{s}, \mathrm{t}-1}$ & 0.15 & 0.24 & 0.00 & 0.00 & 0.37 & 0.42 & 0.14 & 0.22 \\
\hline $\mathrm{XS}_{\mathrm{s}, \mathrm{t}-1}$ & 0.08 & 0.16 & 0.11 & 0.18 & 0.21 & 0.16 & 0.04 & 0.15 \\
\hline \multicolumn{9}{|c|}{ Panel B: Industries affected by both IS and XS } \\
\hline & \multicolumn{2}{|c|}{ Total } & \multicolumn{2}{|c|}{ Agriculture } & \multicolumn{2}{|c|}{ Mining } & \multicolumn{2}{|c|}{ Manufacturing } \\
\hline & Mean & S.D. & Mean & S.D. & Mean & S.D. & Mean & S.D. \\
\hline $\mathrm{IS}_{\mathrm{s}, \mathrm{t}-1}$ & 0.13 & 0.18 & 0.06 & 0.09 & 0.04 & 0.08 & 0.14 & 0.18 \\
\hline $\mathrm{XS}_{\mathrm{s}, \mathrm{t}-1}$ & 0.02 & 0.05 & 0.02 & 0.09 & 0.15 & 0.15 & 0.02 & 0.04 \\
\hline
\end{tabular}

Notes: This table presents descriptive statistics of import and export shares at the industry level. Means and standard deviations are calculated for the whole sample and separately for agriculture, mining and manufacturing sectors. The top panel includes industries that have either IS $=0$ or $\mathrm{XS}=0$. The bottom panel includes industries with nonzero values for both IS and XS. Data is from UN Comtrade.

Table 1.4: Industries most affected by Chinese imports and exports.

\begin{tabular}{cl}
\hline$\Delta \mathrm{IS}_{\mathrm{s}}$ & Industry \\
\hline 0.85 & Manufacture of structural non-refractory clay and ceramic products \\
0.74 & Manufacture of knitted and crocheted fabrics and articles \\
0.69 & Spinning and weaving of man-made textile fibres \\
0.67 & Spinning and weaving of cotton fibres \\
0.64 & Manufacture of steam generators, except central heating and vehicles \\
0.63 & Spinning and weaving of natural textile fibres \\
0.60 & Manufacture of materials and closures for sewing \\
0.56 & Farming of other animals \\
0.54 & Manufacture of railway and tramway locomotives and rolling stock \\
0.54 & Manufacture of unit air-conditioners \\
\hline$\Delta \mathrm{XS}$ & Industry \\
\hline 0.86 & Manufacture of soap and detergents \\
0.49 & Growing of soya beans \\
0.34 & Growing of cotton \\
0.31 & Mining of iron ores \\
0.30 & Mining of manganese ores \\
0.24 & Quarrying of stone, sand and clay \\
0.23 & Manufacture of machine-tools \\
0.19 & Manufacture of other electrical equipments \\
0.18 & Extraction of crude petroleum and natural gas \\
0.17 & Tanning and dressing of leather \\
\hline
\end{tabular}

Notes: The table shows the 10 industries with highest variation in share of imports from China (top panel) and share of exports to China (bottom panel), from 2002 to 2012. Data is from UN Comtrade.

So far, we have looked at how exposure to China is distributed in the cross-section. Still, the empirical strategy used in this work requires that there is intertemporal variation in exposure to trade within industries. To illustrate how Brazilian industries were affected by the growth in Chinese supply and demand for products, Table 1.4 presents the 10 industries with 
highest variation in import shares from China, at the top panel, and in export shares to China, at the bottom panel, from 2002 to 2012.

As expected, we can see that industries most affected by import penetration from China generally belong to the manufacturing sector. The only exception is "Farming of other animals". From this list of top ten industries affected by Chinese import competition, six are related to textiles.

On the other hand, the growth in Chinese demand for Brazilian products is concentrated on primary goods. From these ten industries, two belong to agriculture, the growing of soya beans and cotton, and four are classified as mining and extractive industries, of which the mining of iron ores had the highest increase. This trade pattern is consistent with China's and Brazil's comparative advantages in labor and land, respectively.

Some industries most affected by Chinese demand do not reflect the intuition behind trade patterns. We must keep in mind that import and export shares are not a precise measure of exposure to Chinese growth if industries have low import or export levels, resulting in measurement error in the sample. Since in these cases exposure to trade will be overestimated, it will bias downwards the estimates of trade shocks on plant selection and employment. My results can then be interpreted as a lower bound of the true impact from trade shocks.

\section{4}

Results

\subsection{1 \\ Exit}

In this subsection, I provide the main results regarding the effects of increased supply of imports from China and demand for exports to China on industry selection. The results refer to the estimation of regression 13 assuming a linear probability model for plant exit. I include year and industry fixed effects to control for aggregate and industry factors affecting exit probability. In all regressions, robust standard errors are clustered at the four-digit industry level.

Before moving on to the main results, Table 1.5 presents the results from the first stage estimation. The first two columns of Panel A show first stage regressions for the treatment variables, the share of Chinese imports and exports, with year and three-digit industry fixed effects. Under this specification, the first stage is valid for both $\mathrm{IS}_{\mathrm{s}, \mathrm{t}-1}$ and $\mathrm{XS}_{\mathrm{s}, \mathrm{t}-1}$. Columns three 
and four of Panel A show that the instruments remain valid when I add industry-specific trends to the specification.

Panel B presents the first stage estimation using instruments $\mathrm{IS}_{\mathrm{s}, \mathrm{t}-1}$ and $\mathrm{XS}_{\mathrm{s}, \mathrm{t}-1}$, but includes industry fixed effects and trends at the most disaggregated, four-digit, level. The first two columns illustrate that the instruments are valid under this specification, although the F-statistic decreases for both treatment variables. The last two columns show that, in the presence of industry fixed effects and trends at this disaggregated level, we cannot reject the null hypothesis that instruments are weak. It seems that the simultaneous inclusion of industry fixed effects and trends leaves no extra explanatory power to instrumental variables in the first stage.

The results from Table 1.5 illustrate that there is a trade-off between the validity of the instruments and the inclusion of industry trends at a disaggregated level. In the context of exposure to Chinese trade and firm outcomes, however, the inclusion of industry-specific trends is essential, since they control for simultaneous policies and events that influence the trajectory of firm outcomes during the sampled period. Hence, I provide results on plant exit from the estimation including three-digit industry fixed effects and trends. One consequence from this decision is that the identification of effects of exposure to trade on selection comes from cross-sectional variation within three-digit industries, in addition to variation in the degree of exposure to trade over time.

Table 1.6 reports the main results concerning the relationship between exposure to imports from China and to exports to China and plant exit probability. Kleibergen-Paap F-statistics for weak instruments are included in each column. The first column estimates exit probability by OLS, while the second column uses an instrumental variables strategy estimation. The results from column two point to a positive and significant effect of import competition, measured by the share of imports from China, IS, on plant exit probability. This result is consistent with previous evidence on Chinese import penetration leading to increased competition and selection, such as Bernard et al. (2006a), Iacovone et al. (2013), and Bernard et al. (2004).

The coefficient associated with export shares to China, on the other hand, is negative and statistically significant, meaning that Brazilian plants in comparative advantage industries benefit from the increased demand for their products, resulting in a lower probability of exit. This effect suggests that competition and selection is negatively related to export opportunities, contrary to theoretical predictions in Bernard et al. (2007).

Columns three and four of Table 1.6 confirm that results are not altered 
by the inclusion of plant age as a control variable. I find a negative relationship between exit probability and plant age, as predicted by firm life-cycle models (Hopenhayn, 1992). One interesting point is that the magnitude of the effects for both IS and XS is higher in the instrumental variables specification than in OLS specification. Although it is generally expected that IV coefficients will decrease relative to OLS estimates, the nature of the correlations in this specific context might lead to this result. David et al. (2013) suggests that there might be unobservable Brazilian demand shocks which simultaneously affect plant outcomes and the intensity of trade between Brazil and China, resulting in a stronger relationship estimated via OLS.

Using the estimates in column (4), I find that a 20 percentage point increase in industry import shares from China (one standard deviation) for the mean plant is associated with an increase of 2.6 percentage points in exit probability. For the average plant, this effect is equivalent to a $13.8 \%$ increase in exit probability. Bernard et al. (2006a) reports that Chinese competition leads to an increase of $8.1 \%$ in exit probability for plants in the U.S. However, the variation in industry exposure to Chinese imports is much lower in their sample. Considering an increase of 8 percentage points (one standard deviation) in Chinese export shares, there is a 1.9 percentage point reduction in exit probability. For the average plant, this magnitude is equivalent to a $7.2 \%$ decrease in exit probability.

The baseline specification does not include additional independent variables due to the "bad controls" problem pointed by Angrist and Pischke (2009). Still, it is important to test if my results could be driven by omitted plant characteristics that affect exit probabilities. The first two columns in Table 1.7 present how results change when I add industry-level variables to the baseline specification. Columns three and four additionally include plant characteristics as independent variables. As an attempt to minimize the potential influence of supply and demand shocks from China on plant and industry characteristics, columns five to eight reproduce these results keeping all control variables fixed at their initial levels for all plants.

The results from Table 1.7 confirm that my main results are qualitatively unchanged by adding more independent variables to control for plant and industry characteristics. The effect of exposure to Chinese imports in column four turns statistically to zero, even if the coefficient remains positive. All other IV estimates, however, remain with the same sign as in the baseline results. Consistent with the life cycle literature, both employment and age have a negative effect on the probability of exit (Dunne et al., 1988, 1989). The coefficients for entry rates are positive in all specifications, confirming the con- 
temporaneous relationship between entry and exit rates. I also find that higher industry concentration is positively associated with the likelihood of exit, but this effect is statistically insignificant in three out of four specifications. Lastly, I find that exporting status and skill intensity are positively related to plant exit. 
Table 1.5: First stage estimation

\begin{tabular}{|c|c|c|c|c|}
\hline \multicolumn{5}{|c|}{ Panel A: three-digit industries } \\
\hline & $(1)$ & $(2)$ & $(3)$ & $(4)$ \\
\hline & $\mathrm{IS}_{\mathrm{s}, \mathrm{t}-1}$ & $\mathrm{XS}_{\mathrm{s}, \mathrm{t}-1}$ & $\mathrm{IS}_{\mathrm{s}, \mathrm{t}-1}$ & $\mathrm{XS}_{\mathrm{s}, \mathrm{t}-1}$ \\
\hline $\operatorname{ivIS}_{\mathrm{s}, \mathrm{t}-1}$ & $\begin{array}{c}0.867^{* * *} \\
(0.150)\end{array}$ & $\begin{array}{c}-0.054^{*} \\
(0.029)\end{array}$ & $\begin{array}{c}0.760^{* * *} \\
(0.158)\end{array}$ & $\begin{array}{c}-0.054 \\
(0.035)\end{array}$ \\
\hline $\operatorname{ivXS}_{\mathrm{s}, \mathrm{t}-1}$ & $\begin{array}{c}0.005 \\
(0.018)\end{array}$ & $\begin{array}{c}0.673^{* * *} \\
(0.036)\end{array}$ & $\begin{array}{c}0.009 \\
(0.013)\end{array}$ & $\begin{array}{c}0.679^{* * *} \\
(0.028)\end{array}$ \\
\hline Year fixed effects & Yes & Yes & Yes & Yes \\
\hline Industry fixed effects & Yes & Yes & Yes & Yes \\
\hline Industry trends & No & No & Yes & Yes \\
\hline Observations & $3,331,254$ & $3,331,254$ & $3,331,254$ & $3,331,254$ \\
\hline R-squared & 0.890 & 0.857 & 0.929 & 0.883 \\
\hline F statistic & 19.22 & 256.5 & 17.44 & 295.7 \\
\hline \multicolumn{5}{|c|}{ Panel B: four-digit industries } \\
\hline & $(1)$ & $(2)$ & $(3)$ & $(4)$ \\
\hline & $\mathrm{IS}_{\mathrm{s}, \mathrm{t}-1}$ & $\mathrm{XS}_{\mathrm{s}, \mathrm{t}-1}$ & $\mathrm{IS}_{\mathrm{s}, \mathrm{t}-1}$ & $\mathrm{XS}_{\mathrm{s}, \mathrm{t}-1}$ \\
\hline $\operatorname{ivIS}_{\mathrm{s}, \mathrm{t}-1}$ & $\begin{array}{c}0.870^{* * *} \\
(0.264)\end{array}$ & $\begin{array}{l}-0.0589 \\
(0.0453)\end{array}$ & $\begin{array}{c}0.483^{* *} \\
(0.200)\end{array}$ & $\begin{array}{c}0.00650 \\
(0.0266)\end{array}$ \\
\hline $\operatorname{ivXS}_{\mathrm{s}, \mathrm{t}-1}$ & $\begin{array}{l}-0.144^{*} \\
(0.0772)\end{array}$ & $\begin{array}{c}0.260 * * * \\
(0.0614)\end{array}$ & $\begin{array}{l}-0.0771 \\
(0.0857)\end{array}$ & $\begin{array}{l}-0.0549 \\
(0.0849)\end{array}$ \\
\hline Year fixed effects & Yes & Yes & Yes & Yes \\
\hline Industry fixed effects & Yes & Yes & Yes & Yes \\
\hline Industry trends & No & No & Yes & Yes \\
\hline Observations & $3,331,254$ & $3,331,254$ & $3,331,254$ & $3,331,254$ \\
\hline R-squared & 0.919 & 0.904 & 0.975 & 0.973 \\
\hline F statistic & 8.501 & 12.05 & 3.313 & 0.295 \\
\hline
\end{tabular}

Notes: First stage regressions for plant exit. Dependent variables are the measures of exposure to China, IS and XS, regressed on instrumental variables. Panel A includes three-digit industry fixed effects and trends. Panel B includes four-digit industry fixed effects and trends. Instruments for IS and XS are import shares from China and export shares to China computed for 54 middle-income countries. Data from UN Comtrade and RAIS. Regressions cover data from 2002 to 2010. Robust standard errors clustered at the four-digit industry level in parenthesis. Significance levels: $* 10 \%$, ** $5 \%$, *** $1 \%$. 
Table 1.6: Plant exit.

\begin{tabular}{|c|c|c|c|c|}
\hline & \multicolumn{2}{|c|}{ Exit $_{\text {is }, t+1}$} & \multicolumn{2}{|c|}{ Exit $_{\text {is }, t+1}$} \\
\hline & $(1)$ & $(2)$ & $(3)$ & $(4)$ \\
\hline & OLS & IV & OLS & IV \\
\hline \multirow[t]{2}{*}{$\mathrm{IS}_{\mathrm{s}, \mathrm{t}-1}$} & 0.026 & $0.159^{* *}$ & 0.021 & $0.130^{* *}$ \\
\hline & $(0.026)$ & $(0.071)$ & $(0.022)$ & $(0.064)$ \\
\hline \multirow[t]{2}{*}{$\mathrm{XS}_{\mathrm{s}, \mathrm{t}-1}$} & $-0.219^{* * *}$ & $-0.242^{* * *}$ & $-0.217^{* * *}$ & $-0.248^{* * *}$ \\
\hline & $(0.026)$ & $(0.035)$ & $(0.029)$ & $(0.034)$ \\
\hline \multirow[t]{2}{*}{$\mathrm{Age}_{\text {ist }}$} & & & $-0.005^{* * *}$ & $-0.005^{* * *}$ \\
\hline & & & $(0.0002)$ & $(0.0002)$ \\
\hline Year fixed effects & Yes & Yes & Yes & Yes \\
\hline Industry fixed effects & Yes & Yes & Yes & Yes \\
\hline Industry trends & Yes & Yes & Yes & Yes \\
\hline Observations & $3,331,254$ & $3,331,254$ & $3,331,245$ & $3,331,245$ \\
\hline $\mathrm{R}$-squared & 0.013 & 0.012 & 0.023 & 0.023 \\
\hline $1^{\text {st }}$ stage KP statistic & & 11.39 & & 11.38 \\
\hline
\end{tabular}

Notes: Plant-level OLS and IV regressions. Dependent variable is a dummy variable indicating plant exit. In IV regressions, I instrument IS and XS with import shares from China and export shares to China computed for 54 middleincome countries. Regressions cover data from 2002 to 2010. Data from UN Comtrade and RAIS. Robust standard errors clustered at industry level in parenthesis. Significance levels: ${ }^{*} 10 \%,{ }^{* *} 5 \%,{ }^{* *} 1 \%$. 
Table 1.7: Plant exit - additional controls.

\begin{tabular}{|c|c|c|c|c|c|c|c|c|}
\hline & \multicolumn{4}{|c|}{ Controls varying annually } & \multicolumn{4}{|c|}{ Controls fixed at initial level } \\
\hline & \multicolumn{2}{|c|}{ Exit $_{\text {is }, t+1}$} & \multicolumn{2}{|c|}{ Exit $_{i s, t+1}$} & \multicolumn{2}{|c|}{ Exit $_{\text {is }, \mathrm{t}+1}$} & \multicolumn{2}{|c|}{ Exit $_{\text {is }, \mathrm{t}+1}$} \\
\hline & $\begin{array}{l}(1) \\
\text { OLS }\end{array}$ & $\begin{array}{l}\text { (2) } \\
\text { IV }\end{array}$ & $\begin{array}{l}\text { (3) } \\
\text { OLS }\end{array}$ & $\begin{array}{l}\text { (4) } \\
\text { IV }\end{array}$ & $\begin{array}{l}(5) \\
\text { OLS }\end{array}$ & $\begin{array}{l}\text { (6) } \\
\text { IV }\end{array}$ & $\begin{array}{l}(7) \\
\text { OLS }\end{array}$ & $\begin{array}{l}\text { (8) } \\
\text { IV }\end{array}$ \\
\hline $\mathrm{IS}_{\mathrm{s}, \mathrm{t}-1}$ & $\begin{array}{c}0.018 \\
(0.016)\end{array}$ & $\begin{array}{l}0.107^{*} \\
(0.056)\end{array}$ & $\begin{array}{c}0.026 \\
(0.017)\end{array}$ & $\begin{array}{c}0.091 \\
(0.055)\end{array}$ & $\begin{array}{c}0.027 \\
(0.016)\end{array}$ & $\begin{array}{c}0.122^{* *} \\
(0.053)\end{array}$ & $\begin{array}{l}0.030^{*} \\
(0.016)\end{array}$ & $\begin{array}{c}0.115^{* *} \\
(0.052)\end{array}$ \\
\hline $\mathrm{XS}_{\mathrm{s}, \mathrm{t}-1}$ & $\begin{array}{c}-0.172^{* * *} \\
(0.028)\end{array}$ & $\begin{array}{c}-0.204^{* * *} \\
(0.032)\end{array}$ & $\begin{array}{c}-0.172^{* * *} \\
(0.027)\end{array}$ & $\begin{array}{c}-0.198^{* * *} \\
(0.032)\end{array}$ & $\begin{array}{c}-0.164^{* * *} \\
(0.028)\end{array}$ & $\begin{array}{c}-0.189^{* * *} \\
(0.034)\end{array}$ & $\begin{array}{c}-0.163^{* * *} \\
(0.026)\end{array}$ & $\begin{array}{c}-0.184^{* * *} \\
(0.033)\end{array}$ \\
\hline Age ist & $\begin{array}{c}-0.005^{* * *} \\
(0.0002)\end{array}$ & $\begin{array}{c}-0.005^{* * *} \\
(0.0002)\end{array}$ & $\begin{array}{c}-0.001^{* * *} \\
(0.0004)\end{array}$ & $\begin{array}{c}-0.001 * * * \\
(0.0004)\end{array}$ & $\begin{array}{c}-0.005^{* * *} \\
(0.0002)\end{array}$ & $\begin{array}{c}-0.005^{* * *} \\
(0.0002)\end{array}$ & $\begin{array}{c}-0.003^{* * *} \\
(0.0003)\end{array}$ & $\begin{array}{c}-0.003^{* * *} \\
(0.0003)\end{array}$ \\
\hline Entry rate $_{\text {st }}$ & $\begin{array}{c}0.547^{* * *} \\
(0.099)\end{array}$ & $\begin{array}{c}0.507^{* * *} * \\
(0.106)\end{array}$ & $\begin{array}{c}0.478^{* * *} * \\
(0.097)\end{array}$ & $\begin{array}{c}0.446^{* * *} \\
(0.103)\end{array}$ & $\begin{array}{c}0.549^{* * *} \\
(0.134)\end{array}$ & $\begin{array}{c}0.536^{* * * *} \\
(0.137)\end{array}$ & $\begin{array}{c}0.524^{* * *} \\
(0.134)\end{array}$ & $\begin{array}{c}0.513^{* * *} \\
(0.136)\end{array}$ \\
\hline $\log \left(\right.$ Herfindahl $\left._{\mathrm{st}}\right)$ & $\begin{array}{c}0.107 \\
(0.105)\end{array}$ & $\begin{array}{c}0.104 \\
(0.105)\end{array}$ & $\begin{array}{c}0.216^{* *} \\
(0.103)\end{array}$ & $\begin{array}{c}0.213^{* *} \\
(0.102)\end{array}$ & $\begin{array}{l}-0.041 \\
(0.111)\end{array}$ & $\begin{array}{l}-0.054 \\
(0.111)\end{array}$ & $\begin{array}{c}0.006 \\
(0.110)\end{array}$ & $\begin{array}{l}-0.005 \\
(0.109)\end{array}$ \\
\hline $\log \left(\right.$ Employment $\left._{\text {ist }}\right)$ & & & $\begin{array}{c}-0.052^{* * * *} \\
(0.001)\end{array}$ & $\begin{array}{c}-0.052^{* * *} \\
(0.001)\end{array}$ & & & $\begin{array}{c}-0.029^{* * *} \\
(0.001)\end{array}$ & $\begin{array}{c}-0.029^{* * *} \\
(0.001)\end{array}$ \\
\hline Skill $_{\text {ist }}$ & & & $\begin{array}{c}0.026^{* * *} \\
(0.008)\end{array}$ & $\begin{array}{c}0.026^{* * *} \\
(0.008)\end{array}$ & & & $\begin{array}{c}0.034^{* * *} \\
(0.008)\end{array}$ & $\begin{array}{c}0.034^{* * *} \\
(0.008)\end{array}$ \\
\hline Exporting status $_{\text {ist }}$ & & & $\begin{array}{c}0.041^{* * * *} \\
(0.005)\end{array}$ & $\begin{array}{c}0.041^{* * * *} \\
(0.005)\end{array}$ & & & $\begin{array}{c}0.018^{* * *} \\
(0.005)\end{array}$ & $\begin{array}{c}0.018^{* * * *} \\
(0.005)\end{array}$ \\
\hline Year fixed effects & Yes & Yes & Yes & Yes & Yes & Yes & Yes & Yes \\
\hline Industry fixed effects & Yes & Yes & Yes & Yes & Yes & Yes & Yes & Yes \\
\hline Industry trends & Yes & Yes & Yes & Yes & Yes & Yes & Yes & Yes \\
\hline Observations & $3,331,245$ & $3,331,245$ & $3,331,222$ & $3,331,222$ & $3,331,245$ & $3,331,245$ & $3,331,219$ & $3,331,219$ \\
\hline R-squared & 0.024 & 0.024 & 0.050 & 0.050 & 0.024 & 0.024 & 0.032 & 0.032 \\
\hline $1^{\text {st }}$ stage KP statistic & & 11.06 & & 11.10 & & 11.43 & & 11.46 \\
\hline
\end{tabular}

Notes: Plant-level OLS and IV regressions. Dependent variable is a dummy variable indicating plant exit. The first four columns include industry and plant level control variables. Columns five to eight include plant and industry control variables fixed at their initial levels for all plants. In IV regressions, I instrument IS and XS with import shares from China and export shares to China computed for 54 middle-income countries. Regressions cover data from 2002 to 2010. Data from UN Comtrade and RAIS. Robust standard errors clustered at industry level in parenthesis. Significance levels: * $10 \%, * * 5 \%, * * * 1 \%$. 
Next, I test if the effects of exposure to Chinese trade on plant exit are heterogeneous within industries. There is evidence that firm characteristics play an important role in determining firm outcomes after trade shocks, both theoretically (Melitz, 2003; Bernard et al., 2007) and empirically (Bustos, 2011; Bernard et al., 2006a; Pavcnik, 2002). First, I address whether plant size plays a role in determining the intensity of the effects by including interactions of exposure to Chinese trade, $\mathrm{IS}_{\mathrm{s}, \mathrm{t}-1}$ and $\mathrm{XS}_{\mathrm{s}, \mathrm{t}-1}$, with three size groups. This strategy allows nonlinear effects of employment on exit probability.

The first two columns in Table 1.8 present the basic specification including interactions, while the last two columns include age as a control variable. The results reveal that, in fact, exposure to China does not uniformly affect plants within industries. Increased competition from Chinese imports leads to higher exit probabilities for small plants, but it does not seem to affect selection among medium and large plants. Similarly, higher Chinese demand for exports benefits mostly small and medium plants, resulting in lower exit probabilities for these two groups. Although the effect on exit probability for large firms is also negative in the OLS specification, it loses its statistical significance in the IV estimation, due to an increase in the standard deviation. These results emphasize the importance of including small firms in analyses of firm dynamics, since they are most likely to suffer the negative effects of competition (Head and Ries, 1999). Past work estimating the consequences of Chinese supply growth on firm exit overlook the effects on small firms, because their data is a sample of firms above certain size threshold (Bernard et al., 2006a; Iacovone et al., 2013).

As an additional exercise, Table 1.9 examines how the effects of exposure to trade are heterogeneous on plant skill intensity and exporting status. The first four columns show the results from including interactions of $\mathrm{IS}_{\mathrm{s}, \mathrm{t}-1}$ and $\mathrm{XS}_{\mathrm{s}, \mathrm{t}-1}$ with plants' skill intensity measure, while the last four columns include interactions with plants' exporting status. For each specification, I present OLS and IV estimates, including or excluding plant age as an independent variable.

Even after controlling for each of these heterogeneities, the overall effects of exposure to Chinese trade remain significant and in the same direction as in the baseline results. I find that plants' skill intensity do not alter the way in which exposure to Chinese trade affects industry selection. Exporting status has a negative effect on exit probability following an increase in the penetration of Chinese imports, which decreases the overall impact of exposure to imports on plant exit. This result is consistent with evidence presented in Bernard and Jensen (2002), that the probability of manufacturing plant exit increased with the level of import supply, but decreased for exporting firms. 
However, exit probability still increases for both exporting and non-exporting firms exposed to import competition, as predicted by Muendler (2004). In the OLS specification, I find a positive impact on plant exit for exporters facing an increase in demand from China, but this effect is not significantly different from zero in the instrumental variables estimation. Note that when I control for heterogeneous effects in exporting status, I find that exporters on average have lower probability of exit, compared to the positive relationship in the baseline results from Table 1.6. 
Table 1.8: Plant exit - size groups.

\begin{tabular}{|c|c|c|c|c|}
\hline & \multicolumn{2}{|c|}{ Exit $_{\text {is }, t+1}$} & \multicolumn{2}{|c|}{ Exit $_{\text {is }, t+1}$} \\
\hline & (1) & (2) & (3) & $(4)$ \\
\hline & OLS & IV & OLS & IV \\
\hline \multirow[t]{2}{*}{$\mathrm{IS}_{\mathrm{s}, \mathrm{t}-1} *$ Small $_{\mathrm{ist}}$} & $0.044^{*}$ & $0.153^{* *}$ & $0.044^{* *}$ & $0.140^{* *}$ \\
\hline & $(0.024)$ & $(0.065)$ & $(0.021)$ & $(0.061)$ \\
\hline \multirow{2}{*}{$\mathrm{IS}_{\mathrm{s}, \mathrm{t}-1} *$ Medium $_{\text {ist }}$} & -0.0004 & 0.094 & -0.011 & 0.066 \\
\hline & $(0.025)$ & $(0.063)$ & $(0.023)$ & $(0.059)$ \\
\hline \multirow[t]{2}{*}{$\mathrm{IS}_{\mathrm{s}, \mathrm{t}-1} *$ Large $_{\mathrm{ist}}$} & 0.009 & 0.100 & -0.015 & 0.051 \\
\hline & $(0.025)$ & $(0.064)$ & $(0.025)$ & $(0.060)$ \\
\hline \multirow{2}{*}{$\mathrm{XS}_{\mathrm{s}, \mathrm{t}-1} * \mathrm{Small}_{\mathrm{ist}}$} & $-0.224^{* * *}$ & $-0.237^{* * *}$ & $-0.221^{* * *}$ & $-0.238^{* * *}$ \\
\hline & $(0.026)$ & $(0.038)$ & $(0.028)$ & $(0.037)$ \\
\hline \multirow[t]{2}{*}{$\mathrm{XS}_{\mathrm{s}, \mathrm{t}-1} *$ Medium $_{\text {ist }}$} & $-0.185^{* * *}$ & $-0.271^{* * *}$ & $-0.192^{* * *}$ & $-0.303^{* * *}$ \\
\hline & (0.027) & $(0.076)$ & $(0.033)$ & $(0.097)$ \\
\hline \multirow[t]{2}{*}{$\mathrm{XS}_{\mathrm{s}, \mathrm{t}-1} *$ Large $_{\text {ist }}$} & $-0.185^{* * *}$ & -0.512 & $-0.197^{* * *}$ & -0.630 \\
\hline & $(0.041)$ & $(0.315)$ & $(0.047)$ & $(0.387)$ \\
\hline \multirow[t]{2}{*}{ Small $_{\text {ist }}$} & $0.122^{* * *}$ & $0.114^{* * *}$ & $0.077^{* * *}$ & $0.066^{* * *}$ \\
\hline & $(0.004)$ & $(0.006)$ & $(0.007)$ & $(0.009)$ \\
\hline \multirow[t]{2}{*}{ Medium $_{\text {ist }}$} & $0.023^{* * *}$ & $0.018^{* * *}$ & -0.004 & $-0.011^{* *}$ \\
\hline & $(0.003)$ & $(0.004)$ & $(0.003)$ & $(0.005)$ \\
\hline \multirow[t]{2}{*}{ Age $_{\text {ist }}$} & & & $-0.004^{* * *}$ & $-0.004^{* * *}$ \\
\hline & & & $(0.0004)$ & $(0.0004)$ \\
\hline Year fixed effects & Yes & Yes & Yes & Yes \\
\hline Industry fixed effects & Yes & Yes & Yes & Yes \\
\hline Industry trends & Yes & Yes & Yes & Yes \\
\hline Observations & $3,331,254$ & $3,331,254$ & $3,331,245$ & $3,331,245$ \\
\hline R-squared & 0.027 & 0.027 & 0.033 & 0.032 \\
\hline $1^{\text {st }}$ stage KP statistic & & 3.932 & & 3.928 \\
\hline
\end{tabular}

Notes: Plant-level OLS and IV regressions. Dependent variable is a dummy variable indicating plant exit. In IV regressions, I instrument IS and XS with import shares from China and export shares to China computed for 54 middleincome countries. Regressions cover data from 2002 to 2010. Robust standard errors clustered at industry level in parenthesis. Data is from UN Comtrade and RAIS. Significance levels: * $10 \%, * * 5 \%, * * * 1 \%$. 
Table 1.9: Plant exit - skill and exporting status.

\begin{tabular}{|c|c|c|c|c|c|c|c|c|}
\hline \multirow[b]{2}{*}{ VARIABLES } & \multicolumn{2}{|c|}{ Exit $_{\text {is }, \mathrm{t}+1}$} & \multicolumn{2}{|c|}{ Exit $_{i s, t+1}$} & \multicolumn{2}{|c|}{ Exit $_{\text {is }, t+1}$} & \multicolumn{2}{|c|}{ Exit $_{\text {is }, t+1}$} \\
\hline & $\begin{array}{l}(1) \\
\text { OLS }\end{array}$ & $\begin{array}{l}\text { (2) } \\
\text { IV }\end{array}$ & $\begin{array}{c}(3) \\
\text { OLS }\end{array}$ & $\begin{array}{l}\text { (4) } \\
\text { IV }\end{array}$ & $\begin{array}{c}(5) \\
\text { OLS }\end{array}$ & $\begin{array}{l}\text { (6) } \\
\text { IV }\end{array}$ & $\begin{array}{l}(7) \\
\text { OLS }\end{array}$ & $\begin{array}{l}\text { (8) } \\
\text { IV }\end{array}$ \\
\hline $\mathrm{IS}_{\mathrm{s}, \mathrm{t}-1}$ & $\begin{array}{c}0.027 \\
(0.028)\end{array}$ & $\begin{array}{c}0.167^{* *} \\
(0.071)\end{array}$ & $\begin{array}{c}0.023 \\
(0.024)\end{array}$ & $\begin{array}{c}0.140^{* *} \\
(0.064)\end{array}$ & $\begin{array}{c}0.023 \\
(0.026)\end{array}$ & $\begin{array}{c}0.152^{* *} \\
(0.070)\end{array}$ & $\begin{array}{c}0.020 \\
(0.022)\end{array}$ & $\begin{array}{c}0.128^{* *} \\
(0.064)\end{array}$ \\
\hline $\mathrm{IS}_{\mathrm{s}, \mathrm{t}-1} * \mathrm{Skill}_{\mathrm{ist}}$ & $\begin{array}{c}0.002 \\
(0.025)\end{array}$ & $\begin{array}{l}-0.020 \\
(0.033)\end{array}$ & $\begin{array}{l}-0.005 \\
(0.024)\end{array}$ & $\begin{array}{l}-0.029 \\
(0.032)\end{array}$ & & & & \\
\hline $\mathrm{IS}_{\mathrm{s}, \mathrm{t}-1} *$ Exporting $_{\text {ist }}$ & & & & & $\begin{array}{c}-0.0004 \\
(0.010)\end{array}$ & $\begin{array}{l}-0.012 \\
(0.014)\end{array}$ & $\begin{array}{l}-0.013 \\
(0.011)\end{array}$ & $\begin{array}{c}-0.027^{*} \\
(0.015)\end{array}$ \\
\hline $\mathrm{XS}_{\mathrm{s}, \mathrm{t}-1}$ & $\begin{array}{c}-0.218^{* * *} \\
(0.020)\end{array}$ & $\begin{array}{c}-0.228^{* * *} \\
(0.033)\end{array}$ & $\begin{array}{c}-0.217^{* * *} \\
(0.023)\end{array}$ & $\begin{array}{c}-0.235^{* * *} \\
(0.029)\end{array}$ & $\begin{array}{c}-0.221 * * * \\
(0.025)\end{array}$ & $\begin{array}{c}-0.242^{* * *} \\
(0.034)\end{array}$ & $\begin{array}{c}-0.218^{* * *} \\
(0.028)\end{array}$ & $\begin{array}{c}-0.247^{* * *} \\
(0.033)\end{array}$ \\
\hline $\mathrm{XS}_{\mathrm{s}, \mathrm{t}-1} * \mathrm{Skill}_{\text {ist }}$ & $\begin{array}{c}0.002 \\
(0.032)\end{array}$ & $\begin{array}{l}-0.079 \\
(0.078)\end{array}$ & $\begin{array}{c}0.004 \\
(0.035)\end{array}$ & $\begin{array}{l}-0.068 \\
(0.065)\end{array}$ & & & & \\
\hline $\mathrm{XS}_{\mathrm{s}, \mathrm{t}-1} *$ Exporting $_{\text {ist }}$ & & & & & $\begin{array}{c}0.214^{* * *} \\
(0.054)\end{array}$ & $\begin{array}{c}0.084 \\
(0.096)\end{array}$ & $\begin{array}{c}0.157^{* * *} \\
(0.053)\end{array}$ & $\begin{array}{c}0.018 \\
(0.098)\end{array}$ \\
\hline Age $_{\text {ist }}$ & & & $\begin{array}{c}-0.005^{* * *} \\
(0.0002)\end{array}$ & $\begin{array}{c}-0.005^{* * *} \\
(0.0002)\end{array}$ & & & $\begin{array}{c}-0.005^{* * *} \\
(0.0002)\end{array}$ & $\begin{array}{r}-0.005^{* * *} \\
(0.0002)\end{array}$ \\
\hline Skill $_{\text {ist }}$ & $\begin{array}{c}0.024^{* *} \\
(0.011)\end{array}$ & $\begin{array}{c}0.029^{* *} \\
(0.013)\end{array}$ & $\begin{array}{l}0.022^{*} \\
(0.011)\end{array}$ & $\begin{array}{c}0.026^{* *} \\
(0.013)\end{array}$ & & & & \\
\hline Exporting statusist & & & & & $\begin{array}{c}-0.087^{* * *} \\
(0.003)\end{array}$ & $\begin{array}{c}-0.082^{* * *} \\
(0.004)\end{array}$ & $\begin{array}{c}-0.040^{* * *} \\
(0.004)\end{array}$ & $\begin{array}{c}-0.035^{* * *} \\
(0.005)\end{array}$ \\
\hline Year fixed effects & Yes & Yes & Yes & Yes & Yes & Yes & Yes & Yes \\
\hline Industry fixed effects & Yes & Yes & Yes & Yes & Yes & Yes & Yes & Yes \\
\hline Industry trends & Yes & Yes & Yes & Yes & Yes & Yes & Yes & Yes \\
\hline Observations & $3,331,231$ & $3,331,231$ & $3,331,222$ & $3,331,222$ & $3,331,254$ & $3,331,254$ & $3,331,245$ & $3,331,245$ \\
\hline R-squared & 0.013 & 0.012 & 0.024 & 0.023 & 0.014 & 0.013 & 0.024 & 0.023 \\
\hline $1^{\text {st }}$ stage KP statistic & & 5.721 & & 5.716 & & 5.667 & & 5.665 \\
\hline
\end{tabular}

Notes: Plant-level OLS and IV regressions. Dependent variable is a dummy variable indicating plant exit. In IV regressions, I instrument IS and XS with import shares from China and export shares to China computed for 54 middle-income countries. Regressions cover data from 2002 to 2010. Robust standard errors clustered at industry level in parenthesis. Data is from UN Comtrade and RAIS. Significance levels: * $10 \%, * * 5 \%, * * * 1 \%$. 


\subsection{2 \\ Entry}

Table 1.10 provides some evidence on the effects of shocks stemming from international trade on entry rates and newborn plant characteristics. For each specification, the instrumental variables estimation results are shown on the right of OLS results. All regressions include year fixed effects, three-digit industry fixed effects and trends. The first two columns of the Table present baseline results for plant entry. The results point to an increase in the share of newborn plants in industries experiencing a rise in import competition. For industries where export demand has risen, I find a decrease in the share of newborn plants in the OLS specification, but the effect is not statistically significant in the instrumental variables specification. Using the estimates in column two, I find that a 20 percentage point increase (one standard deviation) in exposure to Chinese imports is associated with a 2.9 percentage point increase in entry rates. Considering the average entry rate, this effect is equivalent to a $23.4 \%$ increase in plant entry.

The last two columns provide estimates using a slightly different definition for the entry dependent variable. In these two columns, I consider newborn plants as all plants entering the market in period $t$, but also all operating plants switching industries between years $t-1$ and $t$. The goal of this specification is to capture actual changes in competition within industries, resulting not only from the entry of new plants, but also from plants that were previously operating in other industries. Bernard et al. (2006a) and Bernard et al. (2010) provide empirical evidence that industry switching is an important margin of adjustment following trade shocks. When I consider industry switching, the magnitude of the effects increases, but results are qualitatively unchanged.

Next, Table 1.11 introduces plant and industry-level variables in the regressions to examine newborn plant characteristics and to check whether baseline results are robust to the inclusion of these variables. Columns one to four present results using entry as the dependent variable. The last four columns of the Table consider the more broad definition of entry, including industry switching. When control variables are introduced in the regressions, the effects of export shares on the share of newborn plants become statistically insignificant in all specifications. The effect of import supply, measured by IS, is still positive in the first six columns, but turns statistically equal to zero when all control variables are included.

From these results, we cannot precisely understand the role of supply and demand shocks on entry rates. One interpretation for the unexpected direction 
of the effects is that industry entry rates simply follow the behavior of exit rates. After the inclusion of control variables, we find that newborn plants are on average smaller than incumbents, and are more skill intensive.

Results in Tables 1.10 and 1.11 are not consistent with theoretical evidence of trade liberalization and firm dynamics. Bernard et al. (2007) demonstrates that an increase in industry export demand raises export opportunities and, consequently, expected profits. Higher expected profits lead to a greater number of entrants, increasing competition in that particular industry. A rise in import competition, on the other hand, should decrease expected profits, resulting in lower entry rates ${ }^{5}$.

The fact that industry entry rates did not positively respond to an increase in Chinese export demand could help us understand the reason why exit rates decreased. One possible explanation is that industries most affected by Chinese demand have high entry and fixed costs of operation, preventing entry to freely adjust to changes in expected profits. This is consistent with evidence provided in Section 1.3 that export demand mainly concentrates in mining industries, which also tend to present high market concentration and high fixed costs of operation. Another possibility why entry might not respond to changes in export opportunities is pointed by Bernard and Jensen (2004). They show that an increase in exports occurs mostly in the intensive margin, within exporting firms, due to high entry costs in the export market (Bernard and Wagner, 2001).

For the sake of completeness, Table 1.12 confirms that entry is concentrated among small firms by interacting the effect of IS and XS with size groups. The first two columns present OLS and IV results for entry, while the last two columns expand the definition of entry to also consider industry switching. Considering size heterogeneity, however, does not change the conclusion on how entry responds to supply and demand shocks resulting from Chinese growth.

Table 1.13 shows that, even when considering the heterogeneity of plant skill and exporting status, the overall effects of import supply and export demand on entry rates are not altered. I find no effect of IS and XS on newborn plants' skill intensity. An interesting result that emerges is that supply shocks decrease the probability of newborn plants being exporters, while demand shocks increase this probability. These relationships suggest that expected profits increase in industries positively affected by Chinese demand, but decrease in industries facing stronger competition from Chinese imports

\footnotetext{
${ }^{5}$ This particular situation is not addressed in Bernard et al. (2007), since trade liberal-
} ization following an autarky scenario still leads to increased export opportunities. 
as in Bernard et al. (2007).

Table 1.10: Plant entry.

\begin{tabular}{lccccc}
\hline & \multicolumn{2}{c}{ Entry } & & \multicolumn{2}{c}{ (Entry or switching $)_{\text {ist }}$} \\
\cline { 2 - 3 } \cline { 5 - 6 } & OLS & IV & & OLS & IV \\
\hline \multirow{2}{*}{ IS $_{\mathrm{s}, \mathrm{t}-1}$} & $0.042^{* *}$ & $0.148^{* * *}$ & & 0.038 & $0.177^{* *}$ \\
& $(0.021)$ & $(0.050)$ & & $(0.031)$ & $(0.068)$ \\
$\mathrm{XS}_{\mathrm{s}, \mathrm{t}-1}$ & $-0.039^{* *}$ & -0.017 & & $-0.069^{* * *}$ & -0.023 \\
& $(0.015)$ & $(0.023)$ & & $(0.021)$ & $(0.032)$ \\
& & & & & \\
Year fixed effects & Yes & Yes & & Yes & Yes \\
Industry fixed effects & Yes & Yes & & Yes & Yes \\
Industry trends & Yes & Yes & & Yes & Yes \\
& & & & \\
Observations & $4,234,067$ & $4,234,067$ & & $5,052,474$ & $5,052,474$ \\
R-squared & 0.008 & 0.008 & & 0.010 & 0.009 \\
$1^{\text {st }}$ stage KP statistic & & 9.462 & & 9.398 \\
\hline
\end{tabular}

Notes: Plant-level OLS and IV regressions. Dependent variable is a dummy variable indicating plant entry. In IV regressions, I instrument IS and XS with import shares from China and export shares to China computed for 54 middle-income countries. Regressions cover data from 2002 to 2012. Data is from UN Comtrade and RAIS. Robust standard errors clustered at industry level in parenthesis. Significance levels: $* 10 \%,{ }^{* *} 5 \%, * * * 1 \%$. 
Table 1.11: Plant entry - additional controls.

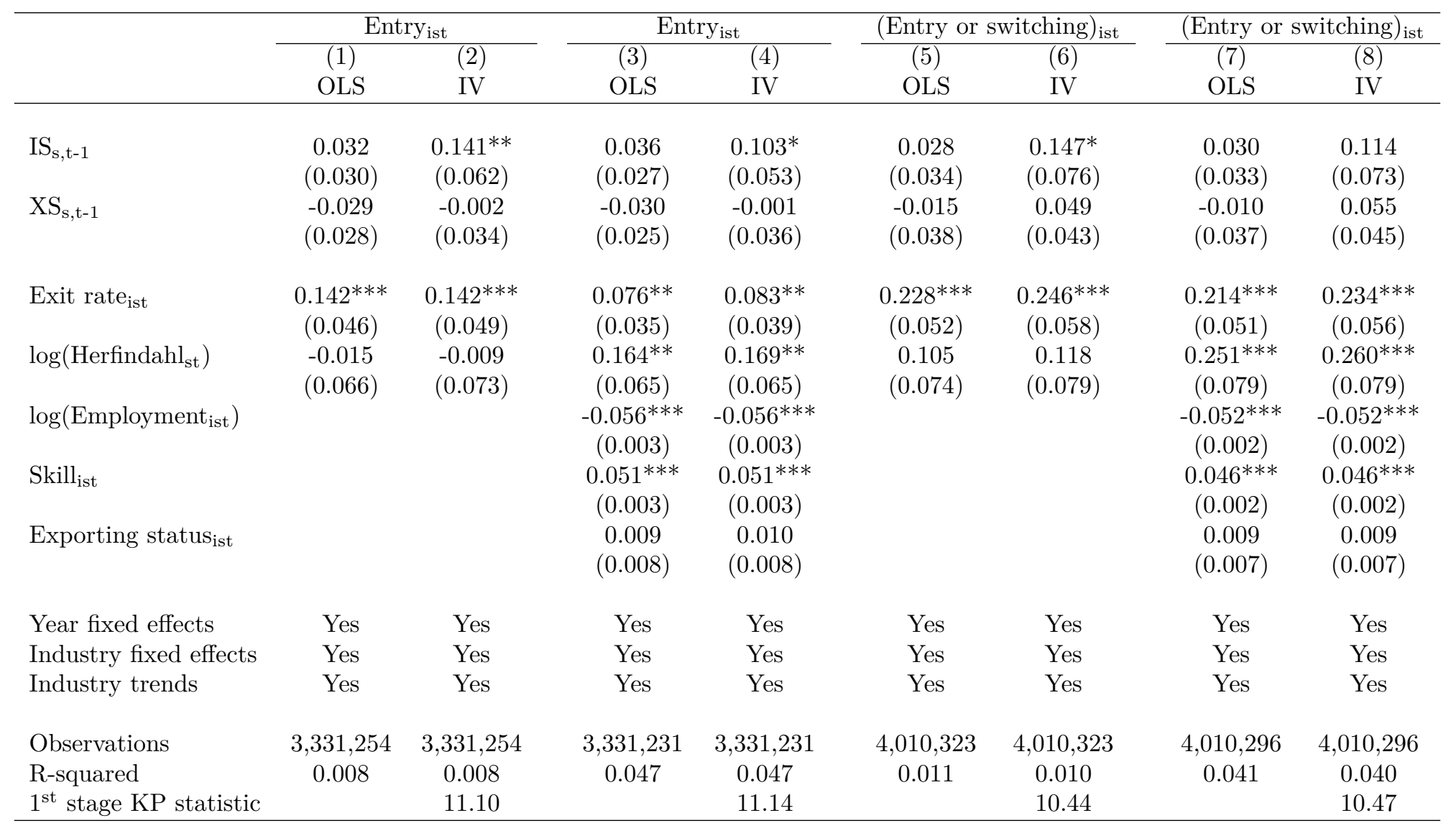

Notes: Plant-level OLS and IV regressions. Dependent variable is a dummy variable indicating plant entry. In IV regressions, I instrument IS and XS with import shares from China and export shares to China computed for 54 middle-income countries. Regressions cover data from 2002 to 2012. Data is from UN Comtrade and RAIS. Robust standard errors clustered at industry level in parenthesis. Significance levels: $* 10 \%, * * 5 \%, * * * 1 \%$. 
Table 1.12: Plant entry - size groups.

\begin{tabular}{|c|c|c|c|c|}
\hline & \multicolumn{2}{|c|}{ Entry $_{\text {ist }}$} & \multicolumn{2}{|c|}{ (Entry or switching) $)_{\text {ist }}$} \\
\hline & (1) & (2) & (3) & (4) \\
\hline & OLS & IV & OLS & IV \\
\hline \multirow[t]{2}{*}{$\mathrm{IS}_{\mathrm{s}, \mathrm{t}-1} *$ Small $_{\mathrm{ist}}$} & $0.051^{* *}$ & $0.129^{* * *}$ & 0.045 & $0.161^{* *}$ \\
\hline & $(0.020)$ & $(0.044)$ & $(0.031)$ & $(0.067)$ \\
\hline \multirow{2}{*}{$\mathrm{IS}_{\mathrm{s}, \mathrm{t}-1} *$ Medium $_{\text {ist }}$} & $0.037^{*}$ & $0.104^{* *}$ & 0.031 & $0.139^{* *}$ \\
\hline & $(0.020)$ & $(0.043)$ & $(0.029)$ & $(0.065)$ \\
\hline \multirow[t]{2}{*}{$\mathrm{IS}_{\mathrm{s}, \mathrm{t}-1} *$ Large $_{\text {ist }}$} & 0.013 & $0.071^{*}$ & 0.016 & $0.117^{*}$ \\
\hline & $(0.019)$ & $(0.042)$ & $(0.029)$ & $(0.065)$ \\
\hline \multirow[t]{2}{*}{$\mathrm{XS}_{\mathrm{s}, \mathrm{t}-1} * \mathrm{Small}_{\text {ist }}$} & $-0.044^{* * *}$ & -0.024 & $-0.076^{* * *}$ & -0.029 \\
\hline & $(0.016)$ & $(0.023)$ & $(0.022)$ & $(0.032)$ \\
\hline \multirow{2}{*}{$\mathrm{XS}_{\mathrm{s}, \mathrm{t}-1} *$ Medium $_{\mathrm{ist}}$} & 0.003 & 0.063 & -0.012 & 0.056 \\
\hline & $(0.024)$ & $(0.069)$ & $(0.029)$ & $(0.064)$ \\
\hline \multirow[t]{2}{*}{$\mathrm{XS}_{\mathrm{s}, \mathrm{t}-1} *$ Large $_{\mathrm{ist}}$} & 0.001 & -0.110 & -0.005 & -0.093 \\
\hline & $(0.025)$ & $(0.158)$ & $(0.025)$ & $(0.153)$ \\
\hline \multirow[t]{2}{*}{ Small $_{\text {ist }}$} & $0.131^{* * *}$ & $0.126^{* * *}$ & $0.123^{* * *}$ & $0.118^{* * *}$ \\
\hline & $(0.004)$ & $(0.004)$ & $(0.003)$ & $(0.004)$ \\
\hline \multirow[t]{2}{*}{ Medium $_{\text {ist }}$} & $0.024^{* * *}$ & $0.019^{* * *}$ & $0.026^{* * *}$ & $0.022^{* * *}$ \\
\hline & $(0.003)$ & $(0.003)$ & $(0.003)$ & $(0.003)$ \\
\hline Year fixed effects & Yes & Yes & Yes & Yes \\
\hline Industry fixed effects & Yes & Yes & Yes & Yes \\
\hline Industry trends & Yes & Yes & Yes & Yes \\
\hline Observations & $4,234,067$ & $4,234,067$ & $5,052,474$ & $5,052,474$ \\
\hline R-squared & 0.026 & 0.025 & 0.023 & 0.023 \\
\hline $1^{\text {st }}$ stage KP statistic & & 3.197 & & 3.172 \\
\hline
\end{tabular}

Notes: Plant-level OLS and IV regressions. Dependent variable is a dummy variable indicating plant entry. In IV regressions, I instrument IS and XS with import shares from China and export shares to China computed for 54 middle-income countries. Regressions cover data from 2002 to 2012. Data is from UN Comtrade and RAIS. Robust standard errors clustered at industry level in parenthesis. Significance levels: $* 10 \%, * * 5 \%$, *** $1 \%$. 
Table 1.13: Plant entry - skill and exporting status.

\begin{tabular}{|c|c|c|c|c|c|c|c|c|}
\hline & \multicolumn{2}{|c|}{ Entry ist } & \multicolumn{2}{|c|}{ Entry ist } & \multicolumn{2}{|c|}{ (Entry or switching) $)_{\text {ist }}$} & \multicolumn{2}{|c|}{$(\text { Entry or switching) })_{\text {ist }}$} \\
\hline & $\begin{array}{l}(1) \\
\text { OLS }\end{array}$ & $\begin{array}{l}(2) \\
\text { IV }\end{array}$ & $\begin{array}{l}\text { (3) } \\
\text { OLS }\end{array}$ & $\begin{array}{l}\text { (4) } \\
\text { IV }\end{array}$ & $\begin{array}{l}(5) \\
\text { OLS }\end{array}$ & $\begin{array}{l}(6) \\
\text { IV }\end{array}$ & $\begin{array}{l}(7) \\
\text { OLS }\end{array}$ & $\begin{array}{l}\text { (8) } \\
\text { IV }\end{array}$ \\
\hline $\mathrm{IS}_{\mathrm{s}, \mathrm{t}-1}$ & $\begin{array}{l}0.035^{*} \\
(0.021)\end{array}$ & $\begin{array}{c}0.139 * * * \\
(0.050)\end{array}$ & $\begin{array}{l}0.040^{*} \\
(0.021)\end{array}$ & $\begin{array}{c}0.141^{* * *} \\
(0.049)\end{array}$ & $\begin{array}{c}0.032 \\
(0.031)\end{array}$ & $\begin{array}{c}0.174^{* *} \\
(0.069)\end{array}$ & $\begin{array}{c}0.036 \\
(0.030)\end{array}$ & $\begin{array}{l}0.171^{* *} \\
(0.068)\end{array}$ \\
\hline $\mathrm{IS}_{\mathrm{s}, \mathrm{t}-1} * \mathrm{Skill}_{\mathrm{ist}}$ & $\begin{array}{c}0.023^{* *} \\
(0.010)\end{array}$ & $\begin{array}{c}0.024 \\
(0.015)\end{array}$ & & & $\begin{array}{c}0.019^{* * *} \\
(0.007)\end{array}$ & $\begin{array}{c}0.007 \\
(0.012)\end{array}$ & & \\
\hline IS $_{\mathrm{s}, \mathrm{t}-1} *$ Exporting $_{\text {ist }}$ & & & $\begin{array}{c}-0.043^{* * *} \\
(0.014)\end{array}$ & $\begin{array}{c}-0.062^{* * *} \\
(0.016)\end{array}$ & & & $\begin{array}{l}-0.032^{*} \\
(0.017)\end{array}$ & $\begin{array}{c}-0.048^{* *} \\
(0.020)\end{array}$ \\
\hline $\mathrm{XS}_{\mathrm{s}, \mathrm{t}-1}$ & $\begin{array}{c}-0.037^{*} \\
(0.019)\end{array}$ & $\begin{array}{l}-0.009 \\
(0.030)\end{array}$ & $\begin{array}{c}-0.040^{* *} \\
(0.015)\end{array}$ & $\begin{array}{l}-0.018 \\
(0.024)\end{array}$ & $\begin{array}{c}-0.064^{* *} \\
(0.025)\end{array}$ & $\begin{array}{l}-0.008 \\
(0.038)\end{array}$ & $\begin{array}{c}-0.070^{* * *} \\
(0.022)\end{array}$ & $\begin{array}{l}-0.023 \\
(0.032)\end{array}$ \\
\hline $\mathrm{XS}_{\mathrm{s}, \mathrm{t}-1} * \mathrm{Skill}_{\text {ist }}$ & $\begin{array}{c}-0.0004 \\
(0.014)\end{array}$ & $\begin{array}{l}-0.037 \\
(0.048)\end{array}$ & & & $\begin{array}{l}-0.014 \\
(0.015)\end{array}$ & $\begin{array}{l}-0.074 \\
(0.050)\end{array}$ & & \\
\hline $\mathrm{XS}_{\mathrm{s}, \mathrm{t}-1} *$ Exporting $_{\text {ist }}$ & & & $\begin{array}{c}0.096^{* * *} \\
(0.029)\end{array}$ & $\begin{array}{c}0.091 \\
(0.071)\end{array}$ & & & $\begin{array}{c}0.105^{* * *} \\
(0.030)\end{array}$ & $\begin{array}{c}0.077 \\
(0.061)\end{array}$ \\
\hline Skill $_{\text {ist }}$ & $\begin{array}{c}0.046^{* * *} \\
(0.005)\end{array}$ & $\begin{array}{c}0.046^{* * *} \\
(0.005)\end{array}$ & & & $\begin{array}{c}0.042^{* * *} \\
(0.003)\end{array}$ & $\begin{array}{c}0.045^{* * *} \\
(0.004)\end{array}$ & & \\
\hline Exporting status $_{\text {ist }}$ & & & $\begin{array}{c}-0.098^{* * *} \\
(0.003)\end{array}$ & $\begin{array}{c}-0.094^{* * *} \\
(0.004)\end{array}$ & & & $\begin{array}{c}-0.089^{* * *} \\
(0.003)\end{array}$ & $\begin{array}{c}-0.085^{* * *} \\
(0.003)\end{array}$ \\
\hline Year fixed effects & Yes & Yes & Yes & Yes & Yes & Yes & Yes & Yes \\
\hline Industry fixed effects & Yes & Yes & Yes & Yes & Yes & Yes & Yes & Yes \\
\hline Industry trends & Yes & Yes & Yes & Yes & Yes & Yes & Yes & Yes \\
\hline Observations & $4,234,044$ & $4,234,044$ & $4,234,067$ & $4,234,067$ & $5,052,447$ & $5,052,447$ & $5,052,474$ & $5,052,474$ \\
\hline R-squared & 0.010 & 0.010 & 0.010 & 0.010 & 0.012 & 0.011 & 0.012 & 0.011 \\
\hline $1^{\text {st }}$ stage KP statistic & & 4.742 & & 4.707 & & 4.706 & & 4.673 \\
\hline
\end{tabular}

Notes: Plant-level OLS and IV regressions. Dependent variable is a dummy variable indicating plant entry. In IV regressions, I instrument IS and XS with import shares from China and export shares to China computed for 54 middle-income countries. Regressions cover data from 2002 to 2012. Data is from UN Comtrade and RAIS. Robust standard errors clustered at industry level in parenthesis. Significance levels: $* 10 \%, * * 5 \%, * * * 1 \%$. 


\subsection{3 \\ Employment}

Lastly, I briefly provide evidence on the effects of trade shocks on plant employment. We have already seen than an increase in competition due to Chinese import penetration leads to increased exit probability for small plants. One possibility is that larger plants also suffer negative consequences of increased competition, which would be reflected in lower employment.

Table 1.14 shows the main first stage regressions. All specifications include year and plant fixed effects. The first two columns additionally include four-digit industry trends, and the last two columns include three-digit industry trends. In both cases we find that, in the presence of plant fixed effects and trends, instruments do not help to predict industry exposure to trade. We cannot reject the null hypothesis that the instruments used are weak, according to Kleibergen-Paap statistics. As an alternative, I provide employment results using a reduced form specification, using instruments directly as treatment variables, and four-digit industry trends.

Table 1.14: First stage - employment.

\begin{tabular}{|c|c|c|c|c|c|}
\hline & \multicolumn{2}{|c|}{ four-digit industry } & & \multicolumn{2}{|c|}{ three-digit industry } \\
\hline & $\begin{array}{c}(1) \\
\mathrm{IS}_{\mathrm{s}, \mathrm{t}-1}\end{array}$ & $\begin{array}{c}(2) \\
\mathrm{XS}_{\mathrm{s}, \mathrm{t}-1}\end{array}$ & & $\begin{array}{c}(3) \\
\mathrm{IS}_{\mathrm{s}, \mathrm{t}-1}\end{array}$ & $\begin{array}{c}(4) \\
\mathrm{XS}_{\mathrm{s}, \mathrm{t}-1}\end{array}$ \\
\hline $\mathrm{ivIS}_{\mathrm{s}, \mathrm{t}-1}$ & $\begin{array}{c}0.111 \\
(0.184)\end{array}$ & $\begin{array}{c}0.038 \\
(0.049)\end{array}$ & & $\begin{array}{l}0.255^{*} \\
(0.149)\end{array}$ & $\begin{array}{c}-0.001 \\
(0.024)\end{array}$ \\
\hline $\operatorname{ivXS} S_{s, t-1}$ & $\begin{array}{l}-0.028 \\
(0.066)\end{array}$ & $\begin{array}{l}0.198^{*} \\
(0.119)\end{array}$ & -0.042 & $\begin{array}{l}0.0001 \\
(0.065)\end{array}$ & $(0.080)$ \\
\hline Year fixed effects & Yes & Yes & & Yes & Yes \\
\hline Plant fixed effects & Yes & Yes & & Yes & Yes \\
\hline Industry trends & Yes & Yes & & Yes & Yes \\
\hline Observations & $2,886,971$ & $2,886,971$ & & $2,886,971$ & $2,886,971$ \\
\hline R-squared & 0.961 & 0.947 & & 0.968 & 0.980 \\
\hline F statistic & 0.332 & 2.752 & & 1.674 & 0.00361 \\
\hline
\end{tabular}

Notes: First stage regressions for plant employment. Dependent variables are the measures of exposure to China, IS and XS, regressed on instrumental variables. The first two columns include four-digit industry fixed effects and trends. The last two columns include three-digit industry fixed effects and trends. Instruments for IS and XS are import shares from China and export shares to China computed for 54 middle-income countries. Regressions cover data from 2002 to 2012 . Robust standard errors clustered at industry level in parenthesis. Significance levels: ${ }^{*} 10 \%, * * 5 \%$, *** $1 \%$.

Table 1.15 investigates the effects of industry exposure to trade on surviving plants' employment. It presents reduced form regressions including year fixed effects, plant fixed effects and four-digit industry trends in all 
specifications. Standard errors are clustered at the four-digit industry level. In the first two columns, I find no significant effects of exposure to import supply and export demand on plant size, even after controlling for plant age. Columns three and four interact exposure to China with plants' skill intensity. The unconditional effects of IS and XS remain statistically equal to zero, but I find a positive and significant coefficient for the interaction between IS and skill intensity. This result does not seem compatible with the previous finding that trade shocks negatively affect plant performance, reflected by higher exit probabilities. The last two columns evaluate how results are heterogeneous considering plants' exporting status. In this last specification, again there are no significant effects of trade shocks on plant employment.

Table 1.16 includes interactions between size groups and trade shocks, IS and XS, to allow for heterogeneous effects of trade shocks on employment. The second column includes plant age as an independent variable. In both columns, we cannot reject the null hypothesis that the coefficients of exposure to Chinese trade are zero, indicating that there are no effects on the employment of surviving plants. In the presence of plant fixed effects, the coefficient associated with age assumes unrealistically large values, although that does not alter the magnitude of estimated effects for IS and XS.

These results are not consistent with previous evidence that increased competition from China leads to lower plant sales (Iacovone et al., 2013). I also find no relationship between increased export demand and plant employment. Tables A.2 and A.1 in the Appendix show that these results are not significantly altered when I consider a simple OLS specification, ignoring instruments. These results support the findings in Foster et al. (2006), that selection is the most important margin of adjustment following trade shocks, responsible for most of the productivity gains from trade.

One possibility is that our results are counterintuitive due to general equilibrium effects. Supply and demand shocks in the context of international trade have two simultaneous effects on firm performance. For example, an increase in the intensity of foreign trade directly affects market competition through import penetration (Eslava et al., 2013; Bernard et al., 2006b). This effect characterizes a negative shock in firms' performance, reducing expected profits. On the other hand, international trade benefits firms by introducing a range of cheaper or higher quality inputs to be used in production (Muendler, 2004). This second effects increases firm productivity and raises expected profits. It is not clear, therefore, whether one effect is dominant over the other. In the future, it would be interesting to try and disentangle these opposing effects to better understand how each channel affects firm performance. 
Table 1.15: Employment.

\begin{tabular}{|c|c|c|c|c|c|c|}
\hline & \multicolumn{6}{|c|}{$\log \left(\right.$ Employment $\left._{\mathrm{i}, \mathrm{t}+1}\right)$} \\
\hline & $\begin{array}{c}(1) \\
\text { Red Form }\end{array}$ & $\begin{array}{c}(2) \\
\text { Red Form }\end{array}$ & $\begin{array}{c}(3) \\
\text { Red Form }\end{array}$ & $\begin{array}{c}(4) \\
\text { Red Form }\end{array}$ & $\begin{array}{c}(5) \\
\text { Red Form }\end{array}$ & $\begin{array}{c}(6) \\
\text { Red Form }\end{array}$ \\
\hline $\operatorname{ivIS}_{\mathrm{s}, \mathrm{t}-1}$ & $\begin{array}{l}-0.037 \\
(0.083)\end{array}$ & $\begin{array}{l}-0.037 \\
(0.083)\end{array}$ & $\begin{array}{l}-0.125 \\
(0.077)\end{array}$ & $\begin{array}{l}-0.125 \\
(0.077)\end{array}$ & $\begin{array}{l}-0.034 \\
(0.083)\end{array}$ & $\begin{array}{l}-0.034 \\
(0.083)\end{array}$ \\
\hline $\mathrm{ivIS}_{\mathrm{s}, \mathrm{t}-1} *$ Skill $_{\mathrm{it}}$ & & & $\begin{array}{c}0.284^{* * *} \\
(0.049)\end{array}$ & $\begin{array}{c}0.284^{* * *} \\
(0.049)\end{array}$ & & \\
\hline ivIS $_{\mathrm{s}, \mathrm{t}-1} *$ Exporting $_{\mathrm{it}}$ & & & & & $\begin{array}{l}-0.101 \\
(0.081)\end{array}$ & $\begin{array}{l}-0.101 \\
(0.081)\end{array}$ \\
\hline $\operatorname{ivXS} S_{s, t-1}$ & $\begin{array}{l}-0.018 \\
(0.062)\end{array}$ & $\begin{array}{l}-0.019 \\
(0.062)\end{array}$ & $\begin{array}{l}-0.034 \\
(0.056)\end{array}$ & $\begin{array}{l}-0.035 \\
(0.056)\end{array}$ & $\begin{array}{l}-0.020 \\
(0.063)\end{array}$ & $\begin{array}{l}-0.020 \\
(0.063)\end{array}$ \\
\hline $\operatorname{ivXS}_{\mathrm{s}, \mathrm{t}-1} *$ Skill $_{\mathrm{it}}$ & & & $\begin{array}{c}0.077 \\
(0.063)\end{array}$ & $\begin{array}{c}0.077 \\
(0.063)\end{array}$ & & \\
\hline ivXS $_{\mathrm{s}, \mathrm{t}-1} *$ Exporting $_{\mathrm{it}}$ & & & & & $\begin{array}{c}0.037 \\
(0.165)\end{array}$ & $\begin{array}{c}0.037 \\
(0.165)\end{array}$ \\
\hline Age $_{i t}$ & & $\begin{array}{c}-454.1 \\
(694,947)\end{array}$ & & $\begin{array}{c}-516.1 \\
(701,987)\end{array}$ & & $\begin{array}{c}-621.7 \\
(690,552)\end{array}$ \\
\hline Skill $_{\text {it }}$ & & & $\begin{array}{l}0.019^{*} \\
(0.010)\end{array}$ & $\begin{array}{l}0.019^{*} \\
(0.010)\end{array}$ & & \\
\hline Expit & & & & & $\begin{array}{c}0.207^{* * *} \\
(0.018)\end{array}$ & $\begin{array}{c}0.207^{* * *} \\
(0.018)\end{array}$ \\
\hline Year fixed effects & Yes & Yes & Yes & Yes & Yes & Yes \\
\hline Plant fixed effects & Yes & Yes & Yes & Yes & Yes & Yes \\
\hline Industry trends & Yes & Yes & Yes & Yes & Yes & Yes \\
\hline Observations & $2,945,992$ & $2,945,982$ & $2,945,971$ & $2,945,961$ & $2,945,992$ & $2,945,982$ \\
\hline R-squared & 0.904 & 0.904 & 0.904 & 0.904 & 0.904 & 0.904 \\
\hline
\end{tabular}

Notes: Plant-level OLS and IV regressions. Dependent variable is plant employment. In IV regressions, I instrument IS and XS with import shares from China and export shares to China computed for 54 middle-income countries. Regressions cover data from 2002 to 2012. Robust standard errors clustered at industry level in parenthesis. Significance levels: $* 10 \%$, ** $5 \%$, *** $1 \%$.

\section{5}

\section{Conclusions}

In this chapter, I evaluate the effects of supply and demand shocks on firm dynamics. I take advantage of the recent Chinese growth, which led to increased competition from Chinese imports in Brazil, but also increased demand for Brazilian exports. Using an instrumental variables approach, I find that plant exit is the most important margin of adjustment following supply and demand shocks. While import competition raises exit probability, higher demand is associated with lower exit for plants in affected industries. However, these effects are not homogeneous, but are concentrated among small firms. These results highlight the importance of using data containing the whole size distribution of firms in the trade literature. I also find that increased exposure to Chinese imports increases entry rates in Brazilian industries. These results are counterintuitive and deserve the attention of future work evaluating trade effects on firm dynamics.

These results support theoretical predictions that trade patterns are 
determined by countries' comparative advantages, and that plant outcomes are affected by supply and demand shocks provenient from international trade. One implication from my findings is that future work should focus on understanding the relationship between supply and demand shocks and plant entry and employment, along with the mechanisms involved in these effects, since our estimates were contrary to theoretical work on trade and firm dynamics. Another interesting question is to understand the short and long-run effects of supply and demand shocks on firm dynamics. My findings suggest that operating firms benefit from a positive demand shock, which is reflected in lower entry rates. However, in the long run, increased export opportunities could lead to higher entry rates, raising competition and selection. 
Table 1.16: Employment - size groups.

\begin{tabular}{|c|c|c|}
\hline \multirow[b]{2}{*}{ VARIABLES } & \multicolumn{2}{|c|}{$\log \left(\right.$ Employment $\left._{\mathrm{i}, \mathrm{t}+1}\right)$} \\
\hline & $\begin{array}{c}(1) \\
\text { Red Form }\end{array}$ & $\begin{array}{c}(2) \\
\text { Red Form }\end{array}$ \\
\hline $\operatorname{ivIS}_{\mathrm{s}, \mathrm{t}-1} *$ Small $_{\mathrm{it}}$ & $\begin{array}{l}-0.032 \\
(0.090)\end{array}$ & $\begin{array}{l}-0.032 \\
(0.090)\end{array}$ \\
\hline $\operatorname{ivIS}_{\mathrm{s}, \mathrm{t}-1} *$ Medium $_{\mathrm{it}}$ & $\begin{array}{c}0.004 \\
(0.087)\end{array}$ & $\begin{array}{c}0.004 \\
(0.087)\end{array}$ \\
\hline ivIS $_{\mathrm{s}, \mathrm{t}-1} *$ Large $_{\mathrm{it}}$ & $\begin{array}{c}-0.110 \\
(0.098)\end{array}$ & $\begin{array}{c}-0.110 \\
(0.098)\end{array}$ \\
\hline $\operatorname{ivXS}_{\mathrm{s}, \mathrm{t}-1} *$ Small $_{\mathrm{it}}$ & $\begin{array}{l}-0.009 \\
(0.051)\end{array}$ & $\begin{array}{l}-0.009 \\
(0.051)\end{array}$ \\
\hline $\operatorname{ivXS}_{\mathrm{s}, \mathrm{t}-1} *$ Medium $_{\mathrm{it}}$ & $\begin{array}{l}-0.097 \\
(0.101)\end{array}$ & $\begin{array}{l}-0.098 \\
(0.101)\end{array}$ \\
\hline $\operatorname{ivXS}_{\mathrm{s}, \mathrm{t}-1} *$ Large $_{\mathrm{it}}$ & $\begin{array}{c}0.072 \\
(0.140)\end{array}$ & $\begin{array}{c}0.072 \\
(0.140)\end{array}$ \\
\hline Small $_{i t}$ & $\begin{array}{c}-1.168^{* * *} \\
(0.042)\end{array}$ & $\begin{array}{c}-1.168^{* * * *} \\
(0.042)\end{array}$ \\
\hline Medium $_{\text {it }}$ & $\begin{array}{c}-0.653^{* * *} \\
(0.021)\end{array}$ & $\begin{array}{c}-0.653^{* * * *} \\
(0.021)\end{array}$ \\
\hline Age $_{i t}$ & & $\begin{array}{c}-474.8 \\
(702,058)\end{array}$ \\
\hline Year fixed effects & Yes & Yes \\
\hline Plant fixed effects & Yes & Yes \\
\hline Industry trends & Yes & Yes \\
\hline Observations & $2,945,992$ & $2,945,982$ \\
\hline R-squared & 0.912 & 0.912 \\
\hline
\end{tabular}

Notes: Plant-level OLS and IV regressions. Dependent variable is plant employment. In IV regressions, I instrument IS and XS with import shares from China and export shares to China computed for 54 middle-income countries. Regressions cover data from 2002 to 2012. Robust standard errors clustered at industry level in parenthesis. Significance levels: $* 10 \%$, ** $5 \%, * * * 1 \%$. 


\section{2}

\section{Energy and Misallocation: Evidence from Brazil ${ }^{1}$}

\section{1 \\ Introduction}

Recent empirical evidence has revealed a high degree of heterogeneity in energy efficiency levels across firms, even in narrowly defined industries (Cherniwchan et al., 2017). From the environmental point of view, this evidence suggests that firms underinvest in energy efficient technologies. In this case, there is considerable room for improvement in energy efficiency levels, reducing aggregate energy consumption and emissions associated with energy generation and use (DeCanio, 1993).

A related strand of literature argues, both empirically and theoretically, that dispersion in firm productivity levels within industries might reflect resource misallocation (Banerjee and Duflo, 2005; Restuccia and Rogerson, 2008; Hsieh and Klenow, 2009). This process is characterized by the presence of distortions that simultaneously affect the allocation of resources in the economy and allow the survival of unproductive firms. Resource misallocation implies that aggregate productivity gains can be obtained by reallocating resources across firms, such that the final allocation reflects firms' relative productivity levels. Hence, the dispersion of energy efficiency levels has another important implication, since it potentially reflects an inefficient allocation of energy usage across firms. Moreover, it implies that resource reallocation within industries could lead to both environmental and economic aggregate gains.

The main goal of this chapter is to describe resource misallocation in Brazilian manufacturing, and to quantify the role of energy use among firms in generating misallocation. Quantifying the degree in energy misallocation is important because it is informative of the attainable environmental gains associated with improvements in resource allocation. We also evaluate how allocation efficiency contributed to the evolution of aggregate productivity and energy efficiency in Brazil, from 2007 to 2015. Finally, we quantify the extent to which distortions in firms' inputs, including energy use, result in

\footnotetext{
${ }^{1}$ Written with Amanda Motta Schutze.
} 
manufacturing productivity losses at the aggregate level. We take advantage of detailed Brazilian firm-level data with information on firms' outputs and inputs, covering 106 manufacturing industries. We focus on electricity as our measure of energy, due to its importance in firms' activities (Allcott et al., 2016) and consistent, yearly information on firms' electricity costs in the data.

First, we use the decomposition proposed by Olley and Pakes (1996) to define a direct measure of energy and resource misallocation. From the decomposition, we describe how the evolution of aggregate energy efficiency and productivity in Brazil were driven by technological changes and by the allocation efficiency of resources across heterogeneous firms. Then, we explore the relationship between energy and resource misallocation, both at the aggregate and industry levels. Furthermore, we apply the model in Hsieh and Klenow (2009) including electricity as an input, and we compute potential aggregate productivity gains from reallocating inputs across firms within industries. In a related experiment, we assess the relative importance of each input in generating resource misallocation. We quantify potential gains implied by the model assuming that there are only either capital or electricity distortions affecting firms' input choices.

Our main contribution is to provide empirical evidence that energy misallocation and resource misallocation are positively related across industries. This result implies that there is no trade-off between energy and economic efficiency, so efforts to improve energy efficiency are closely related to policies directed at improving aggregate productivity. Moreover, resource reallocation across firms has the potential to increase not only aggregate productivity, but also improve aggregate energy efficiency levels. The Olley and Pakes (1996) decomposition reveals that resource misallocation increased from 2007 to 2015, and was the main reason preventing aggregate productivity and energy efficiency growth. During this period, resources were reallocated from the most efficient firms, in terms of productivity and energy use, towards firms with lower efficiency levels.

Empirical estimates from the Hsieh and Klenow (2009) model imply that reallocating resources across firms at the industry level would lead to aggregate productivity gains ranging from $78 \%$ to $96 \%$. However, relative gains from capital reallocation are higher than gains from electricity reallocation. While efficient capital allocation would increase aggregate productivity by $30 \%$, the increase from reaching an efficient electricity allocation would be only $2.5 \%$.

Assunção and Schutze (2017) argue that, in Brazil, policies and financial incentives to promote energy efficiency are mainly focused on household consumption. These policies have mostly been responsive to negative supply 
shocks, instead of being a continuous effort to promote better energy use. As a result, firms have little incentive to invest in more efficient technologies, even if they account for the majority of the country's electricity consumption ${ }^{2}$. Understanding the allocation of energy efficiency across firms can have important policy implications, pointing to actions that improve aggregate energy efficiency, without necessarily increasing individual firms' technology levels.

Inefficient energy allocation across firms could arise due to market failures such as imperfect information (Anderson and Newell, 2004; Bloom et al., 2013), assymetric information and principal-agent problem (Howarth et al., 2000; De Almeida, 1998; Ostertag, 2012), credit constraints (Rohdin et al., 2007; Allcott and Greenstone, 2012) and even energy price uncertainty (Diederen et al., 2003; Löfgren et al., 2008). The existence of an energy misallocation implies that potential gains from improving the allocation of resources in the economy would not only increase aggregate productivity, but also raise wellbeing by reducing emissions and energy use.

Our model is different from that of other papers addressing firm-level energy efficiency such as Copeland and Taylor (2013) or Barrows and Ollivier (2018), since it introduces firm-specific wedges that affect the marginal cost of electricity and, consequently, firms' optimal input choices. The inclusion of wedges is essential in our context, resulting in output losses from inefficient resource allocation. However, one disadvantage from using the framework proposed by Hsieh and Klenow (2009) is that it relies on strong assumptions about the elasticity of supply and demand. Haltiwanger et al. (2018) show that, in the case where these assumptions do not hold, the distortions computed from the data could reflect demand shifts or movements along the marginal cost curve, which are not indicative of inefficiencies faced by the firm.

The rest of the chapter is organized as follows. Section 2.2 describes our data sources. We describe the evolution and the relationship between energy misallocation and resource misallocation at the industry level in Section 2.3. In Section 2.4, we apply the model in Hsieh and Klenow (2009) by including electricity as a production input. Section 2.5 quantifies the potential gains from efficiently allocating resources across firms, and evaluates the relative importance of each distortion in generating resource misallocation. Section 2.6 addresses how our estimates for potential aggregate gains are robust to changes in model hypotheses and parameter values. Section 2.7 concludes.

${ }^{2}$ In 2016, manufacturing firms accounted for $33 \%$ of electricity consumption in Brazil (Empresa de Pesquisa Energética, 2017) 


\section{2 \\ Data}

Our primary source of data is the Pesquisa Industrial Anual (PIA), a restricted-access panel data gathered annually by the Brazilian National Bureau of Statistics (IBGE), from 2007 to $2015^{3}$. PIA contains information on formal firms' production and inputs. It consists of a census of firms with at least 30 workers or with gross revenue above a certain limit ${ }^{4}$, and a random sample of smaller firms which do not qualify for the census sample. We drop smaller firms belonging to the random sample, since information is limited for this group and does not contain, for example, electricity expenditure separately from other sources of energy and data on capital stock.

The variables used from PIA include firm's industry according to the three-digit CNAE 2.0 classification, the number of workers on December 31st, labor compensation, value added, electricity expenditures, and the book-value of capital. We measure labor compensation as the sum of wages, bonuses, benefits and social security contribution to paid employees ${ }^{5}$. The book-value of capital is obtained from information on depreciation, investment, leasing and capital rents via the perpetual inventory method. We deflate all monetary values using the IPA-OG deflator, from Fundação Getúlio Vargas, a three-digit CNAE deflator.

By restricting the analysis to the census sample of RAIS, we use $76 \%$ of firm-level observations available in PIA. This sample of firms corresponds to $97 \%$ of Brazilian employment, but only $15 \%$ of the total number of firms operating in Brazil. One drawback from not including the random sample of firms in PIA is that our results could be biased if smaller firms are more subject to distortions which prevents them from adopting energy efficient technologies. Since smaller firms are probably more prone to restrictions such as credit constraints, we believe that by excluding the random sample from our analysis, our results will underestimate the true potential gains from eliminating distortions that generate energy misallocation ${ }^{6}$.

${ }^{3}$ These are confidential data and have been granted access by IBGE through the use of its restricted access room. The results and conclusions expressed in this chapter are our own and do not necessarily present the views of IBGE. Our results do not constitute official IBGE statistics.

${ }^{4}$ This limit is established yearly. For example, this limit was equal to $\mathrm{R} \$ 12.8$ million in 2015.

${ }^{5}$ Our results are not altered by the exclusion of social security contributions in the measure of labor compensation.

${ }^{6}$ Our results are still comparable to those of Hsieh and Klenow (2009), since their data also includes only firms above certain size or revenue restrictions. 
We input data on firm age and municipality from the Relação Anual de Informações Sociais (RAIS) dataset, collected annually by the Brazilian Labor Ministry, from 2007 to 2013. Every year, all formally registered firms are required to report firm-level information, as well as individual characteristics of all its workers. Although RAIS does not contain any reported information on firms' entry year, we infer entry from the earliest hiring year reported in each firm for the whole sample period. Based on the estimated entry year, we calculate firm age accordingly ${ }^{7}$.

Finally, electricity prices by municipality are calculated based on publicly available data from Agência Nacional de Energia Elétrica (ANEEL), the Brazilian electricity regulatory agency. For each electricity distributor in Brazil, we calculate the annual average industrial tariff charged from 2007 to 2015. Although the average tariff does not perfectly reflect the true electricity cost faced by all firms, it is an excellent approximation. We then associate annual electricity prices to Brazilian municipalities based on the geographical coverage of each distributor, and attribute these prices to firms based on the municipality in which they are located. Since we do not have data on firms' municipalities for 2014 and 2015, we recover this information from firms' appearances in RAIS in previous years, whenever possible.

About $10 \%$ of firms in the data report zero or unreasonably low values of electricity expenditures. In Brazil, the government establishes a minimum charge on electricity bills of $\mathrm{R} \$ 30$, even when there is no consumption at all ${ }^{8}$. Thus, we drop all observations reporting electricity expenditures lower than this minimum charge. We also drop five industries with the lowest number of observations, with consistently less than five observations per year. ${ }^{9}$ The final database comprises 63,431 unique firms in 106 three-digit CNAE industries. A complete list of the industries included in our paper is presented in the Appendix, in Table B.1. Table 2.1 details the number of firms and employment included in PIA for each year of the sample.

Our measure of energy efficiency used in section 2.3 consists on the ratio of value added to electricity expenditure. Ideally, we would like to identify electricity consumption by each firm. Electricity consumption is affected by the price of electricity available to firms in different geographical areas. The idea of this energy efficiency is capturing how much production can be attained with a given consumption of electricity. It is widely adopted in works such as Allcott

\footnotetext{
${ }^{7}$ Since we do not have access to RAIS for the years of 2014 and 2015 , we did not consider any age measure for those years.

${ }^{8}$ Resolução Normativa 414/2010

${ }^{9}$ These sectors are: Extraction of crude petroleum and natural gas; Support activities for other mining and quarrying; Manufacture of coke oven products; Manufacture of magnetic and optical media; Manufacture of military fighting vehicles.
} 
and Greenstone (2012); Fisher-Vanden et al. (2004) and by the International Energy Agency. A similar definition considering emissions is common as well, as in Andersen (2017); Barrows and Ollivier (2018). One disadvantage from using this energy efficiency measure is that it relies on electricity costs, and so it does not capture auto-production of electricity by firms. We also measure electricity usage imperfectly for firms in industries where other sources of energy are especially relevant.

Table 2.1: Number of observations in PIA

\begin{tabular}{lll}
\hline Year & Firms & Employment \\
\hline 2007 & 27,604 & $5,158,598$ \\
2008 & 29,508 & $5,415,605$ \\
2009 & 29,943 & $5,415,981$ \\
2010 & 30,753 & $5,852,775$ \\
2011 & 32,520 & $6,085,518$ \\
2012 & 32,718 & $6,202,386$ \\
2013 & 32,139 & $6,258,764$ \\
2014 & 32,240 & $6,122,721$ \\
2015 & 29,765 & $5,660,443$ \\
\hline
\end{tabular}

Notes: Number of firms and total employment by year. Data from PIA.

\section{3 \\ Energy misallocation}

In this section, we define a measure of productivity and energy efficiency dispersion, and we use it to describe the relationship between energy misallocation and overall resource misallocation at the industry level. We also show how the allocation of resources has affected the evolution of aggregate productivity and energy efficiency levels in Brazil, from 2007 to 2015. We use the decomposition developed by Olley and Pakes (1996), which tracks how the evolution of aggregate productivity is affected by technological innovations and changes in the allocation efficiency of resources. This methodology allows us to identify how the allocation of resources is related to aggregate productivity.

Figure 2.1 illustrates that Brazilian aggregate productivity steadily decreases from 2007 to 2015. Aggregate energy efficiency does not change much during this period, although there seems to be a decline starting in 2013. We now decompose these aggregate measures of efficiency to better understand how they were affected by changes in technology and by changes in the allocation of resources across firms. 
Figure 2.1: Aggregate energy efficiency and aggregate productivity

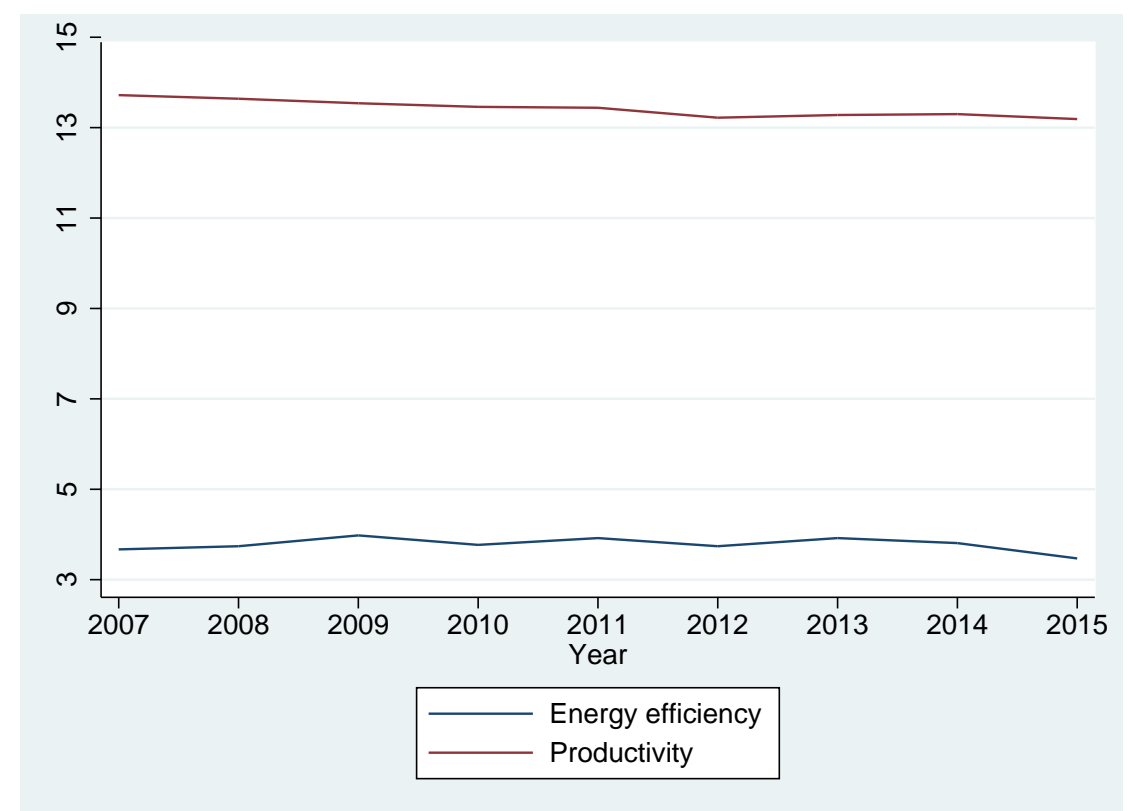

Notes: Aggregate productivity and aggregate energy efficiency by year. Data from PIA and RAIS, from 2007 and 2015.

We denote value added from firm $i$ in industry $s$ by $P_{s i} Y_{s i}$. The aggregate added value of industry $s$ is given by $V_{s}=\sum_{i=1}^{M_{s}} P_{i s} Y_{i s}$, where $M_{s}$ is the number of firms operating in industry $s$. Firm $i$ 's market share is calculated as $\varphi_{i s}=\frac{P_{i s} Y_{i s}}{V_{s}}$.

We define firm-level energy efficiency as the ratio of value added to electricity expenditure, $e_{i s}=P_{i s} Y_{i s} / E_{i s}$, where $E_{i s}$ is electricity expenditure by firm $i$ in industry $s$. The intuition of this measure is that higher energy efficiency levels $e_{i s}$ allow more output to be produced from a given consumption of electricity.

Using the decomposition proposed by Olley and Pakes (1996), we can write the aggregate energy efficiency of industry $s$ as a weighted average of firms' individual energy efficiency levels, using market shares as weights. This term can then be expressed as a function of average energy efficiency and market shares, and deviations from this average value.

$$
e_{s}=\sum_{i=1}^{M s} \varphi_{i s} e_{i s}=\sum_{i=1}^{M s}\left(\bar{\varphi}_{s}+\Delta \varphi_{i s}\right)\left(\bar{e}_{s}+\Delta e_{i s}\right)
$$

where $\bar{\varphi}_{s}$ and $\bar{e}_{s}$ and the unweighted industry averages of market shares and energy efficiency levels. $\Delta \varphi_{i s}$ and $\Delta e_{i s}$ express deviations from the industry average, given by $\Delta \varphi_{i s}=\varphi_{i s}-\bar{\varphi}_{s}$ and $\Delta e_{i s}=e_{i s}-\bar{e}_{s}$.

From the decomposition, we obtain: 


$$
e_{s}=\sum_{i=1}^{M s} \bar{\varphi}_{s} \bar{e}_{s}+\bar{\varphi}_{s} \sum_{i=1}^{M s} \Delta e_{i s}+\bar{e}_{s} \sum_{i=1}^{M s} \Delta \varphi_{i s}+\sum_{i=1}^{M s} \Delta \varphi_{i s} \Delta e_{i s}
$$

The industry sum of deviations from the mean must be zero, by definition, such that $\sum_{i=1}^{M_{s}} \Delta \varphi_{i s}=\sum_{i=1}^{M_{s}} \Delta e_{i s}=0$. Moreover, $\sum_{i=1}^{M_{s}} \bar{\varphi}_{s} \bar{e}_{s}=M_{s} \bar{\varphi}_{s} \bar{e}_{s}=\bar{e}_{s}$, using the fact that $\sum_{i=1}^{M_{s}} \varphi_{i s}=1$. This leaves us with the following expression for industry energy efficiency:

$$
e_{s}=\bar{e}_{s}+\sum_{i=1}^{M s}\left(\varphi_{i s}-\bar{\varphi}_{s}\right)\left(e_{i s}-\bar{e}_{s}\right)
$$

The idea of this decomposition is that aggregate energy efficiency is affected by a technical component, $\bar{e}_{s}$, measuring increases in average efficiency, and a composition component, $\sum_{i=1}^{M s}\left(\varphi_{i s}-\bar{\varphi}_{s}\right)\left(e_{i s}-\bar{e}_{s}\right)$, which captures how the allocation of resources between firms of varying levels of energy efficiency affects the aggregate level of this variable.

We define our measure of electricity allocation in industry $s$, denoted by $\delta_{s}^{e}$, as the composition component described above:

$$
\delta_{s}^{e}=\sum_{i=1}^{M s}\left(\varphi_{i s}-\bar{\varphi}_{s}\right)\left(e_{i s}-\bar{e}_{s}\right)
$$

The efficiency of electricity allocation $\delta_{s}^{e}$ is a measure of the covariance between firms' market shares and energy efficiency in industry $s$. It is negatively related to the degree of misallocation, since higher values of $\delta_{s}^{e}$ imply that electricity is being allocated to firms with high energy efficiency, which in turn increases aggregate energy efficiency in that industry.

We can use the Olley and Pakes (1996) decomposition to define a measure of overall resource misallocation, $\delta_{s}^{\theta}$. We define firm productivity as value added per worker. The allocation measure $\delta_{s}^{\theta}$ is defined analogously to $\delta_{s}^{e}$.

$$
\delta_{s}^{\theta}=\sum_{i=1}^{M s}\left(\varphi_{i s}-\bar{\varphi}_{s}\right)\left(\theta_{i s}-\bar{\theta}_{s}\right)
$$

Again, $\delta_{s}^{\theta}$ can be read as an efficiency measure, a higher delta implies a more efficient allocation of resources, which in turn implies a lower level of misallocation.

Table 2.2 illustrates the decomposition of aggregate energy efficiency and productivity for Brazil from 2007 to 2015. Aggregate energy efficiency decreased from 3.6 in 2007 to 3.47 in 2015, although there is not a clear negative trend in the data. Average firm energy efficiency consistently increases during this period, starting at 2.91 and reaching 3.41 in 2013, but it decreases abruptly to 3.12 in 2015 . The allocation of electricity inputs, on the other 
hand, worsened consistently during the whole period. In 2015, at 0.45 , it falls to $60 \%$ of its initial level.

This Table expresses that, even with an overall improvement in the use of electricity within firms, reflected by average firm efficiency, we find that electricity inputs were reallocated from more energy efficient firms to less energy efficient firms. This fact helps to explain why there was no growth in aggregate energy efficiency during our sample period.

The decomposition of aggregate productivity in Table 2.2 also indicates that the main factor hindering aggregate productivity growth in Brazil is the allocation of resources among heterogeneous firms. Brazilian productivity decreased from 13.72 in 2007 to 13.19 in 2015, but this evolution was not the result of a reduction in firms' average productivity. The main factor explaining the decrease of aggregate productivity is the allocation component, revealing that resources were reallocated from more productive firms to less productive ones.

Table 2.2: Energy efficiency and productivity decomposition

\begin{tabular}{cccccccc}
\hline & \multicolumn{3}{c}{ Energy Efficiency } & & \multicolumn{3}{c}{ Productivity } \\
Year & $e$ & $\bar{e}$ & $\delta^{e}$ & & $\theta$ & $\bar{\theta}$ & $\delta^{\theta}$ \\
\cline { 2 - 4 } \cline { 7 - 9 } 2007 & 3.67 & 2.91 & 0.77 & & 13.72 & 11.61 & 2.11 \\
2008 & 3.74 & 3.04 & 0.70 & & 13.64 & 11.64 & 2.01 \\
2009 & 3.98 & 3.07 & 0.91 & & 13.54 & 11.59 & 1.95 \\
2010 & 3.77 & 3.18 & 0.59 & & 13.46 & 11.65 & 1.82 \\
2011 & 3.92 & 3.23 & 0.69 & & 13.44 & 11.65 & 1.79 \\
2012 & 3.74 & 3.29 & 0.45 & & 13.22 & 11.61 & 1.61 \\
2013 & 3.92 & 3.41 & 0.51 & & 13.28 & 11.65 & 1.63 \\
2014 & 3.81 & 3.37 & 0.44 & & 13.30 & 11.66 & 1.65 \\
2015 & 3.47 & 3.02 & 0.45 & & 13.19 & 11.63 & 1.56 \\
\hline
\end{tabular}

Notes: Decomposition of aggregate energy efficiency and productivity into a technical component, $\bar{e}$ and $\bar{\theta}$, that measure average firm efficiency, and an allocation component, $\delta^{e}$ and $\delta^{\theta}$, that reflects how resources are allocated towards the most efficient firms. Data from PIA and RAIS.

Figure 2.2 plots the relationship between the aggregate measures of resource allocation, $\delta^{e}$ and $\delta^{\theta}$, for each year in our sample. It depicts that there is a positive correlation between the allocation efficiency of energy inputs and the overall allocation efficiency of resources. The Figure also illustrates our result from Table 2.2 that this period was characterized by a decline in the allocation efficiency of resources and energy, as we can see from the falling levels of allocation efficiency over the years. During this period, more productive and energy efficient firms lost market shares, and resources were reallocated to less efficient firms, increasing misallocation. 
Figure 2.2: Aggregate misallocation

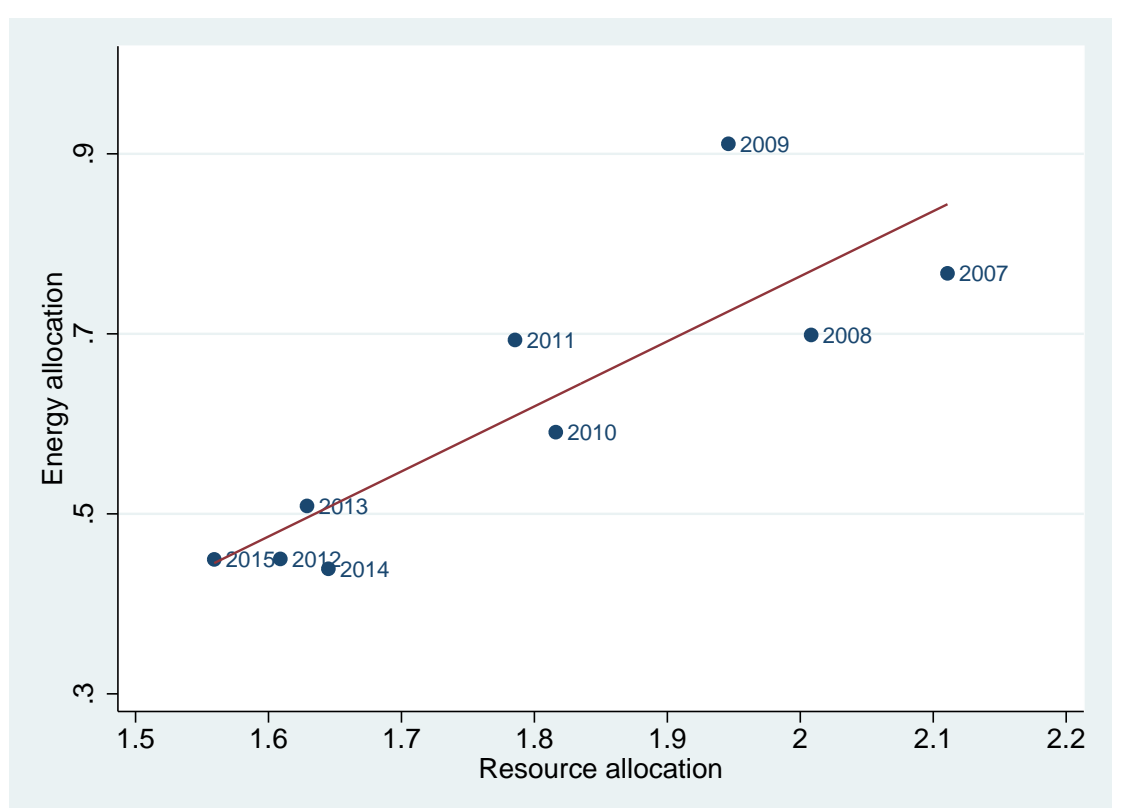

Notes: Aggregate measures of energy allocation, $\delta^{e}$, and resource allocation, $\delta^{e}$, plotted by year. Data from PIA and RAIS.

At the aggregate level, however, dispersion in productivity and energy efficiency levels naturally arise due to differences in industry characteristics such as energy use intensity, production costs and scale. To take these differences into consideration, we now turn to describe the allocation efficiency of resources and energy inputs at the industry level.

Figure 2.3 plots the relationship between the efficiency in energy allocation, $\delta_{s}^{e}$, and in resource allocation, $\delta_{s}^{\theta}$, at the industry level. These measures are computed for each of the 106 mining and manufacturing industries in Brazil, by pooling observations from 2007 to 2015. In Section 2.6, we address if our results are robust to using alternative productivity measures.

Confirming our previous results, we find a positive cross-sectional relationship between $\delta_{s}^{e}$ and $\delta_{s}^{\theta}$, with a correlation coefficient of 0.40 . This result implies that energy allocation efficiency and overall resource allocation efficiency are positively related across industries. In industries where electricity is allocated efficiently, to the most energy efficient firms, resources are generally also allocated to the most productive firms. Hence, we can directly infer that energy misallocation is positively related to resource misallocation. This positive relationship is consistent with evidence that firm-level energy efficiency is one important component in the determination of productivity, since energy efficiency influences firms' optimal decision for other production inputs (Ryan, 2015). Table B.3 in the Appendix reports that these results are not altered when the allocation efficiency measures are computed for a specific year, 2015. 
One important implication from these results is that there is no trade-off between energy allocation efficiency and overall resource allocation efficiency. In particular, it implies that public policy efforts to promote higher energy allocation efficiency should include actions that increase the market share of the most productive firms in each industry.

Figure 2.3: Resource and energy misallocation at the industry level

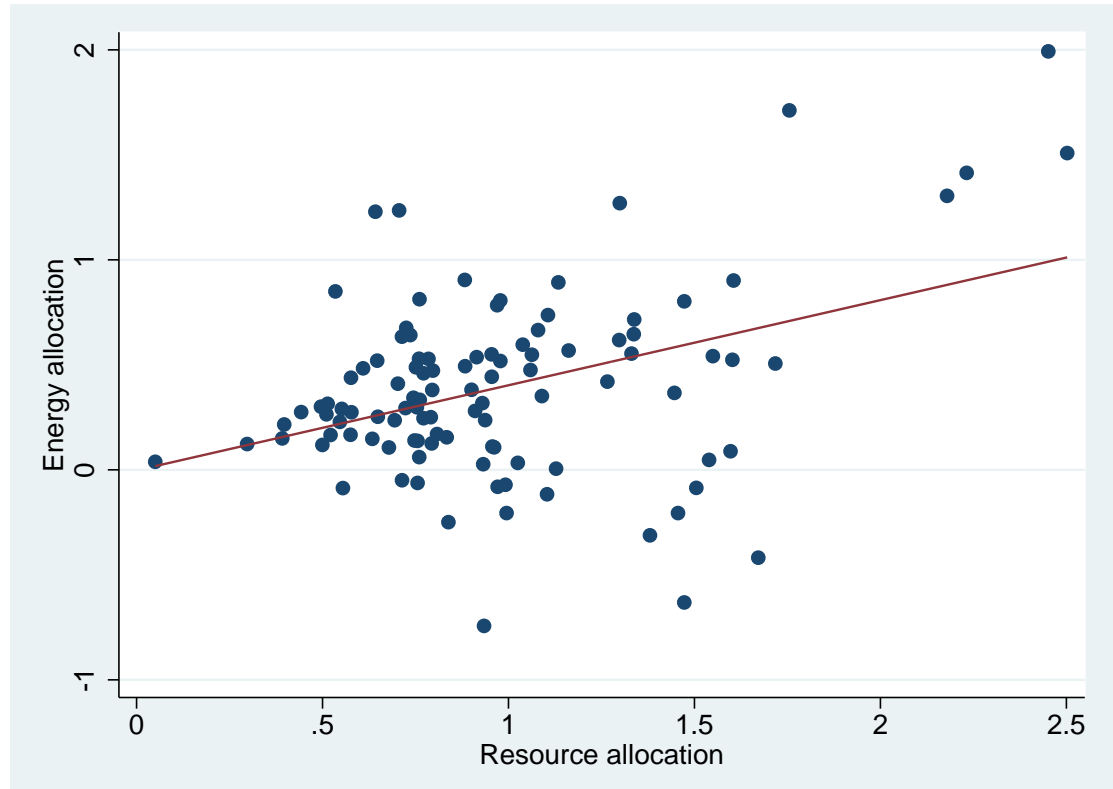

Notes: Measures of energy allocation, $\delta_{s}^{e}$, and resource allocation, $\delta_{s}^{e}$, plotted for each of the 106 three-digit industries in our database. Data from PIA and RAIS.

As a complementary exercise, to provide some evidence on the factors associated with firm performance, we explore the correlation between energy efficiency or productivity and firm characteristics. We run regressions of the form:

$$
\begin{aligned}
& e_{i s t}=\beta_{1} \log \left(E m p_{i s t}\right)+\beta_{2} A g e_{i s t}+\beta_{3} X_{i s t}+\beta_{4} T_{i s t}+\delta_{t}+\delta_{s}+\delta_{d}+\epsilon_{i s t} \\
& \theta_{i s t}=\beta_{1} \log \left(E m p_{i s t}\right)+\beta_{2} A g e_{i s t}+\beta_{3} X_{i s t}+\beta_{4} T_{i s t}+\delta_{t}+\delta_{s}+\delta_{d}+\epsilon_{i s t}
\end{aligned}
$$

We consider both energy efficiency, $e_{i s t}$, and productivity, $\theta_{i s t}$, as dependent variables. Subscripts represent firm $i$, operating in industry $s$, in year $t$. To provide some evidence on the behavior of our efficiency measures over the firm's life cycle, we include firm employment, $\log \left(E m p_{i s t}\right)$, and age $A g e_{i s t}$, as independent variables. We also include electricity prices, $T_{i s t}$. The vector $X_{i s t}$ is a set of firm characteristics possibly associated with energy efficiency and 
Table 2.3: Energy efficiency

\begin{tabular}{lcccc}
\hline & $(1)$ & $(2)$ & $(3)$ & $(4)$ \\
& $\mathrm{e}_{\text {ist }}$ & $\mathrm{e}_{\text {ist }}$ & $\mathrm{e}_{\text {ist }}$ & $\mathrm{e}_{\text {ist }}$ \\
\hline \multirow{3}{*}{$\log \left(\right.$ Employment $\left._{\text {ist }}\right)$} & $0.0859^{* * *}$ & $0.0851^{* * *}$ & $0.154^{* * *}$ & $0.152^{* * *}$ \\
& $(0.00387)$ & $(0.0038)$ & $(0.0098)$ & $(0.0098)$ \\
Age $_{\text {ist }}$ & $-0.0087^{* * *}$ & $-0.0087^{* * *}$ & $0.0584^{* * *}$ & $0.0336^{* * *}$ \\
& $(0.0003)$ & $(0.0003)$ & $(0.0014)$ & $(0.0025)$ \\
Skill $_{\text {ist }}$ & $2.243^{* * *}$ & $2.240^{* * *}$ & $0.334^{* * *}$ & $0.323^{* * *}$ \\
& $(0.0529)$ & $(0.0529)$ & $(0.100)$ & $(0.100)$ \\
Leverage $_{\text {ist }}$ & $-0.179^{* * *}$ & $-0.179^{* * *}$ & $-0.226^{* * *}$ & $-0.226^{* * *}$ \\
& $(0.0020)$ & $(0.0020)$ & $(0.0032)$ & $(0.0032)$ \\
Frac(Family Fist $\left.^{*}\right)$ & $0.328^{* * *}$ & $0.319^{* * *}$ & $0.236^{* *}$ & $0.230^{* *}$ \\
& $(0.0956)$ & $(0.0961)$ & $(0.101)$ & $(0.102)$ \\
Tariff & & $-0.0009^{* * *}$ & & $-0.0010^{* * *}$ \\
& & $(0.0001)$ & & $(0.00008)$ \\
& & & & \\
Year fixed effects & Yes & Yes & Yes & Yes \\
Industry fixed effects & Yes & Yes & Yes & Yes \\
Distributor fixed effects & Yes & Yes & Yes & Yes \\
Firm fixed effects & No & No & Yes & Yes \\
& & & & \\
Observations & 162,421 & 161,531 & 162,421 & 161,531 \\
R-squared & 0.314 & 0.314 & 0.828 & 0.828 \\
\hline
\end{tabular}

Notes: This table presents firm-level regressions of energy efficiency on firm characteristics and the price of electricity. Firm characteristics include employment, age, workers' skill level, firm leverage and the ratio of family members to total employment. Data from PIA. Regressions cover data from 2007 to 2013. Robust standard errors in parenthesis. Significance levels: ${ }^{*} 10 \%,{ }^{* *} 5 \%,{ }^{* * *} 1 \%$.

productivity levels. To test if firms more intensive in human capital are more efficient, on average, $X_{i s t}$ includes a measure of workers' skill level, the fraction of workers with at least a high school degree. We also include a measure of firm leverage, to explore if access to credit alter firm behavior. This measure is computed as the ratio of financial costs to value added. To consider the possibility that firm structure is related to performance, I also include as a control variable the fraction of family members working in the firm relative to total employment. This measure would capture, for example, differences in managerial practices adopted by family firms.

Additionally, we include year fixed effects, $\delta_{t}$, to control for economic events that affect all firms simultaneously, and industry fixed effects, $\delta_{s}$ to control for differences in productivity and energy efficiency levels across activities. We also include electricity distributor fixed effects, $\delta_{d}$, to control for differences in electricity price levels. The regressions are estimated pooling data from 2007 to 2013, the last year for which we have firm age information from RAIS. It is important to note that the goal of this exercise is to describe the 
Table 2.4: Productivity

\begin{tabular}{|c|c|c|c|c|}
\hline & $\begin{array}{l}(1) \\
\theta_{\text {ist }}\end{array}$ & $\begin{array}{l}(2) \\
\theta_{\text {ist }}\end{array}$ & $\begin{array}{l}(3) \\
\theta_{\text {ist }} \\
\end{array}$ & $\begin{array}{l}(4) \\
\theta_{\text {ist }}\end{array}$ \\
\hline $\log \left(\right.$ Employment $\left._{\text {ist }}\right)$ & $\begin{array}{c}0.107^{* * *} \\
(0.0031)\end{array}$ & $\begin{array}{c}0.107^{* * *} * \\
(0.0032)\end{array}$ & $\begin{array}{c}-0.421^{* * *} \\
(0.0086)\end{array}$ & $\begin{array}{c}-0.422^{* * *} \\
(0.0086)\end{array}$ \\
\hline Age $_{\text {ist }}$ & $\begin{array}{c}0.0091^{* * * *} \\
(0.0002)\end{array}$ & $\begin{array}{c}0.0091^{* * *} \\
(0.0002)\end{array}$ & $\begin{array}{c}0.0488^{* * *} \\
(0.0010)\end{array}$ & $\begin{array}{c}0.0470 * * * \\
(0.0018)\end{array}$ \\
\hline Skill $_{\text {ist }}$ & $\begin{array}{c}3.563^{* * *} \\
(0.0423)\end{array}$ & $\begin{array}{c}3.561^{* * *} \\
(0.0423)\end{array}$ & $\begin{array}{l}0.164^{* *} \\
(0.0768)\end{array}$ & $\begin{array}{c}0.163^{* *} \\
(0.0769)\end{array}$ \\
\hline Leverage $_{\text {ist }}$ & $\begin{array}{c}-0.0856^{* * *} \\
(0.0016)\end{array}$ & $\begin{array}{c}-0.0856^{* * *} \\
(0.0016)\end{array}$ & $\begin{array}{c}-0.201^{* * *} \\
(0.0028)\end{array}$ & $\begin{array}{c}-0.202^{* * *} \\
(0.0028)\end{array}$ \\
\hline Frac(Family ist $)$ & $\begin{array}{c}2.376^{* * *} \\
(0.0891)\end{array}$ & $\begin{array}{c}2.370^{* * *} \\
(0.0895)\end{array}$ & $\begin{array}{c}0.968^{* * *} \\
(0.0898)\end{array}$ & $\begin{array}{c}0.967^{* * *} \\
(0.0901)\end{array}$ \\
\hline Tariff $_{\text {ist }}$ & & $\begin{array}{l}-0.00001 \\
(0.00008)\end{array}$ & & $\begin{array}{l}-0.00005 \\
(0.00006)\end{array}$ \\
\hline Year fixed effects & Yes & Yes & Yes & Yes \\
\hline Industry fixed effects & Yes & Yes & Yes & Yes \\
\hline Distributor fixed effects & Yes & Yes & Yes & Yes \\
\hline Firm fixed effects & No & No & Yes & Yes \\
\hline Observations & 162,421 & 161,531 & 162,421 & 161,531 \\
\hline R-squared & 0.341 & 0.340 & 0.821 & 0.821 \\
\hline
\end{tabular}

Notes: This table presents firm-level regressions of productivity on firm characteristics and the price of electricity. Firm characteristics include employment, age, workers' skill level, firm leverage and the ratio of family members to total employment. Data from PIA. Regressions cover data from 2007 to 2013. Robust standard errors in parenthesis. Significance levels: ${ }^{*} 10 \%,{ }^{* *} 5 \%,{ }^{* * *} 1 \%$.

relationship between energy efficiency, productivity and firm characteristics. The results should not be interpreted as causality. The first two columns of Table 2.3 show that there is a positive relationship between firm employment and energy efficiency. This result could reflect the fact that larger firms invest more in energy efficiency due to capital availability or access to credit, or because this investments are profitable for firms operating at a larger scale. Age, on the other hand, is negatively related to energy efficiency. One possible explanation for this result is that firms adopt new technology available at the time they are born. However, as firms age, they do not update their production process as new technologies are made available.

We also find that human capital is positively associated with energy efficiency, as measured by our skill proxy. Firm leverage is negatively associated with energy efficiency, while a high share of family employees is usually associated with higher levels of efficiency. In column two, we find a negative relationship between electricity prices and energy efficiency, which is not consistent with empirical findings (Barrows and Ollivier, 2018). One possible 
reason for this counterintuitive result is that our measure of energy efficiency is computed with electricity expenditure, while ideally we would like to measure consumption. If prices increase, then electricity expenditures will naturally rise.

In the last two columns of Table 2.3, we include firm fixed effects. These results use intra-firm variation over time to identify the effects of firm characteristics on energy efficiency. The relationship between energy efficiency and firm employment intensifies, meaning that firms improve their efficiency in the usage of electricity as they grow. In this specification, the effect of age on energy efficiency turns from negative to positive, which suggests firms invest in energy efficient technologies over their life cycle. The relationship between energy efficiency and the other variables considered are not altered with the inclusion of firm fixed effects.

Table 2.4 presents similar estimates to illustrate firm characteristics associated with high productivity. The first two columns include year, distributor and industry fixed effects. We find that both employment and age are positively associated with productivity, consistent with theoretical and empirical evidence (Hopenhayn, 1992; Dunne et al., 1988). This result is consistent with theoretical predictions that firms' optimal employment is increasing in productivity. Human capital and the fraction of family members are positively related to productivity, while leverage is negatively related, similar to our findings for energy efficiency. We find no effect of electricity prices on productivity. Columns three and four additionally include firm fixed effects to control for unobserved firm-specific characteristics that are constant over time. We find that the inclusion of firm fixed effects results in a negative relationship between productivity and employment. This, however, could be a reflection of our productivity measure, which declines linearly with employment.

In this section, we have shown that there is a positive relationship between the misallocation of energy and overall resource misallocation. Moreover, allocation efficiency in Brazil has not improved over the last decade, preventing aggregate productivity growth. This result suggests the presence of distortions which prevent the growth of the most productive firms. In the next section, we identify the prevalence of distortions affecting resource allocation and quantify the potential gains from reallocating resources across firms.

\section{4}

\section{Theoretical framework}

In this section, we introduce electricity into the model developed by Hsieh 
and Klenow (2009) to allow distortions affecting electricity allocation across firms. The model allows us to infer firm-specific distortions leading to nonoptimal input choices. Based on these distortions, we can quantify potential aggregate productivity gains from reallocating resources across firms. Finally, the model also provides us with an intuitive productivity measure taking into consideration firms' electricity use.

The framework is a standard version of a monopolistic competition model with heterogeneous firms deriving from Melitz (2003). There is a single final good $Y$ produced under perfect competition by combining inputs $Y_{s}$ from $S$ intermediate manufacturing industries.

$$
Y=\prod_{s=1}^{S} Y_{s}^{\rho_{s}}
$$

where $\rho_{s}$ is the industry share of industry $s$ and $\sum_{s=1}^{S} \rho_{s}=1$. The first order condition from profit maximization implies that:

$$
P_{s} Y_{s}=\rho_{s} P Y
$$

Where $P_{s}$ is the price of intermediate good $Y_{s}$, and $P$ is the price of the final good $Y$, where $P \equiv \prod_{s=1}^{S}\left(\frac{P_{s}}{\rho_{s}}\right)^{\rho_{s}}$ is normalized to one.

In each industry $s$, there are $M_{s}$ firms producing differentiated goods $Y_{i s}$ in a monopolistically competitive environment. The constant elasticity of substitution aggregation of these $M_{s}$ goods results in the intermediate good $Y_{s}$.

$$
Y_{s}=\left(\sum_{i=1}^{M_{s}} Y_{i s}^{\frac{\sigma-1}{\sigma}}\right)^{\frac{\sigma}{\sigma-1}}
$$

where $\sigma$ is the elasticity of substitution between differentiated goods.

Each differentiated good $Y_{i s}$ in industry $s$ is produced by a firm $i$ according to a constant returns to scale Cobb-Douglas technology production function. Firms use capital, labor and electricity as inputs. Input shares $\alpha_{s}, \beta_{s}$ and $1-\alpha_{s}-\beta_{s}$ are constant across firms within industry $s$, but are allowed to vary across industries. Firms are heterogeneous in their physical productivity $\theta_{i s}$, and thus production functions are given by:

$$
Y_{i s}=\theta_{i s} K_{i s}^{\alpha_{s}} L_{i s}^{\beta_{s}} E_{i s}^{1-\alpha_{s}-\beta_{s}}
$$

There are firm-specific distortions which alter inputs' marginal costs, reflecting forces such as market failures or governmental policies that distort 
firms' optimal input choices. Output distortions $\tau_{Y i s}$ affect the marginal product of all three inputs simultaneously, while distortions $\tau_{K i s}$ and $\tau_{\text {Eis }}$ affect the marginal revenue of capital and electricity relative to that of labor.

Hsieh and Klenow (2009) thinks of output distortions as reflecting government size restrictions, output subsidies or transportation costs, while capital distortions are likely the result of credit constraints or subsidized access to credit. In the context of electricity, distortions can be interpreted as the failure of prices to account for negative externalities resulting from energy use, or credit constraints that prevent firms from adopting energy efficient technologies. They could also reflect imperfect information which requires managers to incur in costs, either financial or opportunity costs, to learn about available energy efficiency investments.

Wages $w$, the rental price of capital $R$ and electricity prices $T$ are constant across firms and industries, so that profits are given by:

$$
\pi_{i s}=\left(1-\tau_{Y i s}\right) P_{i s} Y_{i s}-w L_{i s}-\left(1+\tau_{K i s}\right) R K_{i s}-\left(1+\tau_{E i s}\right) T E_{i s}
$$

The profit maximization problem defines that the price chosen by each firm is a fixed markup over its marginal cost:

$$
P_{i s}=\left(\frac{\sigma}{\sigma-1}\right)\left(\frac{R}{\alpha_{s}}\right)^{\alpha_{s}}\left(\frac{w}{\beta_{s}}\right)^{\beta_{s}}\left(\frac{T}{1-\alpha_{s}-\beta_{s}}\right)^{1-\alpha_{s}-\beta_{s}} \frac{1}{\theta_{i s}} \frac{\left(1+\tau_{K i s}\right)^{\alpha_{s}}\left(1+\tau_{E i s}\right)^{1-\alpha_{s}-\beta_{b}}}{\left(1-\tau_{Y i s}\right)}
$$

Distortions alter optimal input choices because marginal revenue is equated to the after-tax marginal cost of inputs. From firms' profit maximization problem, we can obtain expressions for the marginal revenue of labor (MRPL), capital (MRPK) and electricity (MRPE):

$$
\begin{aligned}
& M R P L_{i s}=w \frac{1}{\left(1-\tau_{Y i s}\right)} \\
& M R P K_{i s}=R \frac{\left(1+\tau_{\text {Kis }}\right)}{\left(1-\tau_{Y i s}\right)} \\
& M R P E_{i s}=T \frac{\left(1+\tau_{\text {Eis }}\right)}{\left(1-\tau_{Y i s}\right)}
\end{aligned}
$$

From first order conditions of the profit maximization problem, we can infer firm-specific distortions in a given year from relative input use and parameter values: 


$$
\begin{gathered}
1+\tau_{K i s}=\frac{\alpha_{s}}{\beta_{s}} \frac{w L_{i s}}{R K_{i s}} \\
1+\tau_{\text {Eis }}=\frac{1-\alpha_{s}-\beta s}{\beta_{s}} \frac{w L_{i s}}{T E_{i s}} \\
1-\tau_{Y i s}=\frac{\sigma}{\sigma-1} \frac{w L_{i s}}{\beta_{s} P_{i s} Y_{i s}}
\end{gathered}
$$

The presence of distortions can also be inferred from the observed dispersion in revenue productivity (TFPR) across firms, which is defined as physical productivity (TFPQ) multiplied by the output price of firm $i^{10}$.

$$
\begin{gathered}
\text { TFPQ } Q_{i s}=\theta_{i s}=\frac{Y_{i s}}{K_{i s}^{\alpha_{s}} L_{i s}^{\beta_{s}} E_{i s}^{1-\alpha_{s}-\beta_{s}}} \\
T F P R_{i s}=P_{i s} \theta_{i s}=\frac{P_{i s} Y_{i s}}{K_{i s}^{\alpha_{s}} L_{i s}^{\beta_{s}} E_{i s}^{1-\alpha_{s}-\beta_{s}}}
\end{gathered}
$$

Revenue productivity can be written as a function of the marginal revenue product of inputs:

$$
T F P R_{i s}=\frac{1}{\sigma-1}\left(\frac{M R P K_{i s}}{\alpha_{s}}\right)^{\alpha_{s}}\left(\frac{M R P L_{i s}}{\beta_{s}}\right)^{\beta_{s}}\left(\frac{M R P E_{i s}}{1-\alpha_{s}-\beta_{s}}\right)^{1-\alpha_{s}-\beta_{s}}
$$

Substituting the expressions for each marginal revenue product, we finally obtain the expression for TFPR which we take to the data:

$$
T F P R_{i s}=\frac{\sigma}{\sigma-1}\left(\frac{R}{\alpha_{s}}\right)^{\alpha_{s}}\left(\frac{w}{\beta_{s}}\right)^{\beta_{s}}\left(\frac{T}{1-\alpha_{s}-\beta_{s}}\right)^{1-\alpha_{s}-\beta_{s}} \frac{\left(1+\tau_{K i s}\right)^{\alpha_{s}}\left(1+\tau_{E i s}\right)^{1-\alpha_{s}-\beta_{b}}}{\left(1-\tau_{Y i s}\right)}
$$

From equation 2-23, we see that if firm-specific distortions are zero, revenue productivity is constant and depends only on parameter values. Hence, TFPR dispersion across firms results exclusively from distortions $\tau_{Y \text { is }}, \tau_{K i s}$ and $\tau_{\text {Eis }}$. If resources were allocated based on firms' physical productivity, then the output of the most productive firms would increase, and their prices would decrease such that TFPR would be constant in equilibrium.

From the expression above, we can define industry TFP as a function of firms' TFP, weighted by their TFPR relative to the industry average.

$$
T F P_{s}=\left[\sum_{i=1}^{M s}\left(\theta_{i s} \frac{\overline{T F P R}_{s}}{T F P R_{i s}}\right)^{\sigma-1}\right]^{\frac{1}{\sigma-1}}
$$

\footnotetext{
${ }^{10}$ The definition of revenue productivity and its distinction from physical productivity is presented in Foster et al. (2008).
} 
Where the average revenue productivity, TFPR, in industry $s$ is given by:

$$
\overline{T F P R}_{s}=\frac{\sigma}{\sigma-1}\left(\frac{R}{\alpha_{s} \sum_{i=1}^{M_{s}} \frac{1-\tau_{Y i s}}{1+\tau_{K i s}} \frac{P_{i s} Y_{i s}}{P_{s} Y_{s}}}\right)^{\alpha_{s}}\left(\frac{w}{\beta_{s} \sum_{i=1}^{M_{s}}\left(1-\tau_{Y i s}\right) \frac{P_{i s} Y_{i s}}{P_{s} Y_{s}}}\right)^{\beta_{s}}\left(\frac{T}{1-\alpha_{s}-\beta \sum_{i=1}^{M_{s}} \frac{1-\tau_{Y i s}}{1+\tau_{E i s}} \frac{P_{i s} Y_{i s}}{P_{s} Y_{s}}}\right)^{1-\alpha_{s}-\beta_{s}}
$$

We can now derive an expression that allows us to compute physical productivity from the data. We can infer firm output from revenue at a given elasticity of demand, since this elasticity $\sigma$ implies a direct relationship between firms' revenues, quantities and prices.

$$
\theta_{i s}=\kappa_{s} \frac{\left(P_{i s} Y_{i s}\right)^{\frac{\sigma}{\sigma-1}}}{K_{i s}^{\alpha_{s}} L_{i s}^{\beta_{s}} E_{i s}^{1-\alpha_{s}-\beta_{s}}}, \text { where } \kappa_{s}=w^{1-\alpha_{s}} \frac{\left(P_{s} Y_{s}\right)^{-\frac{1}{\sigma-1}}}{P_{s}}
$$

The scalar $\kappa$ depends on the value of $P_{s}$, which is not observable in the data. Nevertheless, $\kappa_{s}$ is constant across firms in industry $s$, and so does not affect relative productivities and potential reallocation gains. We will therefore set $\kappa=1$.

In the absence of firm-specific distortions, marginal revenue products are equalized across firms and industry TFP is given by:

$$
\bar{\theta}_{s}=\left(\sum_{i=1}^{M s} \theta_{i s}^{\sigma-1}\right)^{\frac{1}{\sigma-1}}
$$

Finally we can define the relationship between actual and efficient levels of aggregate output. First we calculate the ratio of actual to efficient TFP for each industry, then aggregate this measure by considering industries' output shares.

$$
\frac{Y}{Y_{\text {efficient }}}=\prod_{s=1}^{S}\left[\sum_{i=1}^{M s}\left(\frac{\theta_{i s}}{\bar{\theta}_{s}} \frac{\overline{T F P R}_{s}}{T F P R_{i s}}\right)^{\sigma-1}\right]^{\frac{\rho_{s}}{\sigma-1}}
$$

This expression quantifies aggregate losses due to the inefficient use of resources between firms. It allows us to compute the potential aggregate output gains if resources were efficiently allocated within all industries.

\section{5}

\section{Potential gains}


So far, we have shown that there is considerable variation in the degree of energy misallocation at the industry level. We also provide evidence that energy misallocation is positively related to overall resource misallocation. In this section, our aim is to quantify resource misallocation in Brazil. We use the model developed by Hsieh and Klenow (2009) to quantify potential aggregate productivity gains taking into consideration the existence of distortions affecting firms' electricity use.

Empirical evidence reveals that the allocation of resources across firms is not only determined by their productivity levels, but also by other external factors affecting firm input choices, for example, labor market regulations, financial constraints, fiscal benefits or subsidized credit. Given industries' productivity distribution, the misallocation of resources across firms reduces potential industry and aggregate output (Restuccia and Rogerson, 2008; Buera et al., 2011; Bartelsman et al., 2013; Hsieh and Klenow, 2009). The theoretical framework presented in Section 2.4 provides a way of identifying distortions affecting firms' input choices and, consequently, enables us to compute how much aggregate productivity would increase in a hypothetical situation where all distortions are eliminated. Lastly, we provide additional evidence on the determinants of misallocation by computing potential aggregate gains in counterfactual scenarios, to identify the relative importance of distortions.

We take the model to the data by measuring labor inputs as labor compensation, to account for heterogeneity in human capital. We later show how results are robust to defining labor as firm employment. We set industry capital shares $\alpha_{s}$ and labor shares $\beta_{s}$ to those observed in the data for each industry. Industry shares are calculated based on aggregate value added.

Following Hsieh and Klenow (2009), we set the rental price of capital to $R=0.1$, considering a 0.05 interest rate and 0.05 depreciation rate. We also set the elasticity of substitution between differentiated goods as $\sigma=3$, although we analyze the response of our results to a larger value of $\sigma$ in our robustness checks in Section 2.6. We set electricity prices to $440 \mathrm{R} \$ / \mathrm{kWh}$, the average electricity price in our sample of firms.

To avoid our results being driven by outlier firms, we compute TFPQ and TFPR for all firms in a given year, then drop the top and bottom $1 \%$ firms in the distribution of $\log \left(T F P R_{i s} / \overline{T F P R}_{s}\right)$ and $\log \left(\theta_{i s} / \bar{\theta}_{s}\right)$ across industries. Once we drop outlier firms, we compute once again industry measures $L_{s}, K_{s}$, $E_{s}, P_{s} Y_{s}, \overline{T F P R}_{s}$ and $\bar{\theta}_{s}$, and industry shares $\rho_{s}$.

Figure 2.4 plots the distribution of physical productivity, $\log \left(\theta_{i s} M_{s}^{\frac{1}{\sigma-1}}\right)$ for 2015, the latest year in our sample. There is considerable dispersion in physical productivity across firms. The heavy left tail of productivity distri- 
bution is consistent with theoretical and empirical evidence documenting that misallocation worsens selection and allows unproductive firms to artificially survive alongside productive ones.

Table 2.5 plots some concrete measures of dispersion for physical productivity, $\log (T F P Q)$, in 2007, 2011 and 2015: the standard deviation, the difference between the $75^{\text {th }}$ and $25^{\text {th }}$ percentiles and between the $90^{\text {th }}$ and $10^{\text {th }}$ percentiles. In 2015, the ratio of physical productivity between the $75^{\text {th }}$ and $25^{\text {th }}$ percentiles in Brazil was 3.85, while the ratio between the $90^{\text {th }}$ and $10^{\text {th }}$ percentiles was equal to 15.48 . To provide an idea for the magnitude of this dispersion, we can compare this result to the one in Hsieh and Klenow (2009). They report that, for the latest year in each sample, the ratio between the $75^{\text {th }}$ and $25^{\text {th }}$ percentiles is equal to 5.0 in India, 3.6 in China and 3.2 in the United States ${ }^{11}$.

Figure 2.4: Distribution of TFPQ

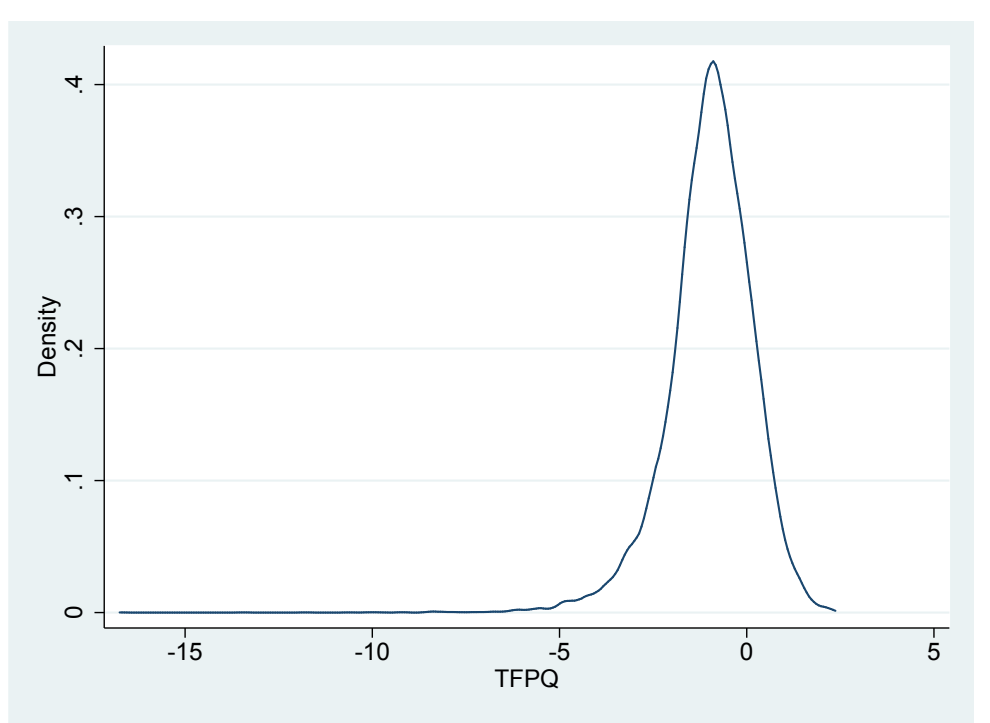

Notes: Distribution of physical productivity, $\log \left(T F P Q_{i s} M_{s}^{\frac{1}{\sigma-1}}\right)$, where $\mathrm{TFPQ}_{\text {is }} \equiv$ $\frac{Y_{i s}}{K_{i s}^{\alpha} L_{i s}^{\beta} E_{i s}^{1-\alpha-\beta}}$.

Figure 2.5 plots the distribution of revenue productivity $T F P R$, $\log \left(T F P R_{i s} / \overline{T F P R}_{s}\right)$, for Brazilian manufacturing firms in 2015. Table 2.6 presents dispersion statistics for three years of the sample, 2007, 2011 and 2015. Our model implies that, in the absence of distortions, revenue productivity is constant across firms. Hence, the dispersion of TFPR depicted in Figure 2.5 and Table 2.6 illustrates the degree of misallocation in the Brazilian economy. The dispersion of TFPR is increasing from 2007 to 2011, implying a reallocation of resources towards unproductive firms. From 2011 to 2015, the

\footnotetext{
${ }^{11}$ When comparing our results to those of Hsieh and Klenow (2009) and other studies, we should take into consideration that the sampling frame and period are different for each country. Comparisons between countries should be made with caution.
} 
Table 2.5: Dispersion of TFPQ

\begin{tabular}{llll}
\hline & 2007 & 2011 & 2015 \\
\hline S.D. & 1.07 & 1.09 & 1.16 \\
$75-25$ & 1.22 & 1.29 & 1.35 \\
$90-10$ & 2.49 & 2.59 & 2.74 \\
$\mathrm{~N}$ & 25,334 & 30,386 & 25,135 \\
\hline
\end{tabular}

Notes: This table plots dispersion measures of physical productivity, $\log (\mathrm{TFPQ})$. For plant $i$ in industry $s, \mathrm{TFPQ}_{\mathrm{is}} \equiv \frac{Y_{i s}}{K_{i s}^{\alpha} L_{i s}^{\beta} E_{i s}^{1-\alpha-\beta}}$. S.D. $=$ standard deviation, $75-25=$ difference between $75^{\text {th }}$ and $25^{\text {th }}$ percentiles, $90-10=$ difference between $90^{\text {th }}$ and $10^{\text {th }}$ percentiles. $\mathrm{N}=$ number of observations. Data from PIA and RAIS.

dispersion of TFPR remains roughly constant. Overall, there is a deterioration in resource allocation efficiency from 2007 to 2015, but the magnitude of this change is small. In 2007, the ratio of revenue productivity between the $75^{\text {th }}$ and $25^{\text {th }}$ percentiles was equal to 2.36 , and by 2015 it had decreased to 2.38 . Hsieh and Klenow (2009) reports ratios of 2.2 in India, 2.3 in China and 1.7 in the United States, suggesting a higher degree of misallocation of resources in Brazil relative to the U.S.

Figure 2.5: Distribution of TFPR

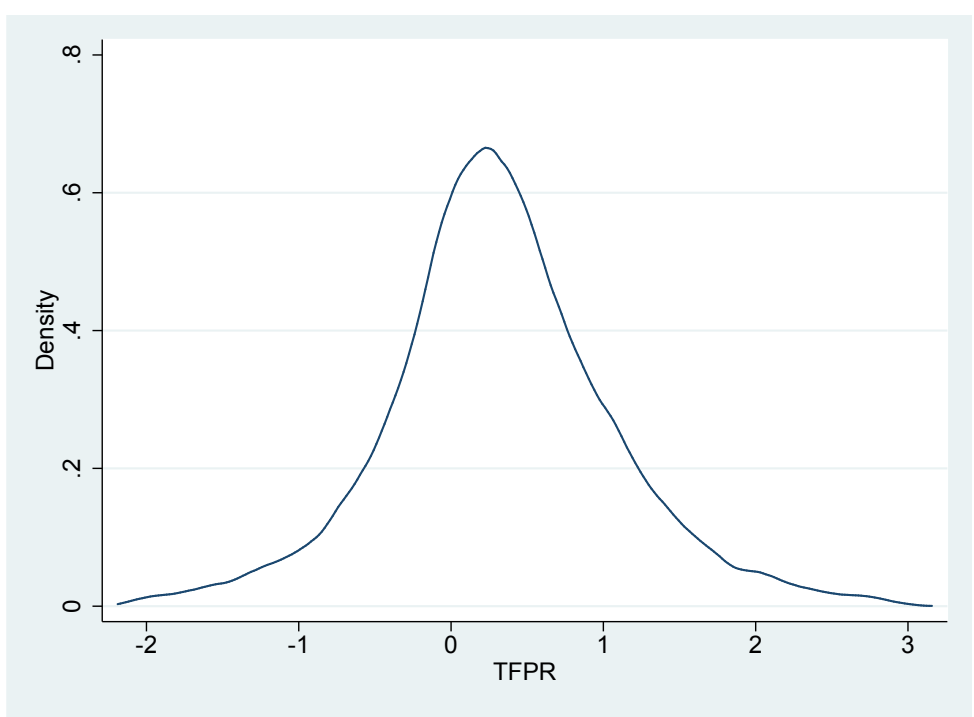

Notes: Distribution of revenue productivity, $\log \left(T F P R_{i s} / \overline{T F P R}_{s}\right)$, where $\mathrm{TFPR}_{\text {is }} \equiv$ $\frac{P_{i s} Y_{i s}}{K_{i s}^{\alpha} L_{i s}^{\beta} E_{i s}^{1-\alpha-\beta}}$.

We now calculate the potential gains in aggregate manufacturing productivity from equalizing the marginal product of inputs within each three-digit industry. Unlike Hsieh and Klenow (2009), we do not use the United States as a benchmark for the minimum dispersion in marginal products that can be achieved in practice. A full equalization of TFPR across firms might not be feasible due to the presence of measurement error in the data, adjustment costs 
Table 2.6: Dispersion of TFPR

\begin{tabular}{llll}
\hline & 2007 & 2011 & 2015 \\
\hline S.D. & 0.73 & 0.76 & 0.76 \\
$75-25$ & 0.86 & 0.88 & 0.87 \\
$90-10$ & 1.78 & 1.85 & 1.85 \\
$\mathrm{~N}$ & 25,334 & 30,386 & 25,135 \\
\hline
\end{tabular}

Notes: This table plots dispersion measures of revenue productivity, $\log (\mathrm{TFPR})$. For plant $i$ in industry $s, \mathrm{TFPR}_{\mathrm{is}} \equiv \frac{P_{i s} Y_{i s}}{K_{i s}^{\alpha} L_{i s}^{\beta} E_{i s}^{1-\alpha-\beta}}$. S.D. $=$ standard deviation, $75-25=$ difference between $75^{\text {th }}$ and $25^{\text {th }}$ percentiles, $90-10=$ difference between $90^{\text {th }}$ and $10^{\text {th }}$ percentiles. $\mathrm{N}=$ number of observations. Data from PIA and RAIS.

or markup variation, for example, which are omitted from the model. Thus, our results should be interpreted as an upper bound for potential output gains in mining and manufacturing, given our sample of firms.

The ratio of actual aggregate output to efficient output is computed for each industry according to:

$$
\frac{Y}{Y_{\text {efficient }}}=\prod_{s=1}^{S}\left[\sum_{i=1}^{M s}\left(\frac{\theta_{i s}}{\bar{\theta}_{s}} \frac{\overline{T F P R}_{s}}{T F P R_{i s}}\right)^{\sigma-1}\right]^{\frac{\rho_{s}}{\sigma-1}}
$$

From equation 2-29, we compute potential aggregate output gains as $\left(Y_{\text {efficient }} / Y\right)-1$. Table 2.7 presents the potential aggregate output gains in Brazil for 2007 to 2015. Our estimates imply that reallocating resources to the point of fully equalizing TFPR within industries would lead to output gains ranging from $77.9 \%$ to $96.2 \%$. These results are comparable to the $86 \%$ gains estimated for China by Hsieh and Klenow (2009), and 85\% gains reported for South Korea by Kim et al. (2017). Busso et al. (2013) perform similar estimates for the Brazilian manufacturing sector, for years from 2000 to 2005. Their results imply aggregate productivity gains that are lower than ours, ranging from 41 to $49 \%$.

The potential gains from eliminating misallocation reported in Table 2.7 fluctuate from 2007 to 2012, and are falling from 2012 onwards. Overall, there was an increase in potential gains during the whole period, from $81.7 \%$ in 2007 to $83.2 \%$ in 2015 . This result is consistent with increasing TFPR dispersion over the sample period, indicating a rise in the misallocation of resources.

The results derived from the model are consistent with our findings in Section 2.3, that resource allocation efficiency has deteriorated from 2007 to 2015. Nevertheless, this relationship is not very clear from the estimated potential gains from reallocation, and there are some years for which gains increase significantly. One possibility for these inconsistent results is that the potential gains computed from the model are being affected by changes in the 
instruments, where reallocating resources across firms would increase output in $15.8 \%$. In this industry, firms' input use closely reflects their physical productivity levels. One interesting fact from Table 2.8 is that the dispersion in potential gains from industries with highest misallocation (highest potential gains) is much higher than the dispersion observed for the most efficient industries.

Table 2.8: Highest and lowest gains from equalizing TFPR (\%)

\begin{tabular}{clc}
\hline \multicolumn{2}{l}{ Panel A: Industries with highest potential gains } & TFP gains \\
CNAE & Industry description & 290.44 \\
192 & Manufacture of refined petroleum products & 171.10 \\
182 & Service activities related to printing & 154,82 \\
221 & Manufacture of rubber products & 146.31 \\
161 & Sawmilling and planing of wood & 139.78 \\
241 & Manufacture of pig iron and iron alloys & 139.16 \\
202 & Manufacture of inorganic chemicals & 139.07 \\
285 & Manufacture of machinery for mining, quarrying and construction & 138.85 \\
105 & Manufacture of dairy products & 138.84 \\
232 & Manufacture of cement & 137.66 \\
309 & Manufacture of other transport equipment n.e.c. & \\
\hline Panel B: Industries with lowest potential gains & TFP gains \\
CNAE & Industry description & 25.30 \\
272 & Manufacture of batteries and accumulators & 25.10 \\
291 & Manufacture of cars & 25.07 \\
303 & Manufacture of railway locomotives and rolling stock & 24.56 \\
072 & Mining of non-ferrous metal ores & 24.55 \\
263 & Manufacture of communication equipment & 23.77 \\
122 & Manufacture of tobacco products & 21.92 \\
171 & Manufacture of pulp & 19.99 \\
121 & Processing of tobacco & 17.65 \\
295 & Engine restoration and rebuilding for motor vehicles & 15.81 \\
322 & Manufacture of musical instruments &
\end{tabular}

Notes: This table presents the top 10 industries with highest potential gains from reallocating resources resulting in constant TFPR within industries (Panel A), and the top 10 industries with the lowest potential gains (Panel B). Gains are computed as $100\left(\frac{Y_{\text {efficient }}}{Y}-1\right)$, where $\frac{Y}{Y_{\text {efficient }}}=\prod_{s=1}^{S}\left[\sum_{i=1}^{M s}\left(\frac{\theta_{i s}}{\bar{\theta}_{s}} \frac{\overline{T F P R_{s}}}{T F P R_{i s}}\right)^{\sigma-1}\right]^{\frac{\rho_{s}}{\sigma-1}}$ and $\operatorname{TFPR}_{\mathrm{is}} \equiv \frac{P_{i s} Y_{i s}}{K_{i s}^{\alpha} L_{i s}^{\beta} E_{i s}^{1-\alpha-\beta}}$.

Finally, we focus on understanding the role of distortions in generating resource misallocation. Table 2.9 provides estimates of aggregate potential gains from eliminating a subset of, but not all, distortions simultaneously. We consider only the last year in our sample, 2015. The first line of Table 2.9 tells us that by eliminating distortions affecting the allocation of capital relative to labor, $\tau_{K i s}$, aggregate productivity would increase by $30.3 \%$. However, eliminating electricity distortions, $\tau_{\text {Eis }}$, would lead to a productivity level only $2.4 \%$ higher.

If we compute hypothetical gains from eliminating misallocation generated by output distortions, $\tau_{Y i s}$, in addition to capital or electricity distortions, productivity gains would be $83.5 \%$ and $5.9 \%$, respectively. Lastly, simultane- 
ously eliminating capital and electricity distortions would result in productivity gains of $33.0 \%$. This experiment reveals that although all distortions, $\tau_{Y i s}, \tau_{K i s}$ and $\tau_{\text {Eis }}$, play a part in generating overall misallocation, distortions that affect the cost of capital relative to labor, along with output distortions, account for most of the resource misallocation observed in Brazil.

Table 2.9: TFP gains from equalizing TFPR within industries (\%)

\begin{tabular}{ll}
\hline Distortions & Gains in 2015 (\%) \\
\hline$\tau_{K}$ & 30.30 \\
$\tau_{E}$ & 2.47 \\
$\tau_{K}, \tau_{E}$ & 33.08 \\
$\tau_{Y}, \tau_{K}$ & 83.54 \\
$\tau_{Y}, \tau_{E}$ & 5.96 \\
\hline
\end{tabular}

Notes: Potential productivity gains assuming the presence of different combinations of distortions, depicted in the first column. Gains are computed as $100\left(\frac{Y_{\text {efficient }}}{Y}-1\right)$, where $\frac{Y}{Y_{\text {efficient }}}=\prod_{s=1}^{S}\left[\sum_{i=1}^{M s}\left(\frac{\theta_{i s}}{\bar{\theta}_{s}} \frac{\overline{T F P R}}{T F P R_{i s}}\right)^{\sigma-1}\right]^{\frac{\rho_{s}}{\sigma-1}}$ and $\mathrm{TFPR}_{\mathrm{is}} \equiv \frac{P_{i s} Y_{i s}}{K_{i s}^{\alpha} L_{i s}^{\beta} E_{i s}^{1-\alpha-\beta}}$.

\section{6 \\ Robustness checks}

In this section, we provide robustness checks to understand how our results are affected by slight modifications in our assumptions and parameter values.

First, we test how the relationship between energy and resource misallocation from Figure 2.3 is altered when we use different productivity measures to compute the degree of resource misallocation.

In Figure B.1, we plot this relationship using a TFP productivity measure considering labor, capital and electricity as inputs. We also compute the physical productivity, TFPQ, defined in Section 2.4, and plot the results in Figure B.2. As we can see, the positive relationship between resource and energy misallocation measures across industries is not affected by these alternative productivity measures. Figure B.3 shows that the positive relationship between energy and resource allocation efficiency is not altered by our decision to calculate these measures for 2015, instead of pooling observations from all year.

Next, we analyze how our baseline results from quantifying potential reallocation gains in Table 2.7 are robust to measuring firm size as the number of employees, instead of labor compensation. In our baseline estimation, we 
measure labor inputs as labor compensation to control for differences in skills and hours worked across firms. However, Hsieh and Klenow (2009) argue that it is possible that wages are determined by other factors, such as rent sharing between firms and workers. The first line in Table 2.10 shows that, when measuring labor as the number of employees, potential reallocation gains in 2015 are equal to $92.78 \%$, compared to $83.26 \%$ from our baseline estimates. Hsieh and Klenow (2009) find that measuring labor inputs with employment decreases potential gains, and they interpret these findings as evidence that wages amplify TFPR differences. For Brazil, wages reduce TFPR differences.

As a final robustness check, we examine how a larger elasticity of substitution between differentiated products, $\sigma$, affect our results. By setting $\sigma$ to 5 , potential gains from resource reallocation increase from $83.26 \%$ in our baseline estimates to $172.31 \%$, as presented in the second line of Table 2.10. This illustrates how our baseline results should be interpreted as a lower bound to potential gains.

Table 2.10: TFP gains from equalizing TFPR within industries (\%)

\begin{tabular}{llll}
\hline Distortions & 2007 & 2011 & 2015 \\
\hline$L_{i s}$ & 86.69 & 98.23 & 92.78 \\
$\sigma=5$ & 157.12 & 171.99 & 172.31 \\
\hline
\end{tabular}

Notes: Robustness checks for potential productivity gains from equalizing TFPR within industries. $L_{i s}$ : firm labor is measured as number of workers. $\sigma=5$ : elasticity of substitution between differentiated goods is set as 5. Gains are computed as $100\left(\frac{Y_{\text {efficient }}}{Y}-1\right)$, where $\frac{Y}{Y_{\text {efficient }}}=$ $\prod_{s=1}^{S}\left[\sum_{i=1}^{M s}\left(\frac{\theta_{i s}}{\bar{\theta}_{s}} \frac{\overline{T F P R_{s}}}{T F P R_{i s}}\right)^{\sigma-1}\right]^{\frac{\rho_{s}}{\sigma-1}}$ and $\mathrm{TFPR}_{\mathrm{is}} \equiv \frac{P_{i s} Y_{i s}}{K_{i s}^{\alpha} L_{i s}^{\beta} E_{i s}^{1-\alpha-\beta}}$.

\section{7 \\ Conclusions}

We use detailed firm-level data with information on electricity expenditures for Brazil, and we find that the degree of resource and energy misallocation are positively related, both at the industry and aggregate levels. This result has important policy implications, since it indicates that there is no trade-off between productive efficiency and environmental gains. Policies promoting the growth of the most productive firms in every industry will lead not only to better resource allocation and higher aggregate productivity, but also improve aggregate energy efficiency and reduce negative externalities associated with energy generation and consumption. We also find that, since 2007, resources were reallocated towards unproductive firms, increasing resource and energy misallocation. Our results suggest that this was the main factor limit- 
ing aggregate productivity and energy efficiency growth in Brazil during this period.

We apply the model in Hsieh and Klenow (2009) to quantify aggregate gains from resource reallocation taking into consideration distortions that affect firms' energy use. Although our estimates reveal substantial gains from resource reallocation, capital distortions are relatively more important than energy distortions in generating resource misallocation and productivity losses.

One limitation from our work is that we consider only one energy source: electricity. Other energy sources could be particularly important for some industries, resulting in imprecision of our energy efficiency estimates. In the near future, it will be very important to evaluate how our results regarding allocation of energy and resources change when we use electricity priced to recover electricity consumption. Our next steps also include evaluating how electricity distortions identified by our theoretical framework are related to energy efficiency levels. This analysis would illustrate the role of resource reallocation in improving aggregate energy efficiency.

Our finding support that the efficiency in energy allocation should be better investigated, as it provides a source of improvement in aggregate energy efficiency and productivity without the need of technological innovations or improving the levels of energy efficiency of individual firms. 


\section{3}

\section{Firm life cycle and the service sector}

\section{1 \\ Introduction}

Recently, firm life cycle growth has been pointed as an important determinant of aggregate output and productivity across countries. Hsieh and Klenow (2014) and Akcigit et al. (2016) highlight that there is a variety of factors, such as institutional and market characteristics, that lower growth incentives for manufacturing firms in developing countries. The growth of productive firms as they age is essential to generate competition and selection, which eliminates unproductive firms from the market and raises aggregate productivity.

So far, there has been little theoretical and empirical evidence on firm life cycle dynamics for the service sector, mainly due to a lack of detailed data including service firms. It is important to understand the determinants of service sector performance, since this sector accounts for a growing share of both developing and developed countries' activities. Table 3.1 illustrates that tertiary activities, which include services and retail, represent a significant share of countries' employment and output.

Although of critical importance, the literature agrees that service productivity is low compared to other industries (Busso et al., 2013; Arbache, 2015; Van Biema and Greenwald, 1997). Convergence of aggregate service productivity across countries is also limited relative to manufacturing, due to the low technology transfer and adoption that characterizes industries with low product tradability (Rodrik, 2013).

In this chapter, I describe that firm life cycle employment growth in Brazil is lower for the service sector, relative to manufacturing. I then test if life cycle determinants pointed by the literature can account for the growth differential between the two sectors, and describe how firm exit is linked to firm characteristics. I focus the analysis on Brazil due to the availability of detailed firm-level data for the service sector. Moreover, Brazil is a developing country with a high participation of service activities in the economy. Table 
3.2 shows the composition of Brazilian activities and illustrates that services account for more than $35 \%$ of the formal labor force.

The main contribution of the analysis is to provide a comprehensive description of firm characteristics and performance over the life cycle. There is little evidence on the causes for the slow productivity growth observed in the service sector, so this work is an initial attempt to describe service performance and suggest possible barriers to firm growth. Another contribution of this chapter is the use of unique firm level data that is representative for all formal service firms. My primary source of data for this paper is the Relação Anual de Informações Sociais (RAIS), a detailed administrative panel data containing the universe of formal Brazilian firms. Unlike most firm-level data, it provides detailed information on service firms, as well as manufacturing firms. It also includes the entire size-distribution of formal firms, which makes it ideal for describing firm life cycle performance. I also use the Pesquisa Anual de Serviços (PAS) database, containing detailed input and revenue data for

I find that lower life cycle growth in the service sector relative to manufacturing is robust to controlling for a set of industry characteristics and institutional backgrounds. I also show that higher average size growth in manufacturing cannot be accounted for by higher exiting rates among smaller firms. However, my results suggest that selection is an important component driving the life cycle differences between the two sectors. Exit rates in manufacturing are higher than in services, and they are more concentrated among smaller and younger firms. These facts combined imply that competition and selection are more intense in manufacturing.

I show that firm productivity and employment are more strongly related in manufacturing than in services, suggesting that employment is limited by external factors. Lastly, I test whether higher monitoring costs faced by service firms could account for the slower employment growth relative to manufacturing. Assuming that supervision activities are performed primarily by family members, I describe the relationship between family employees and firm size. The fraction of family employees is higher in service firms relative to manufacturing, even when controlling for firm employment and age. I also find that the number of family members strongly predicts firm size for service firms, which suggests that high monitoring costs could be an important factor limiting firm growth.

My work builds upon the recent literature on the relationship between firm life cycle dynamics and aggregate productivity. Hsieh and Klenow (2014) finds that differences in life cycle dynamics in manufacturing could account for the lower aggregate productivity observed in Mexico and India relative to 
the United States. Akcigit et al. (2016) develops a model with a particular mechanism through which firm dynamics affect productivity. In their model, institutional differences affect firms' capacity to grow due to managerial efficiency. In countries with less firm growth, there is less selection and, consequently, lower aggregate productivity.

Among papers focusing on the service sector, Audretsch et al. (2004) and Teruel-Carrizosa (2010) test the hypothesis that growth rates and size are unrelated across firms, known as Gibrat's law. They reject the hypotesis, finding that growth rates and size are negative related at the firm level. Arbache (2015) describes service productivity in Brazil using data from PAS, which is also partly used in this paper. He documents that productivity levels vary significantly across industries and over time, and that firm-level productivity and employment are negatively related.

The goal of this paper is most similar to that of Lotti (2007), which tests the validity of stylized facts on firm life cycle to the service sector using Italian data. She documents that well-know life cycle facts are valid not only for manufacturing, but also service firms. However, she does not address the intensity of life cycle growth in services relative to manufacturing, neither tests for determinants of life cycle growth in the service sector.

The rest of the chapter is developed as follows. Section 3.2 presents stylized facts of firm life cycle and describes the determinants of life cycle growth pointed by the literature. Section 3.3 describes the data used in this paper. Section 3.4 characterizes the differences in life cycle employment growth for manufacturing and services in Brazil, and Section 3.5 describes the patterns of firm exit. Section 3.6 aims to provide additional evidence on life cycle determinants for the service sector. First, it describes the relationship between firm employment and productivity, and then tests if monitoring costs could limit firm growth by preventing the hiring of outside managers. Section 3.7 concludes.

\section{2}

\section{Firm life cycle dynamics}

In this section, I present some well known stylized facts concerning firm life cycle dynamics that will guide the empirical work in Sections 3.4 and 3.5. I also list determinants of life cycle growth according to recent empirical and theoretical work. Evans (1987), Hall (1986) and Dunne et al. (1989) provide the first comprehensive set of evidence on firm life cycle by describing the patterns of firm entry, exit and growth for manufacturing firms in the United 
Table 3.1: Tertiary sector shares of employment and GDP (2010)

\begin{tabular}{lcc}
\hline Country & Employment Share & GDP Share \\
\hline Brazil & $\mathbf{7 5 \%}$ & $\mathbf{6 9 \%}$ \\
United States & $81 \%$ & $78 \%$ \\
Germany & $70 \%$ & $69 \%$ \\
China & $49 \%$ & $44 \%$ \\
Russia & $64 \%$ & $61 \%$ \\
India & $27 \%$ & $55 \%$ \\
Korea & $69 \%$ & $59 \%$ \\
Ghana & $43 \%$ & $49 \%$ \\
World & $51 \%$ & $67 \%$ \\
LA and Caribbean & $68 \%$ & $61 \%$ \\
\hline
\end{tabular}

Notes: Employment shares and GDP shares for the tertiary sector, including services and retail, in selected countries. Data from the International Labour Organization.

Table 3.2: Brazilian sector employment share in 2012 (\%)

\begin{tabular}{lc}
\hline & Employment Share \\
\hline Agriculture & 03.10 \\
Manufacturing & 17.22 \\
Utilities & 00.52 \\
Construction & 05.96 \\
Retail & 18.86 \\
Services & $\mathbf{3 5 . 3 6}$ \\
Public Administration & 18.94 \\
\hline
\end{tabular}

Notes: Composition of Brazilian employment in 2012. Data from RAIS.

States. Since their work, these facts have been described and confirmed in different countries and even industries, and have been used as a benchmark for a variety of theoretical work on firm dynamics (Hopenhayn, 1992; Luttmer, 2007; Albuquerque and Hopenhayn, 2004).

The first set of facts we explore imply that employment is not constant during a firms' life. When firms are born, they are smaller relative to other firms in the same industry (Dunne et al., 1988). Firm size and age are positively related. As firms age, they expand their activities, resulting in employment and market share growth (Evans, 1987; Dunne et al., 1989; Hsieh and Klenow, 2014). In Section 3.2.1, I summarize some of the most common hypotheses given by the literature to explain firm life cycle growth. Basically, firm growth over the life cycle can be interpreted as the loosening of restrictions to firm size, as the dissemination of product information and accumulation of demand, or even as the result of industry characteristics.

Most work finds that firm growth rates are decreasing in firm size, contrary to Gibrat's law, which also implies higher growth rates for young 
firms (Dunne et al., 1989; Hall, 1986; Evans, 1987). Audretsch (1995) points that there is a positive relationship between the growth of young firms and the industry minimum efficient scale. Exiting firms are small in size relative to the average firm (Dunne et al., 1988), and the average size of exiting firms is affected by industry characteristics such as scale, fixed costs, and competition.

Firms' exit probabilities are also not constant over the life cycle. The probability of exit faced by a firm is decreasing in age and size (Evans, 1987; Dunne et al., 1989; Hsieh and Klenow, 2014). Entry and exit rates at the industry level are persistent, since they reflect industry characteristics, in addition to general economic conditions (Dunne et al., 1988). In a given year, entry and exit rates are highly and positively related within industries, and respond to current economic shocks (Bartelsman et al., 2005; Lotti, 2007).

\subsection{1}

\section{Firm life cycle determinants}

Atkeson and Kehoe (2005) provide a general understanding of growth determinants over the life cycle of firms. They argue that employment substantially grows during the life cycle due to the accumulation of organizational capital, which is defined as plant specific knowledge. The level of organizational capital is determined, for example, by the accumulation of firm-specific human capital, and learning by doing. According to Hsieh and Klenow (2014), it is also the result from firms' investment in process efficiency, product quality, and efforts to reach distant markets. Many studies have focused on investigating specific factors and their role in either directly restricting firm growth or reducing incentives for growth. These factors affecting firm life cycle can originate from demand or supply-side restrictions. They can naturally arise due to sectoral or local characteristics, or they can be the result of market failures, policies and institutions.

The importance of demand on firm outcomes has long been considered in theoretical work (Caminal and Vives, 1999; Radner, 2003; Fishman and Rob, 2003; Bar-Isaac and Tadelis, 2008). Foster et al. (2016) shows empirical evidence that demand is a key factor in explaining firm employment growth over the life cycle. Informational frictions and reputation mechanisms are some of the factors that could result in the observed size differences between newborn and mature firms. They show that productivity is a poor predictor of size for newborn firms, even in highly homogeneous industries such as roasted coffee beans, cement and manufactured ice.

Over time, consumers learn about the product and its quality, and 
the firm increases its employment following a raise in demand. The authors show that a demand accumulation process accounts for a considerable part of the observed relationship between firm age and average size in the United States. This mechanism is likely to be more pronounced in industries with differentiated products, or products for which quality cannot be easily inferred.

The presence of credit constraints also imply that firm life cycle growth is driven by the loosening of restrictions over time. In theoretical models such as Cooley and Quadrini (2001), Albuquerque and Hopenhayn (2004) and Clementi and Hopenhayn (2006), credit constraints arise due to limited liability or asymmetric information, and imply that firm size do not fully reflect productivity levels, as it is restricted by access to credit. As firms age, they accumulate savings from profits, which allows them to grow and slowly overcome credit constraints. These models are able to explain the empirical facts that size increases with age, exit probabilities decrease with age, and that younger firms will grow at higher rates, on average.

Empirical evidence provided by Cabral and Mata (2003) also points to credit constraints as an important component in the evolution of firm size distribution. The limitation caused by these constraints on firm growth is especially relevant for younger firms, with its effects on firm size decreasing over the life cycle. In addition to affecting firm growth, Buera et al. (2011) reveals that financial constraints can affect the selection of firms operating in a market, given a distribution of entrepreneurial ability. This effect is more pronounced in industries with higher capital intensity.

The economic environment also affects firm growth over the life cycle by shaping incentives for firm growth. For example, Levy (2008) shows that taxes and labor regulations can disproportionately affect larger firms, reducing firm growth through costs imposed by these policies. Pagés (2010) expresses that programs benefiting small and medium entrerprises (SME) create the risk of "developing a large mass of very small enterprises that survive thanks to public subsidies and creating many low productivity jobs that could have been high productivity jobs if created elsewhere". She argues that such programs would generate higher welfare gains if targeted at all firms, not just small ones. Furthermore, programs should be limited to formal firms, creating incentives for formalization.

Illustrating the more general role of institutions, Akcigit et al. (2016) argue that the efficiency of delegation is a determinant of firm life cycle growth and dynamics that is especially relevant in developing countries. Delegation efficiency facilitates the decentralization of decisions and allows firm growth by the hiring of outside managers. They develop a model in which entrepreneurs 
have a fixed-time endowment, which means firm growth depends on hiring managers to overlook the production process. In the presence of a weak rule of law, low contract enforcement, lack of trust, or low human capital, delegation efficiency will be low and firms will have lower incentives to invest in new technologies and expand their production. They calibrate the theoretical model and quantify that delegation efficiency accounts for $5 \%$ of productivity and $15 \%$ of income differences between the U.S and India.

These results complement the experimental evidence provided in Bloom et al. (2013), which finds that poor managerial practices are partly responsible for firms' low productivity and growth in the Indian textile industry. They also show that slow life cycle growth results in weak selection, allowing the survival of unproductive family firms. While informational barriers are the main reason for poor managerial practices adopted by firms, expansion incentives are also reduced due to the rule of law and lack of trust in non-family members.

Theoretical work has extensively documented the role of international trade on firm dynamics. Melitz (2003) develops a trade model in the context of heterogeneous firms, and describes that international trade enables the most productive domestic firms to grow by selling their products abroad. An additional effect of trade is the intensified competition resulting from international firms operating in the domestic market. As a result, unproductive domestic firms are eliminated from the market, increasing average productivity of operating firms. Bernard et al. (2007) shows that these results also emerge in a context where countries have distinct comparative advantages.

Trade costs can reflect barriers actively imposed by the government, such as import taxes and quotas, or transportation costs resulting from infrastructure. Trade costs can also reflect idiosyncratic industry characteristics. For a given institutional environment, we expect trade to be more intense in industries where products are easily transported and exchanged. Gervais and Jensen (2013) documents that, on average, service industries are less tradable than manufacturing industries. However, they perform a counterfactual analysis and conlude that liberalization of service trade could lead to welfare gains comparable to those in the manufacturing sector.

Another determinant of firm life cycle growth that relies solely on intrinsic industry characteristics is production scale. Audretsch (1995) reports that there is a positive relationship between the minimum production scale and growth rates of young firms. Selection is also partly determined by industry scale in classical models of firm dynamics. In Hopenhayn (1992), firms' decision to exit is based on expected profits, which in turn are affected by the scale of the production and fixed costs. 


\section{3 Data}

This work uses data primarily from the Relação Anual de Informações Sociais (RAIS), an administrative dataset collected by the Brazilian Ministry of Labor containing the universe of formal workers and firms in Brazil ${ }^{1}$. I have access to data from 2002 through 2012. RAIS is an annual panel where each observation corresponds to a worker employed by an establishment at some point during the reference year. In this chapter, I group establishments to obtain information at the firm level.

This dataset is suitable for the goal of describing plant life cycle because it includes the entire size distribution of formally registered firms and covers all industries, including the service sector. Usually, firm-level data is only available for plants above a certain size threshold. In this case, if young plants are small, they will be disproportionately omitted from the sample, and the resulting database will not be representative across the age distribution.

I use RAIS to obtain information on firm employment on December $31^{\text {st }}$, workers' hiring year, age, entry and exit years, municipality and industry as measured by four-digit CNAE activity codes. The panel structure of the database allows me to infer exit from observing operating firms each year. I define exit as a categorical variable equal to one in year $t$ for firm $i$ if this firm is missing from the data in all subsequent periods. Exit rates in year $t$ are are defined as the ratio of the number exiting firms to operating firms in year $t$.

RAIS does not provide reported information on firm entry, so I proxy entry year as the earliest hiring year reported by each firm, considering all workers and years for which we have data on that specific firm ${ }^{2}$. From that entry year, I compute age measures for each firm, considering that newborn firms are one year old. This entry measure is also adopted in Cabral and Mata (2003) and Brummund and Connolly (2018). The underlying assumption for this entry proxy is that there is at least one worker hired during the firm creation. Job turnover implies that, as firms get older, this assumption is less likely to hold. For this reason, I only consider firms up to twenty years old in the analysis. Entry rates are defined as the ratio of newborn firms in year $t$ to the number of operating firms in year $t-1$.

Most papers infer firm entry year from observing the first time each firm appears in the data. However, since my data does not include a long time span,

${ }^{1}$ The dataset does not include self-employed workers

${ }^{2}$ I also consider the hiring year of employees not active on December 31st, as they provide an additional source of information on the establishments' entry year into the market. 
this method would only permit identifying firms up to 10 years old. Another reason why I believe this entry proxy is a better option for measuring age is that firms frequently disappear from RAIS for one or more years ${ }^{3}$. Since all formal establishments are required to submit the RAIS questionnaire, it is not clear why this happens ${ }^{4}$, but it implies that observing firms' presence in the data might not be a very accurate entry measure.

I work with a random sample of establishments due to the large size of the original RAIS dataset. I list all manufacturing and service firms included in the data and randomly sample $30 \%$ of them. Then, I recover observations from all years for the sampled firms. I limit the sample to firms that do not switch between manufacturing and services during the observed period ${ }^{5}$. To ensure that the data used is consistent throughout this chapter, I further limit the data by dropping industries that are not included in my secondary source of data, described below ${ }^{6}$.

One limitation from the RAIS dataset is that it does not contain any information on firms' production and inputs, necessary to compute productivity measures. Another limitation, as detailed in the second chapter, is that RAIS does not account for informal firms and for informal workers hired by formal firms. This limitation is especially relevant in the service sector, since informality tends to be concentrated in service and retail activities (Maloney, 2004).

The final dataset contains data from 623,352 unique firms. Table C.1 in the Appendix details the yearly number of observations for manufacturing and services. To provide a better look into the composition of the service sector, Table C.2 presents the share of firms and employment in service activities.

To analyze additional firm characteristics, I base part of my results on two other datasets: Pesquisa Industrial Anual (PIA) and Pesquisa Anual de Serviços (PAS) for manufacturing and service firms, respectively, from 2002 to 2012, both annually collected by Instituto Brasileiro de Geografia e Estatística $(\mathrm{IBGE})^{7}$. These datasets contain detailed information on the inputs used in

\footnotetext{
${ }^{3}$ In the sample used in this work, $12 \%$ of establishments disappear at least once. It is more common for firms to disappear for a short period of time, as $65 \%$ percent of disappearing plants are absent for only one year.

${ }^{4}$ The most plausible explanation is that establishments may simply have not filled in the questionnaire, or its activities were suspended during that year. Another possibility is that those establishments had an invalid identifier.

${ }^{5}$ Industry switchers account for $6 \%$ of establishments.

${ }^{6}$ I drop observations from three two-digit industries: Financial intermediation (CNAE 66), Insurance (CNAE 66) and Health and social work (CNAE 85).

${ }^{7}$ These are confidential data and have been granted access by IBGE through the use of its restricted access room. The results and conclusions expressed in this chapter are our own and do not necessarily present the views of IBGE. Our results do not constitute official IBGE statistics.
} 
the production process and on outputs such as revenues and profits, and its main goal is to provide information on the performance of various industries in Brazil.

The datasets cover all active formal Brazilian firms ${ }^{8}$. Both PIA and PAS are panels consisting of two samples: a deterministic sample and a survey sample. Firms in the deterministic sample are included in the dataset with probability one. Firms in the surveyed sample are randomly selected based on its number of employees, industry and location. In PIA, the deterministic sample consists of manufacturing firms with at least 30 workers, or with gross revenue larger than some threshold which is established differently for every year ${ }^{9}$. It is important to note that, until 2006, PIA only surveyed firms with at least 5 workers. In PAS, the deterministic sample consists of service firms with at least 20 employees, but also includes smaller firms operating in more than one state or with revenue levels consistent with firms in the deterministic sample ${ }^{10}$. PAS does not include information on Financial intermediation, Insurance, as well as Health and social work industries.

The variables used from PIA and PAS include number of workers on December $31^{\text {st }}$, value added, number of owners, partners and family members working for the firm, and three-digit CNAE industry codes. I deflate value added using a three-digit industry deflator. I measure firm productivity as value added per worker. PIA and PAS do not contain information on firms' age or entry and exit year, so I input this information from RAIS.

The final data from PIA and PAS contains 298,438 unique firms. Table C.3 in the Appendix presents the annual number of observations from each sample, separately for PIA and PAS.

\section{4}

\section{Employment over life cycle}

In this section, I describe employment and life cycle growth for manufacturing and service firms in Brazil. To ensure that the results are not driven by outliers, I do not consider firms above the $99^{\text {th }}$ employment percentile when calculating descriptive statistics. When characterizing firm life cycle growth, I classify outlier observations for each age, and then drop firms with at least one outlier observation. There is vast documentation that the firm-size distribution is right-skewed, reflecting the fact that industries are composed of a large

\footnotetext{
${ }^{8}$ It does not cover public administration and private non-profit organizations.

${ }^{9}$ For example, in 2012 this threshold was $\mathrm{R} \$ 10.4$ million.

${ }^{10}$ Unlike PIA, PAS does not state a specific revenue threshold over which firms are included in the deterministic sample.
} 
share of small firms and a few very large firms (Coad, 2007; Cabral and Mata, 2003; Bartelsman et al., 2005). Descriptive statistics are highly sensitive to the inclusion of outlier firms.

To avoid results being biased by the age measure, I restrict the analysis to firms up to 20 years old. However, results are not altered when I consider firms of all ages. I do not calculate exit for the year of 2011. The regular absence of firms in the data described in Section 3.3 implies that inferring exit from observing firms for a single year is imprecise.

First, I infer scale differences between sectors from the average size of operating, newborn and exiting firms by year. Table 3.3 illustrates that average firm size does not vary abruptly across years, and that firms in the manufacturing sector are on average larger than service firms. The average manufacturing firm employs 13.6 workers, while in service industries the average size is 7.2. This fact suggests that the manufacturing sector is defined by higher fixed costs and a higher minimum efficient scale of operation, below which firms choose to exit the market. This is a common assumption in works dealing with multisector models, such as Buera et al. (2011). Consistent with life cycle stylized facts, newborn firms are smaller than the average operating firm (Dunne et al., 1988). Exiting firms are also smaller than the average firm, but larger than newborn firms.

Table 3.3: Average firm size by year

\begin{tabular}{cccccccc}
\hline & \multicolumn{3}{c}{ Manufacturing } & & \multicolumn{3}{c}{ Services } \\
\cline { 2 - 4 } \cline { 6 - 8 } Year & Operating & Newborn & Exiting & & Operating & Newborn & Exiting \\
\hline 2002 & 12.69 & 4.87 & 5.36 & & 6.92 & 3.29 & 3.81 \\
2003 & 12.67 & 5.03 & 5.38 & & 6.89 & 3.40 & 3.83 \\
2004 & 13.23 & 5.30 & 5.57 & & 6.90 & 3.36 & 3.75 \\
2005 & 13.18 & 5.11 & 5.82 & & 6.96 & 3.44 & 4.15 \\
2006 & 13.26 & 5.18 & 5.45 & & 7.02 & 3.40 & 4.07 \\
2007 & 13.73 & 5.31 & 5.47 & & 7.11 & 3.49 & 3.68 \\
2008 & 13.63 & 4.99 & 5.39 & & 7.20 & 3.55 & 3.72 \\
2009 & 13.29 & 4.66 & 5.03 & & 7.20 & 3.56 & 3.60 \\
2010 & 13.29 & 4.78 & 5.55 & & 7.30 & 3.50 & 3.54 \\
2011 & 13.83 & 4.57 & - & & 7.41 & 3.46 & - \\
2012 & 13.62 & 4.26 & - & & 7.45 & 3.50 & - \\
\hline
\end{tabular}

Notes: Average size of operating, newborn and exiting firms by year. Calculated separately for manufacturing and services. Data from RAIS.

Next, I describe the relationship between the average size of surviving firms and age. Figure 3.1 plots average size by age relative to newborn firms, to control for scale differences between the two sectors. The first thing we note about Figure 3.1 is that both manufacturing and services display a positive monotonic relationship between average plant size and age within sectors. This 
fact is consistent with both theoretical and empirical evidence on life cycle growth (Jovanovic, 1982; Evans, 1987; Hopenhayn, 1992; Hsieh and Klenow, 2014).

It also reveals that employment life cycle growth is more intense in manufacturing than in service firms, and the difference in growth between sectors seems to be increasing with firm age. In Brazil, the average 20-year-old manufacturing firm is 7.92 times larger than the average newborn firm, and 2.53 times larger than the average 10-year-old firm. Meanwhile, the average 20-year-old service firm is 4.70 times larger than newborn firms, and 1.85 times larger than 10-year-olds. The growth of 20-year-old relative to newborn manufacturing firms is similar to the magnitude of approximately 6 pointed by Hsieh and Klenow (2014) and 7 times pointed by Atkeson and Kehoe (2005) for the United States. Figure C.1 in the Appendix illustrates that the results are not altered if firm entry is computed based on observing when firms first appear in the data.

Figure 3.1: Employment over the life cycle

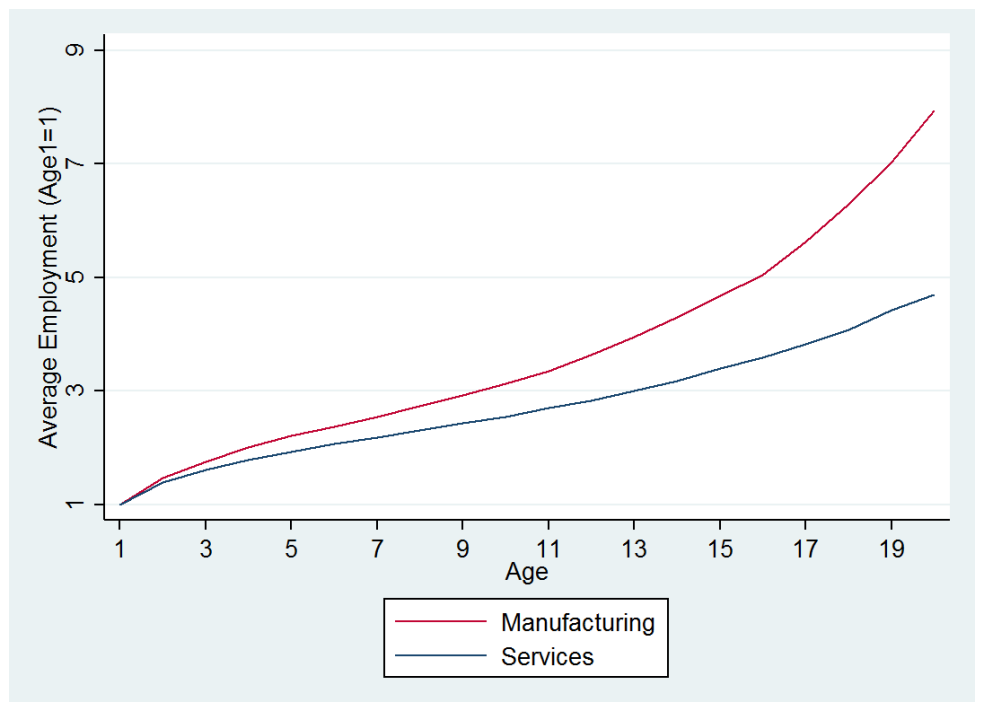

Notes: This figure plots average firm employment by age, for manufacturing and service firms. Data from RAIS, from 2002 to 2012.

In an attempt to provide more robust evidence on firm life cycle growth, I estimate regressions of log employment on a quadratic specification of firm age, separately for manufacturing and services, so that we can visualize the magnitude of growth in each sector.

$$
\log \left(E m p_{i s t}\right)=\beta_{1} A g e_{i s t}+\beta_{2} A g e_{i s t}^{2}+\epsilon_{i s t}
$$

where $E m p_{i s t}$ and $A g e_{i s t}$ are, respectively, employment and age for firm $i$, in sector $s$ and year $t$. I present the results from a quadratic specification to pro- 
vide evidence on the linear and nonlinear effects of firm age on employment. The qualitative results and statistically significant difference between manufacturing and services remain when I alternatively consider a linear specification, or a more flexible specification including dummies for each age.

The first two columns of Table 3.4 contain the results from these baseline regressions. They show that the positive relationship between firm size and age depicted in Figure 3.1 is maintained. Firm growth for manufacturing firms, as measured by the linear effect of age on firm employment, is statistically higher than in services. The coefficient for $\mathrm{Age}^{2}$ is negative and statistically significant, which suggests that firm growth rates are positively related, but decreasing, with firm age. Declining growth rates with age have been widely documented in studies such as Hall (1986), Dunne et al. (1989) and Albuquerque and Hopenhayn (2004).

It is likely that the relationship depicted in Figure 3.1 partly reflects year-specific events that affect firm employment, and size differences between cohorts. For every cohort of plants, initial size and growth are affected by economic conditions at that specific point in time. To account for this possibility, regressions in columns three and four of Table 3.4 add year and cohort fixed effects. The effect of firm age on employment rises for both sectors, but previous results are unchanged. The observed employment growth in manufacturing is statistically higher than in services.

To further test how sector characteristics and external factors account for the higher life cycle growth observed in manufacturing relative to service firms, I run regressions with a series of control variables, in addition to year and cohort fixed effects. The first possibility I address is that scale differences lead to a slower employment growth throughout firm life cycle in services. As we have seen in Section 3.2.1, a smaller scale of production reduces growth incentives and simultaneously worsens market selection. To roughly control for scale differences between manufacturing and services, I compute average newborn firms' employment at the four-digit industry level over the sample period. The idea is that average newborn employment contains information on fixed costs and the minimum scale of operation necessary for firm survival. I include this measure in the regressions as a proxy for industry scale. The results in columns five and six show that the magnitude of the effects in each sector are not affected by the inclusion of the scale measure.

A more conservative way to control for differences in scale in the regression is to include four-digit industry fixed effects, which captures unobserved industry characteristics that are fixed over time. This specification also captures other constant industry characteristics such as intrinsic product trad- 
ability. Service goods are naturally less tradable than manufacturing goods (Gervais and Jensen, 2013), which could limit the growth of productive firms (Melitz, 2003; Bernard et al., 2007) and inhibit technology transfers that lead to increased productivity (Rodrik, 2013). Columns seven and eight report that the inclusion of industry fixed effects barely changes the magnitude of the relationship between age and employment, and manufacturing life cycle growth remains statistically higher than in services.

Another possibility is that growth in service firms is lower due to regulations or human capital availability. According to Akcigit et al. (2016), delegation efficiency differences resulting from regulations or human capital levels have an important role in determining life cycle growth and selection. If service activities are concentrated in municipalities with stricter regulation or lower human capital, then the aggregate growth in service industries will seem lower than in services.

To test whether differences in local market conditions account for higher life cycle growth in manufacturing relative to services, I estimate regression 3-1 including municipality fixed effects. Note, however, that this specification does not control for differences in regulation across sectors. Due to the low number of observations in each municipality, I do not include cohort fixed effects in this specification, so that the variation in the data is sufficient for estimating the effect of age on employment. Columns nine and ten indicate that the inclusion of municipality fixed effects reduces the effect of firm age on employment, but does not alter the main fact that manufacturing firms grow faster as they age.

So far, I have use cross-sectional variation between firm age and employment to investigate the intensity in life cycle growth. As a final experiment, I test for the possibility that life cycle growth differences between manufacturing and services are driven by intrinsic firms characteristics. For example, selection into entrepreneurship could result in more productive entrepreneurs starting firms in manufacturing activities rather than in services. Also, it is possible that manufacturing entrepreneurs are more educated, or with better managerial practices than in services.

To account for this mechanism, I add firm fixed effects in the baseline regression, along with year fixed effects. This approach controls for constant individual characteristics, and uses intra-firm variation to identify the effect of age on employment. In the last two columns of Table 3.4, we can see that growth differences between the two sectors virtually disappear. In a more flexible specification where I include age dummies, we infer that manufacturing firms' growth is initially higher than in services, but at 10 years of age, this difference becomes statistically insignificant. This result suggests that life 
cycle differences are mainly driven by firm-specific characteristics, rather than industry factors or market failures. 
Table 3.4: Regressions of size by age

\begin{tabular}{|c|c|c|c|c|c|c|}
\hline & \multicolumn{2}{|c|}{ Log(Employment) } & \multicolumn{2}{|c|}{ Log(Employment) } & \multicolumn{2}{|c|}{ Log(Employment) } \\
\hline & $\begin{array}{l}\text { Manuf. } \\
\text { (1) }\end{array}$ & $\begin{array}{l}\text { Serv. } \\
(2)\end{array}$ & $\begin{array}{c}\text { Manuf. } \\
(3)\end{array}$ & $\begin{array}{c}\text { Serv. } \\
(4)\end{array}$ & $\begin{array}{l}\text { Manuf. } \\
(5)\end{array}$ & $\begin{array}{c}\text { Serv. } \\
(6)\end{array}$ \\
\hline Age & $0.131^{* * *}$ & $0.096^{* * *}$ & $0.185^{* * *}$ & $0.149^{* * *}$ & $0.183^{* * *}$ & $0.148^{* * *}$ \\
\hline $\mathrm{Age}^{2}$ & $\begin{array}{c}(0.0009) \\
-0.00283^{* * *} \\
(0.00005)\end{array}$ & $\begin{array}{c}(0.0005) \\
-0.00236^{* * *} \\
(0.00002)\end{array}$ & $\begin{array}{c}(0.0030) \\
-0.00455^{* * *} \\
(0.00006)\end{array}$ & $\begin{array}{c}(0.0018) \\
-0.00416^{* * *} \\
(0.00003)\end{array}$ & $\begin{array}{c}(0.0030) \\
-0.00456^{* * *} \\
(0.00006)\end{array}$ & $\begin{array}{c}(0.0017) \\
-0.00418^{* * *} \\
(0.00003)\end{array}$ \\
\hline Year fixed effects & No & No & Yes & Yes & Yes & Yes \\
\hline Cohort fixed effects & No & No & Yes & Yes & Yes & Yes \\
\hline Scale $4 \mathrm{~d}$ proxy & No & No & No & No & Yes & Yes \\
\hline Industry $4 \mathrm{~d}$ fixed effects & No & No & No & No & No & No \\
\hline Municipality fixed effects & No & No & No & No & No & No \\
\hline Firm fixed effects & No & No & No & No & No & No \\
\hline Observations & 745,843 & $2,011,781$ & 745,843 & $2,011,781$ & 745,831 & $2,011,781$ \\
\hline \multirow[t]{3}{*}{$\mathrm{R}$ squared } & 0.118 & 0.073 & 0.125 & 0.079 & 0.142 & 0.110 \\
\hline & \multicolumn{2}{|c|}{ Log(Employment) } & \multicolumn{2}{|c|}{ Log(Employment) } & \multicolumn{2}{|c|}{ Log(Employment) } \\
\hline & $\begin{array}{l}\text { Manuf. } \\
(7)\end{array}$ & $\begin{array}{l}\text { Serv. } \\
(8)\end{array}$ & $\begin{array}{l}\text { Manuf. } \\
(9)\end{array}$ & $\begin{array}{l}\text { Serv. } \\
(10)\end{array}$ & $\begin{array}{c}\text { Manuf. } \\
\text { (11) }\end{array}$ & $\begin{array}{l}\text { Serv. } \\
(12)\end{array}$ \\
\hline Age & $\begin{array}{c}0.180^{* * *} * \\
(0.0029)\end{array}$ & $\begin{array}{c}0.156^{* * *} \\
(0.0016)\end{array}$ & $\begin{array}{c}0.131^{* * *} \\
(0.0009)\end{array}$ & $\begin{array}{c}0.098^{* * *} \\
(0.0005)\end{array}$ & $\begin{array}{c}0.084^{* * *} \\
(0.0011)\end{array}$ & $\begin{array}{c}0.071^{* * *} \\
(0.0005)\end{array}$ \\
\hline $\mathrm{Age}^{2}$ & $\begin{array}{c}-0.00453^{* * *} \\
(0.00006)\end{array}$ & $\begin{array}{c}-0.00410^{* * * *} \\
(0.00003)\end{array}$ & $\begin{array}{c}-0.00283^{* * *} \\
(.000053)\end{array}$ & $\begin{array}{c}-0.00240^{* * *} \\
(0.00002)\end{array}$ & $\begin{array}{c}-0.00397^{* * *} \\
(0.00006)\end{array}$ & $\begin{array}{c}-0.00289^{* * *} \\
(0.00002)\end{array}$ \\
\hline Year fixed effects & Yes & Yes & Yes & Yes & Yes & Yes \\
\hline Cohort fixed effects & Yes & Yes & No & No & No & No \\
\hline Scale $4 \mathrm{~d}$ proxy & No & No & No & No & No & No \\
\hline Industry $4 \mathrm{~d}$ fixed effects & Yes & Yes & No & No & No & No \\
\hline Municipality fixed effects & No & No & Yes & Yes & No & No \\
\hline Firm fixed effects & No & No & No & No & Yes & Yes \\
\hline Observations & 745,843 & $2,011,781$ & 745,631 & $2,011,543$ & 745,843 & $2,011,781$ \\
\hline $\mathrm{R}$ squared & 0.169 & 0.182 & 0.173 & 0.106 & 0.030 & 0.037 \\
\hline
\end{tabular}

Notes: This table presents the results from firm-level regressions of employment on age, considering a quadratic specification. Regressions are performed separately for the manufacturing and service sectors.

Data from RAIS. Regressions cover data from 2002 to 2012. Robust standard errors in parenthesis. Significance levels: * $10 \%, * * 5 \%, * * * 1 \%$. 
Figure 3.2: Employment growth of surviving firms

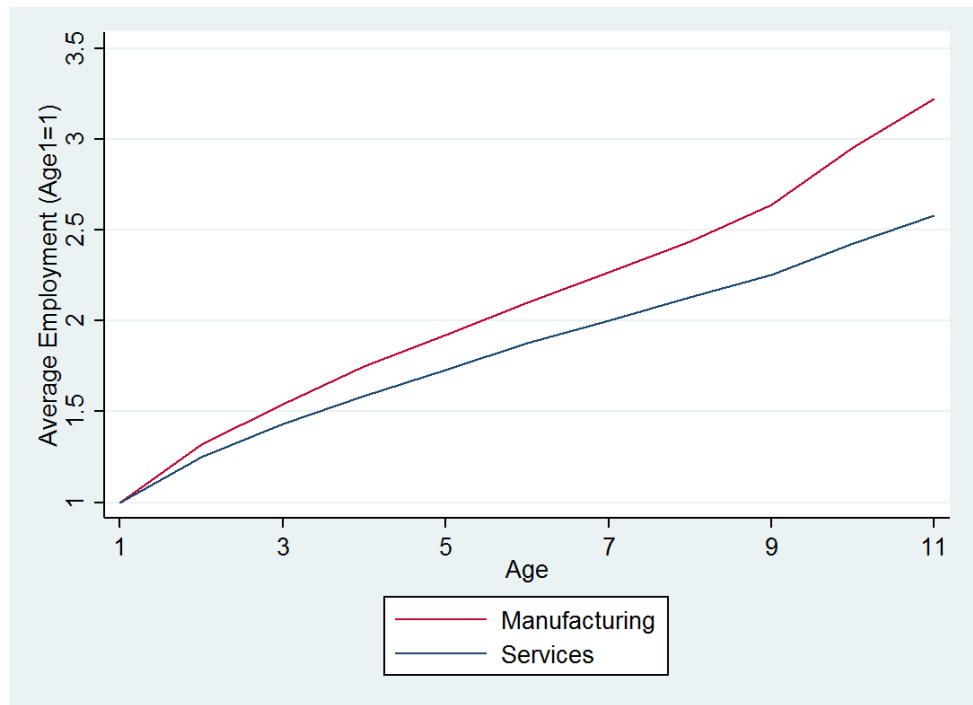

Notes: This figure plots the average firm growth of surviving firms. Growth of surviving firms at a given age is computed by comparing average firm employment at that age with the average employment of those same firms when they were newborn. I keep the sample constant so firm growth does not reflect average employment growth due to firm selection. Data from RAIS.

Even if the growth of surviving firms was identical in both manufacturing and services, higher exit among manufacturing small firms could generate the pattern presented in Figure 3.1. The average size of surviving firms by age is subject to selection bias, since it is affected by the growth of surviving firms, but also by the average size of exiting firms. If exit is concentrated among small firms, then the average size of surviving firms will overestimate actual firm growth.

To infer firm life cycle employment growth while controlling for selection bias, I use an approach similar to that in Hsieh and Klenow (2014). Figure 3.2 plots the growth of average employment relative to newborn firms, considering a balanced panel for each age group. Firms which did not survive are not taken into account when computing average size growth. Since this approach requires a balanced panel, I am only able to compute life cycle growth for firms up to 11 years old.

The interpretation for Figure 3.2 is that the average size of manufacturing firms which survived up to at least 11 years of age is 3.22 times higher than the average size of these same plants when they were born. The 11 year-old corresponding growth inferred from simply computing average size by age is 3.35. For the service sector, firms surviving up to age 11 are 2.57 times larger than their average newborn employment. The equivalent 11-year service growth implied by Figure 3.1 is 2.69. The employment growth rate inferred from using a balanced panel of firms is slightly lower than from simply comparing average 
size by age, in accordance with the fact that exiting firms are smaller than average in both sectors. Confirming previous results, I find that firm life cycle growth is more intense in manufacturing, and that service firms do not seem to be catching up with manufacturing as they age.

\section{5}

\section{Selection}

Firm exit is an important dimension of firm dynamics. In this section, I describe exit rates over the life cycle and examine the role of selection in explaining higher average employment growth in manufacturing relative to services.

Figure 3.3: Entry and exit rates by year

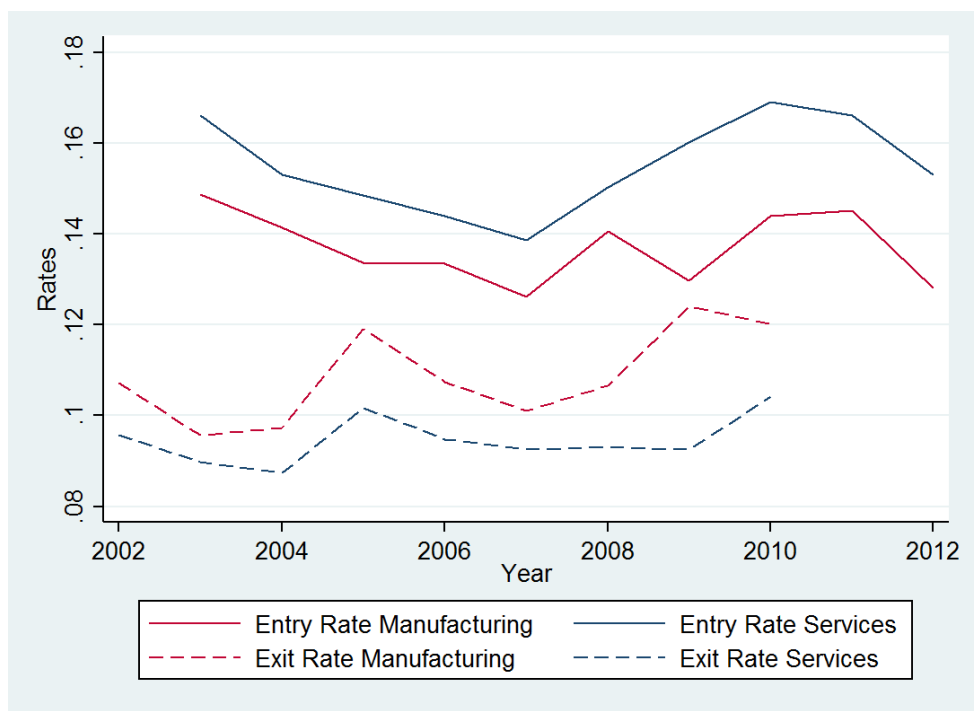

Notes: This figure plots entry and exit rates for manufacturing and services. Data from RAIS, from 2002 to 2012.

Figure 3.3 depicts yearly entry and exit rates for manufacturing and services, from 2002 to 2012. As detailed in Section 3.3, there is no entry rate information for 2002, and no exit rates for 2011 and 2012. Consistent with prior literature on firm dynamics, there are persistent differences in entry and exit rates across industries (Dunne et al., 1988). Entry rates are higher is services than in manufacturing industries in all years of the database. However, exit rates are lower in services. The fact that net entry rates is higher in services is similarly reported in Lotti (2007). While this fact could reflect the ongoing expansion of service activities, it could also be a sign of lower competition and selection.

Theoretical models directly incorporating creative destruction as a selection mechanism, such as Atkeson and Kehoe (2005) and Akcigit et al. (2016), 
argue that lower exit rates could be the result of lower growth over the firm life cycle. If productive firms do not grow and increase their market shares, they do not generate the competition needed to push unproductive firms out of the market.

Figure 3.3 confirms that entry and exit rates are highly contemporaneously correlated across sectors, and that cyclicality plays an important part in determining entry and exit in a given year. Moreover, entry and exit rates are positively correlated in a given year, although this relationship seems less pronounced in the data.

Exit probabilities reflecting the rates presented in Figure 3.3 depend not only on industry attributes and aggregate macroeconomic conditions, but also on firm-level characteristics. Empirical evidence shows that exit is negatively related to firm age, and that this relationship is valid even when holding firm size fixed (Evans, 1987; Dunne et al., 1989; Hsieh and Klenow, 2014). Lotti (2007) confirms that this pattern is also present in the service sector. Furthermore, these studies show that exit is concentrated among smaller firms, given firm age. Next, I characterize these stylized facts for manufacturing and service firms in Brazil, and describe the intensity of selection in both sectors.

First, I focus on the evolution of sector exit rates over the life cycle. Figure 3.4 reveals that exit rates decrease monotonically with firm age for both manufacturing and services. Exit rates are highest among newborn firms and very similar in both sectors. They decline at a decreasing rate, and seem to stabilize for firms around 15 years of age. In manufacturing, 18.05\% of firms exit the market during their first year of operation, compared to $18.67 \%$ in services. This magnitude is similar to the estimates reported in Bartelsman et al. (2005) for OCDE countries, in which 20 to $40 \%$ of firms exit the market within two years of their entry.

However, I find that the fall in exit rates over firm life cycle is faster in manufacturing than in the service sector. For 10-year-old firms, these rates are, respectively, $8.02 \%$ and $5.79 \%$. Exit rates reach their minimum at firms with 20 years of operation, of which $5.41 \%$ of manufacturing and $2.89 \%$ of service firms exit the market.

The negative relationship between exit rates and age in Figure 3.4 simultaneously reflects the effect of age and employment on firm exit probability. To test the role of age and employment on selection, I run a Probit regression where the dependent variable is a dummy indicating plant exit of firm $i$, in industry $s$ and year $t, E x i t_{i s t}$, and explanatory variables are plant age, $A g e_{i s t}$, and the $\log$ of employment, $\log \left(E m p_{i s t}\right)$. 
Figure 3.4: Exit rates by age

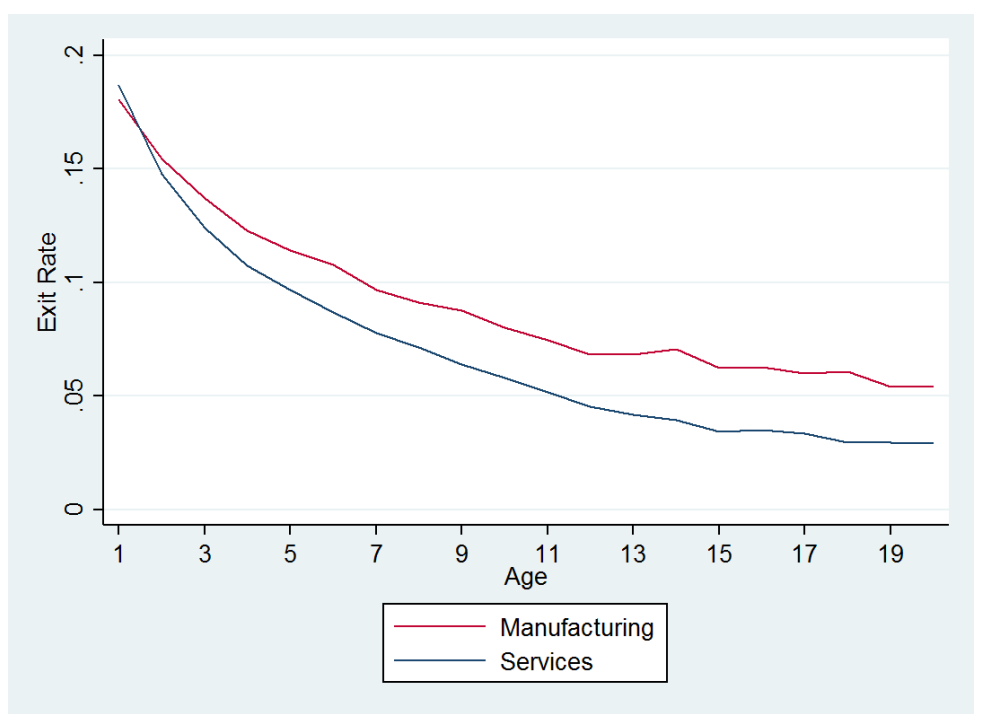

Notes: This figure plots exit rates by age, separately for manufacturing and services. Data from RAIS, from 2002 to 2012.

$$
\operatorname{Pr}\left(\text { Exit }_{i s t}\right)=\Phi\left(\alpha_{1} \log \left(E m p_{i s t}\right)+\alpha_{2} A g e_{i s t}+\delta_{t}+\delta_{c}+\delta_{i}+\epsilon_{i s t}\right)
$$

In addition to inferring the individual effect of employment and age on firm exit probabilities, this strategy allows me to control for unobservables that affect firm exit. I introduce year fixed effects, $\delta_{t}$, to allow for economic shocks simultaneously affecting all firms' exit probabilities. I also introduce cohort and four-digit industry fixed effects, $\delta_{c}$ and $\delta_{i}$, to control for constant industry and cohort characteristics that are related to exit outcomes.

The first two columns of Table 3.5 present that, in fact, there is a negative relationship between firm size, measured by employment, and exit, as previously pointed by the literature. This relationship is statistically significant in both sectors, but the magnitude of the manufacturing coefficient is higher than the one in services. This result points to the fact that selection in manufacturing industries is concentrated in smaller firms, and thus an increase in size more intensively reduces the probability of firm exit. Mata (1994) highlights that size is an important determinant of survival in the presence of economies of scale, which could at least partly explain higher selection in manufacturing. He argues that, in high scale industries, "smaller firms are more likely to leave the industry, since the cost penalty they experience vis-à-vis larger companies may make their position harder to sustain".

Columns three and four in Table 3.5 confirm that exit probability is decreasing in firm age. The magnitude of the impact of age on exit is higher for 
service firms, but the coefficients for manufacturing and services is statistically insignificant. The last two columns of the table reveal that our previous results are not affected by simultaneously controlling for firm size and age. The magnitude of the effect of age on firm exit decreases once employment is accounted for, but it remains negative and statistically significant. According to Evans (1987) and Dunne et al. (1989), the negative relationship between exit rates and age can be interpreted as firms becoming more competitive as they age, either through a learning mechanism or simply due to selection. In the theoretical model presented in Hopenhayn (1992), controlling simultaneously for firm employment and age provides information on firms' productivity levels.

The results imply that selection over life cycle is weaker for service firms, and that exit is less concentrated among smaller firms. These facts suggest that selection and life cycle growth are closely related. In the next section, I explore mechanisms that rely on firm characteristics and test how they are likely to generate the life cycle pattern in the data. 
Table 3.5: Exit probability

\begin{tabular}{|c|c|c|c|c|c|c|}
\hline & \multicolumn{2}{|c|}{ Exit } & \multicolumn{2}{|c|}{ Exit } & \multicolumn{2}{|c|}{ Exit } \\
\hline & $\begin{array}{l}\text { Manuf. } \\
(1)\end{array}$ & $\begin{array}{c}\text { Serv. } \\
(2)\end{array}$ & $\begin{array}{c}\text { Manuf. } \\
(3)\end{array}$ & $\begin{array}{c}\text { Serv. } \\
(4)\end{array}$ & $\begin{array}{c}\text { Manuf. } \\
(5)\end{array}$ & $\begin{array}{c}\text { Serv. } \\
(6)\end{array}$ \\
\hline Log(Employment) & $\begin{array}{c}-0.0538^{* * *} \\
(0.0003)\end{array}$ & $\begin{array}{c}-0.0454^{* * *} \\
(0.0002)\end{array}$ & & & $\begin{array}{c}-0.0538^{* * *} \\
(0.0003)\end{array}$ & $\begin{array}{c}-0.0454^{* * *} \\
(0.0002)\end{array}$ \\
\hline Age & & & $\begin{array}{c}-0.0065^{* * *} \\
(0.0006)\end{array}$ & $\begin{array}{c}-0.0071^{* * *} * \\
(0.0003)\end{array}$ & $\begin{array}{c}-0.0014^{* *} \\
(0.0006)\end{array}$ & $\begin{array}{c}-0.0034^{* * *} \\
(0.0003)\end{array}$ \\
\hline Year fixed effects & Yes & Yes & Yes & Yes & Yes & Yes \\
\hline Industry fixed effects & Yes & Yes & Yes & Yes & Yes & Yes \\
\hline Cohort fixed effects & Yes & Yes & Yes & Yes & Yes & Yes \\
\hline Observations & 603,266 & $1,577,952$ & 603,266 & $1,577,952$ & 603,266 & $1,577,952$ \\
\hline $\mathrm{R}$ squared & 0.062 & 0.064 & 0.025 & 0.039 & 0.062 & 0.064 \\
\hline
\end{tabular}

Notes: This table presents estimates from Probit regressions in which the dependent variable is a dummy indicating firm exit. Independent variables include the log of firm employment and firm age. Data from RAIS. Regressions cover data from 2002 to 2010. Robust standard errors in parenthesis. Significance levels: * 10\%, ** $5 \%, * * * 1 \%$. 


\section{6}

\section{Firm Characteristics}

In this section, I aim to provide additional insight on the determinants of firm life cycle growth by describing the relationship between firm characteristics and employment. First, I analyze the relationship between firm productivity and employment, a key prediction in theoretical models of firm dynamics. I also test the role of age-related distortions in explaining this relationship in the data for manufacturing and services. Finally, I address how delegation efficiency and monitoring costs could account for lower employment growth in services relative to manufacturing.

I take advantage of more detailed firm information provided in the PIA and PAS databases to perform the experiments in this section. Table 3.6 reports descriptive statistics for the main variables used in this chapter, and shows that data in PIA and PAS are comparable to data in RAIS. This table uses data from 2007 onwards to ensure the comparability of the data. In previous years, the sampling frame in PIA does not include firms with less than 5 workers. In the analysis, I include year fixed effects to ensure that this sampling frame does not affect my results.

Table 3.6 summarizes that the average employment and firm age for manufacturing and services are comparable in the different data sources. The fraction of newborn and exiting firms is higher in RAIS than in PIA and PAS. This is probably due to the fact that imputed entry and exit information from RAIS is highly concentrated among small firms, which are part of the random sample in PIA and PAS. Thus, estimates of entry and exit are imprecise in data obtained from IBGE.

\subsection{1}

\section{Productivity and employment}

Theoretical models of firm life cycle growth imply that there is a direct positive relationship between firm productivity and employment (Hopenhayn, 1992; Luttmer, 2007). In Section 3.2.1, I describe that there are a number of factors associated with slower firm life cycle growth. These factors can arise due to market failures, regulation, public policies, or even due to industry characteristics, such as scale and tradability. In the presence of these factors, the relationship between firm productivity and size is weakened.

The goal of this subsection is to describe the intensity of the crosssectional relationship between employment and productivity levels in man- 
Table 3.6: Descriptive Statistics

\begin{tabular}{lccccc}
\hline & \multicolumn{2}{c}{ Manufacturing } & & \multicolumn{2}{c}{ Services } \\
\cline { 2 - 3 } \cline { 5 - 6 } \cline { 5 - 6 } Panel A: RAIS & Mean & S.D. & & Mean & S.D. \\
Employment & 13.69 & 25.75 & & 7.29 & 13.30 \\
Age & 8.82 & 7.49 & & 8.62 & 8.49 \\
Entry & 0.11 & 0.31 & & 0.12 & 0.33 \\
Exit & 0.11 & 0.31 & & 0.09 & 0.29 \\
& & & & \\
\hline Panel B: PIA and & PAS & & & \\
Employment & 14.66 & 0.19 & & 5.20 & 0.11 \\
Age & 8.02 & 0.08 & & 7.05 & 0.11 \\
Entry & 0.05 & 0.00 & & 0.06 & 0.00 \\
Exit & 0.04 & 0.00 & & 0.10 & 0.01 \\
& & & & \\
Productivity & 33652.84 & 521.50 & & 33783.35 & 1137.63 \\
Family members & 1.29 & 0.01 & & 1.45 & 0.01 \\
\hline
\end{tabular}

Notes: This table presents descriptive statistics by sector, computed separately for each database used. Data from RAIS, PIA and PAS, from 2007 to 2012.

ufacturing and services, and to shed some additional light on the determinants of firm life cycle growth. I start by running firm-level regressions of productivity on employment:

$$
\log \left(\operatorname{Prod}_{i s t}\right)=\gamma \log \left(E m p_{i s t}\right)+\delta_{t}+\delta_{c}+\delta_{i}+\epsilon_{i s t}
$$

where $\log \left(\operatorname{Prod}_{i s t}\right)$ is the $\log$ of productivity measured as added value per worker, and $\log \left(E m p_{i s t}\right)$ is the log of employment. I include year fixed effects to control for economic events simultaneously affecting all firms' productivity, and for differences in price levels. Even if prices are deflated, it is important to control for changes in price levels due to other factors such as increasing demand, which is specially important in service industries. I also add cohort and industry fixed effects to control for constant unobserved factors that affect productivity.

The first two columns of Table 3.7 report the results from a simple specification that does not include any fixed effects. I find that there is a positive overall relationship between employment and productivity in the manufacturing sector, but a negative relationship in services. The result that employment and productivity could be inversely related is counterintuitive and contrary to both theoretical and empirical evidence on firm dynamics that focuses on manufacturing activities.

However, Arbache (2015) reports similar results for the Brazilian service sector using PAS as his source of data. He finds that average productivity is highest for firms with up to 2 workers, for all years in his sample. Arbache 
(2015) does not investigate possible reasons behind this negative relationship, but suggests that it is possibly driven by institutional factors, low scale and capital levels. An analogous result is extensively documented for the agricultural sector, in which farm size is inversely related to land productivity (Sen, 1962; Berry and Cline, 1979), although there is no consensus as to the exact cause of this relationship (Assunção and Braido, 2007).

Subsequent columns of Table 3.7 illustrate that results are robust to the inclusion of year and cohort fixed effects in columns three and four, and year, cohort and industry fixed effects in columns five and six. The magnitude of the correlation between size and productivity decreases with the inclusion of these controls. In column six, the relationship for services is statistically insignificant.

Through a more detailed inspection of the data, I find that the negative relationship between size and productivity in services is mainly driven by high productivity levels of firms with only one worker. A possibility is that the measure of productivity used, value added per worker, drops very fast with an increase in size for small firms, creating the negative relationship observed in the data. Hence, Panel B of Table 3.7 describes the estimates of equation 3-3 excluding all one-worker firms.

In columns seven and eight of Table 3.7, we see that the correlation between firm employment and productivity increases in both sectors with the exclusion of firms with only one worker. The observed relationship turns to positive in services. However, it is statistically weaker when compared to manufacturing. As I add fixed effects in columns nine to twelve, the employment coefficients for manufacturing decrease, while it increases for services. In the last two columns of the Table, however, the inclusion of year, cohort and industry fixed effects results in coefficients statistically equal in both sectors. 
Table 3.7: Productivity and firm size

\begin{tabular}{|c|c|c|c|c|c|c|}
\hline \multicolumn{7}{|l|}{ Panel A: Whole sample } \\
\hline & \multicolumn{2}{|c|}{ Productivity } & \multicolumn{2}{|c|}{ Productivity } & \multicolumn{2}{|c|}{ Productivity } \\
\hline & $\begin{array}{l}\text { Manuf. } \\
\text { (1) }\end{array}$ & $\begin{array}{l}\text { Serv. } \\
(2)\end{array}$ & $\begin{array}{l}\text { Manuf. } \\
(3)\end{array}$ & $\begin{array}{c}\text { Serv. } \\
(4)\end{array}$ & $\begin{array}{l}\text { Manuf. } \\
(5)\end{array}$ & $\begin{array}{c}\text { Serv. } \\
(6)\end{array}$ \\
\hline Log(Employment) & $0.0992^{* * *}$ & $-0.1030^{* * *}$ & $0.0759^{* * *}$ & $-0.0546^{* *}$ & $0.0606^{* * *}$ & -0.0176 \\
\hline & $(0.0120)$ & $(0.0302)$ & $(0.0114)$ & $(0.0224)$ & $(0.0113)$ & $(0.0180)$ \\
\hline Year fixed effects & No & No & Yes & Yes & Yes & Yes \\
\hline Cohort fixed effects & No & No & Yes & Yes & Yes & Yes \\
\hline Industry $4 \mathrm{~d}$ fixed effects & No & No & No & No & Yes & Yes \\
\hline Observations & 385,113 & 517,880 & 382,617 & 480,939 & 382,421 & 478,169 \\
\hline $\mathrm{R}$ squared & 0.009 & 0.006 & 0.050 & 0.061 & 0.147 & 0.264 \\
\hline \multicolumn{7}{|c|}{ Panel B: Excluding firms with Employment=1 } \\
\hline & \multicolumn{2}{|c|}{ Productivity } & \multicolumn{2}{|c|}{ Productivity } & \multicolumn{2}{|c|}{ Productivity } \\
\hline & $\begin{array}{l}\text { Manuf. } \\
(7)\end{array}$ & $\begin{array}{c}\text { Serv. } \\
(8)\end{array}$ & $\begin{array}{c}\text { Manuf. } \\
(9)\end{array}$ & $\begin{array}{c}\text { Serv. } \\
(10)\end{array}$ & $\begin{array}{c}\text { Manuf. } \\
\text { (11) }\end{array}$ & $\begin{array}{c}\text { Serv. } \\
(12)\end{array}$ \\
\hline Log(Employment) & $0.1470 * * *$ & $0.0438^{*}$ & $0.114^{* * *}$ & $0.0639^{* * *}$ & $0.0933^{* * *}$ & $0.0779^{* * *}$ \\
\hline & $(0.0131)$ & $(0.0261)$ & $(0.0103)$ & $(0.0179)$ & $(0.0101)$ & $(0.0139)$ \\
\hline Year fixed effects & No & No & Yes & Yes & Yes & Yes \\
\hline Cohort fixed effects & No & No & Yes & Yes & Yes & Yes \\
\hline Industry $4 \mathrm{~d}$ fixed effects & No & No & No & No & Yes & Yes \\
\hline Observations & 383,839 & 494,437 & 381,972 & 473,844 & 381,776 & 471,079 \\
\hline $\mathrm{R}$ squared & 0.017 & 0.001 & 0.054 & 0.067 & 0.155 & 0.272 \\
\hline
\end{tabular}

Notes: This table presents estimates from regressions of firm productivity on employment. Panel A performs the regressions using data from the whole sample, while Panel B includes only firms with at least two workers. Data from PIA and PAS. Regressions cover data from 2002 to 2012. Robust standard errors clustered at industry level in parenthesis. Significance levels: * $10 \%, * * 5 \%, * * * 1 \%$. 
Figure 3.5: Average productivity by employment groups

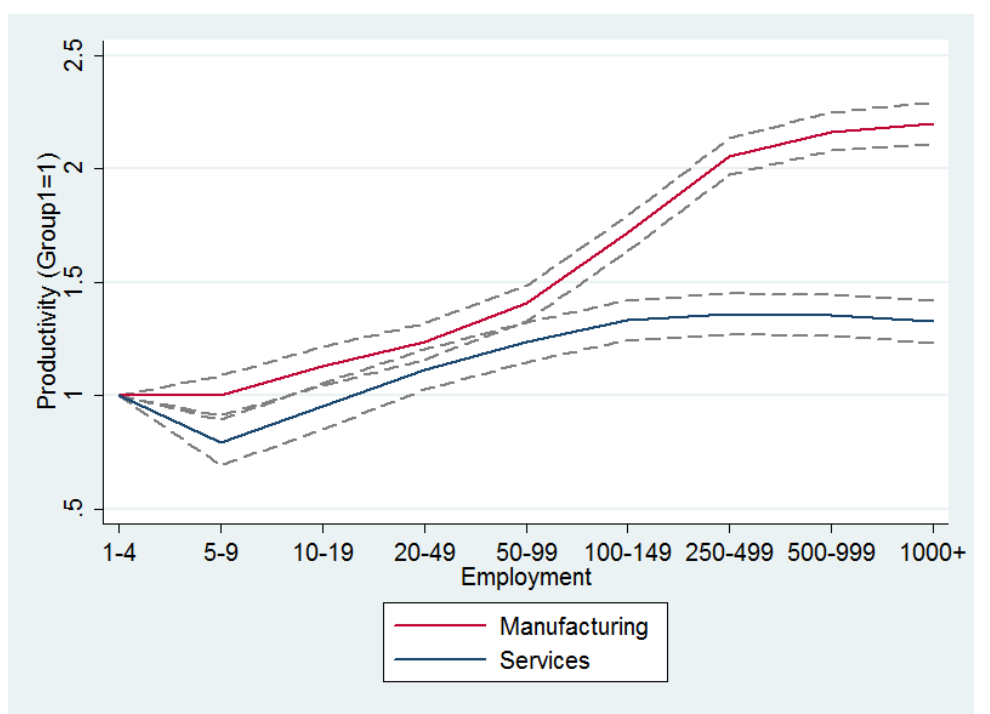

Notes: This figure plots average productivity for 9 size groups, defined based on firm employment. Data from PIA and PAS, from 2002 to 2012.

Figure 3.6: Average productivity by employment groups (Emp $>1)$

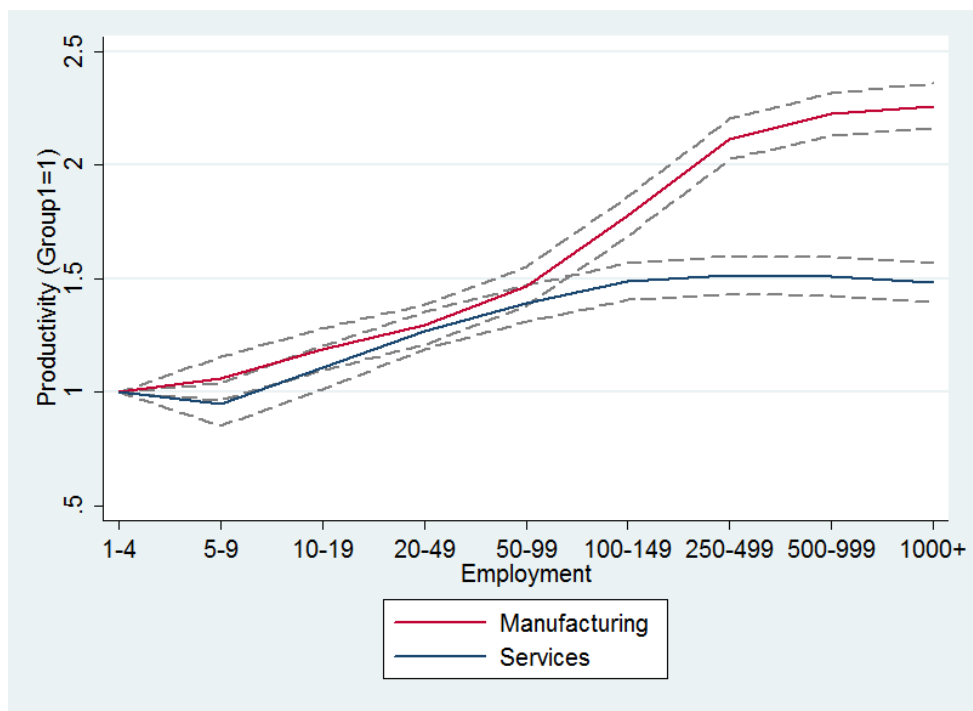

Notes: This figure plots average productivity for 9 size groups, defined based on firm employment. It includes only firms with at least 2 workers. Data from PIA and PAS, from 2002 to 2012.

To better illustrate how productivity evolves with firm size in the crosssection, Figure 3.5 presents average productivity for 9 employment groups, as defined by the Bureau of Labor Statistics. Values are normalized so that productivity equals one for firms with up to 4 workers. Figure 3.6 also plots average productivity by size group, but excludes firms with only one worker. These Figures show that average productivity growth is similar in both factors for firms with up to 99 workers. However, the average manufacturing firm with 
a thousand workers is 50\% more productive than firms with 50-99 workers, while in services average productivity stagnates at the 50-99 workers category, and does not increase for subsequent size groups.

Next, I check if the weaker relationship between employment and productivity in services could be accounted for by age-related distortions that significantly affect the growth of young, productive firms. It is possible that the relationship just described is not constant across ages. In this case, a weaker correlation between size and productivity for young firms, relative to older firms, imply the existence of restrictions on firm size that are relaxed as firms age. Age-related restrictions on firm size could be interpreted as credit constraints (Buera et al., 2011; Albuquerque and Hopenhayn, 2004), or as the accumulation of demand over time (Foster et al., 2016).

Even if age-related restrictions are constant across sectors, it is possible that service firms are more exposed to credit constraints due to the lower average size of firms, and to demand accumulation, due to unobserved quality and product differentiation. The first two tables of Table 3.8 estimate equation 3-3 including age group dummies. I find that previous conclusions from Figure 3.5 remain with the inclusion of age controls.

In columns three and four, I include interactions between the log of firm employment and age groups, to test if the employment-productivity relationship is distinct for firms in different stages of their life cycle. Consistent with the literature addressing age-related distortions, the relationship between firm employment and size is positively related with age, as expressed by the increasing magnitude of the interaction terms. However, the intensity of this relationship seems to evolve similarly as firms age in manufacturing and services. This result weakens the hypothesis that demand accumulation or credit constraints are key factors inhibiting the growth of productive firms in services.

Slower firm life cycle growth in services, relative to manufacturing, seems to arise partly due to weaker selection, as we have seen in Section 3.5. One possible factor associated to weaker selection in services is the lack of employment growth of productive firms, which leads to lower competition and selection by allowing the survival of small and unproductive firms. Upon investigating the presence of age-related distortions, however, I find evidence that restrictions to younger firms' growth, such as demand accumulation and credit constraints similarly affect both sectors. 
Table 3.8: Productivity, firm size and age

\begin{tabular}{|c|c|c|c|c|}
\hline & \multicolumn{2}{|c|}{ Log(Productivity) } & \multicolumn{2}{|c|}{ Log(Productivity) } \\
\hline & $\begin{array}{l}\text { Manuf. } \\
\text { (1) }\end{array}$ & $\begin{array}{c}\text { Serv. } \\
(2)\end{array}$ & $\begin{array}{c}\text { Manuf. } \\
(3)\end{array}$ & $\begin{array}{l}\text { Serv. } \\
(4)\end{array}$ \\
\hline \multirow[t]{2}{*}{ Log(Employment) } & $0.0514^{* * *}$ & -0.0131 & $-0.0775^{* *}$ & $-0.109^{* * *}$ \\
\hline & $(0.0127)$ & $(0.0184)$ & $(0.0315)$ & $(0.0373)$ \\
\hline \multirow{2}{*}{ Age Group (4-6) } & -0.0180 & -0.0200 & $-0.197^{* *}$ & -0.110 \\
\hline & $(0.0416)$ & $(0.0561)$ & $(0.0929)$ & $(0.0906)$ \\
\hline \multirow[t]{2}{*}{ Age Group (7-10) } & -0.0715 & -0.118 & $-0.373^{* * *}$ & $-0.266^{*}$ \\
\hline & $(0.0632)$ & $(0.113)$ & $(0.111)$ & $(0.160)$ \\
\hline \multirow[t]{2}{*}{ Age Group (11-15) } & $-0.165^{*}$ & -0.238 & $-0.590^{* * *}$ & $-0.540^{* * *}$ \\
\hline & $(0.0967)$ & $(0.159)$ & $(0.138)$ & $(0.175)$ \\
\hline \multirow[t]{2}{*}{ Age Group (16-20) } & $-0.219^{*}$ & -0.315 & $-0.778^{* * *}$ & $-0.747^{* * *}$ \\
\hline & $(0.130)$ & $(0.245)$ & $(0.165)$ & $(0.275)$ \\
\hline \multirow{2}{*}{ Log(Employment)* Age Group (4-6) } & & & $0.0919^{* *}$ & $0.0774^{*}$ \\
\hline & & & $(0.0362)$ & $(0.0431)$ \\
\hline \multirow[t]{2}{*}{ Log(Employment)* Age Group (7-10) } & & & $0.143^{* * *}$ & $0.113^{* *}$ \\
\hline & & & $(0.0388)$ & $(0.0539)$ \\
\hline \multirow[t]{2}{*}{ Log(Employment)* Age Group (11-15) } & & & $0.194^{* * *}$ & $0.190^{* * *}$ \\
\hline & & & $(0.0415)$ & $(0.0476)$ \\
\hline \multirow[t]{2}{*}{ Log(Employment)* Age Group (16-20) } & & & $0.242^{* * *}$ & $0.235^{* * *}$ \\
\hline & & & $(0.0419)$ & $(0.0549)$ \\
\hline Year fixed effects & Yes & Yes & Yes & Yes \\
\hline Cohort fixed effects & Yes & Yes & Yes & Yes \\
\hline Industry $3 \mathrm{~d}$ fixed effects & Yes & Yes & Yes & Yes \\
\hline Observations & 299,653 & 448,716 & 299,653 & 448,716 \\
\hline $\mathrm{R}$ squared & 0.136 & 0.250 & 0.140 & 0.253 \\
\hline
\end{tabular}

Notes: This table presents estimates from regressions of firm productivity on employment and age, including interactions between employment and age groups. Panel A performs the regressions using data from the whole sample, while Panel B includes only firms with at least two workers. Data from PIA and PAS. Regressions cover data from 2002 to 2012. Robust standard errors clustered at industry level in parenthesis. Significance levels: * $10 \%, * * 5 \%$, $* * * 1 \%$. 


\subsection{2}

\section{Monitoring costs}

Lastly, I test if higher monitoring costs could limit employment in service firms. Low delegation efficiency levels in developing countries inhibit firm growth through the hiring of outside managers (Akcigit et al., 2016). If the nature of service activities requires a higher share of managers to supervise workers, than components of delegation efficiency such as labor regulation or lack of trust are likely to be specially harmful for service firms' growth.

Bloom et al. (2013) presents empirical evidence that, in an environment where delegation efficiency is low, the number of family members can strongly predict firm size. They document that, in Indian textile firms, constraints on management practices limit firm growth and are an important factor in determining low productivity levels and selection.

Theoretical work also suggests that, if worker performance is affected by supervision, then the number of family members is an important determinant of firm size. Feder (1985) develops a model in which increasing marginal costs of supervision, in a context of credit constraints, is able to generate the negative relationship between land use and productivity documented for the agricultural sector.

I exploit detailed information available in PIA and PAS to analyze how the number of family members influences employment for manufacturing and service firms. I proxy for family members using the reported number of owners, partners and unpaid family members working for each firm. Even if partners and owners are not family members, it is reasonable to assume that they cultivate a close relationship and trust one another. From now on, I refer to this measure as the number of family members.

The main assumption made in this subsection is that higher monitoring costs or lower levels of delegation efficiency, as defined by Akcigit et al. (2016), make it more difficult to hire outside managers, thus limiting firm growth. This mechanism leads to a higher proportion of family members working for the firm, maximizing the available time to manage production and monitor workers.

First, I describe differences in the fraction of family members for the average firm in both sectors as a primary evidence of monitoring costs. The average fraction of family members in total employment for service firms is $62.38 \%$, surprisingly higher than $23.16 \%$ in manufacturing. At first, this result may seem to arise due to average size differences between sectors. However, Table 3.9 shows that the fraction of family members employed in service firms is higher than in manufacturing, even when controlling for firm employment 
and age. I run firm-level regressions of the fraction of family members on the log of employment and age. As previously discussed, I include year, cohort and three-digit industry fixed effects.

$$
\operatorname{Frac}\left(\text { Family }_{\text {ist }}\right)=\rho_{0}+\rho_{1} \log \left(\text { Emp }_{\text {ist }}\right)+\rho_{2} A g e_{i s t}+\delta_{t}+\delta_{c}+\delta_{i}+\epsilon_{i s t}
$$

The first two columns of Table 3.9 show that the fraction of family employees is decreasing in firm employment. However, the unconditional fraction of family employees, as expressed by the constant $\rho_{0}$, is still higher in services than in manufacturing. In columns three and four, I find that the fraction of family employees is also decreasing in firm age. Columns five and six simultaneously include controls for firm employment and age. Service firms still present significantly higher fraction of family employees than manufacturing, and this difference is statistically significant. I also find that age does not contain any additional information on the fraction of family employees once employment is controlled for. These results can be interpreted as evidence that there's a higher need for monitoring in services than in manufacturing, given firm employment.

To provide additional evidence that service firms might be constrained due to the time available for monitoring workers, I now describe how the number of family employees predicts overall firm employment. I aim to identify the correlation between family members and firm size, while controlling for firm age, and year, cohort and industry fixed characteristics that influence firm size. Table 3.10 presents estimates from the regression:

$$
\log \left(\text { Family }_{\text {ist }}\right)=\rho_{0}+\rho_{1} \log \left(E_{\text {mp }} p_{\text {ist }}\right)+\rho_{2} A g e_{i s t}+\delta_{t}+\delta_{c}+\delta_{i}+\epsilon_{\text {ist }}
$$

Columns one and two reveal that the number of family employees is correlated with firm size in both sectors. From the magnitude of the standard errors, however, we infer that the relationship between family employees and size is statistically equal in manufacturing relative to services. The last two columns of Table 3.10 illustrate that results are not altered by the inclusion of firm age as a control variable. 
Table 3.9: Fraction of family members

\begin{tabular}{|c|c|c|c|c|c|c|}
\hline & \multicolumn{2}{|c|}{ Prop(Family) } & \multicolumn{2}{|c|}{ Prop(Family) } & \multicolumn{2}{|c|}{ Prop(Family) } \\
\hline & $\begin{array}{c}\text { Manuf. } \\
\text { (1) }\end{array}$ & $\begin{array}{l}\text { Serv. } \\
(2)\end{array}$ & $\begin{array}{c}\text { Manuf. } \\
(3)\end{array}$ & $\begin{array}{c}\text { Serv. } \\
(4)\end{array}$ & $\begin{array}{c}\text { Manuf. } \\
(5)\end{array}$ & $\begin{array}{c}\text { Serv. } \\
(6)\end{array}$ \\
\hline \multirow[t]{2}{*}{ Constant } & $0.487^{* * *}$ & $0.739^{* * *}$ & $0.210^{* * *}$ & $0.422^{* * *}$ & $0.418^{* * *}$ & $0.672^{* * *}$ \\
\hline & $(0.0113)$ & $(0.0172)$ & $(0.0219)$ & $(0.0271)$ & $(0.0281)$ & $(0.0274)$ \\
\hline \multirow[t]{2}{*}{ Log(Employment) } & $-0.0958^{* * *}$ & $-0.178^{* * *}$ & & & $-0.103^{* * *}$ & $-0.185^{* * *}$ \\
\hline & $(0.0024)$ & $(0.0052)$ & & & $(0.0028)$ & $(0.0055)$ \\
\hline \multirow[t]{2}{*}{ Age } & & & $-0.0064^{* * *}$ & $-0.0138^{* * *}$ & 0.0017 & 0.0009 \\
\hline & & & $(0.0011)$ & $(0.0016)$ & $(0.0014)$ & $(0.0020)$ \\
\hline Year fixed effects & Yes & Yes & Yes & Yes & Yes & Yes \\
\hline Cohort fixed effects & Yes & Yes & Yes & Yes & Yes & Yes \\
\hline Industry $3 \mathrm{~d}$ fixed effects & Yes & Yes & Yes & Yes & Yes & Yes \\
\hline Age fixed effects & No & No & No & No & No & No \\
\hline Observations & 438,922 & 619,159 & 347,197 & 550,790 & 347,197 & 550,790 \\
\hline $\mathrm{R}$ squared & 0.326 & 0.405 & 0.059 & 0.086 & 0.320 & 0.403 \\
\hline
\end{tabular}

Notes: This table presents estimates from firm-level regressions of the fraction of family employees relative to employment on the log of employment and firm age. Data from PIA and PAS. Regressions cover data from 2002 to 2012 . Robust standard errors clustered at industry level in parenthesis. Significance levels: * $10 \%,{ }^{* *}$ $5 \%, * * * 1 \%$. 
Table 3.10: Employment and family members

\begin{tabular}{lccccc}
\hline & \multicolumn{2}{c}{ Log(Employment) } & & \multicolumn{2}{c}{ Log(Employment) } \\
\cline { 2 - 3 } \cline { 5 - 6 } & Manuf. & Serv. & & Manuf. & Serv. \\
& $(1)$ & $(2)$ & & $(3)$ & $(4)$ \\
\hline Log(Family) & $0.682^{* * *}$ & $0.714^{* * *}$ & & $0.639^{* * *}$ & $0.714^{* * *}$ \\
& $(0.0214)$ & $(0.0316)$ & & $(0.0223)$ & $(0.0297)$ \\
Age & & & & $0.0601^{* * *}$ & $0.0687^{* * *}$ \\
& & & & $(0.0046)$ & $(0.0100)$ \\
Year fixed effects & Yes & Yes & & Yes & Yes \\
Cohort fixed effects & Yes & Yes & & Yes & Yes \\
Industry 3d fixed effects & Yes & Yes & & Yes & Yes \\
Observations & 341,904 & 507,084 & & 277,290 & 456,039 \\
R squared & 0.300 & 0.268 & & 0.254 & 0.299 \\
\hline
\end{tabular}

Notes: This table presents estimates from firm-level regressions of the log of employment on age and the log of family members working in the firm. Data from PIA and PAS. Regressions cover data from 2002 to 2012. Robust standard errors clustered at industry level in parenthesis. Significance levels: * $10 \%,{ }^{* *}$ $5 \%, * * * 1 \%$.

The result that the number of family employees is an important determinant of firm size is consistent with the results presented in 3.4, in which firm-specific characteristics are the main reason behind the observed differences between life cycle growth in manufacturing and services.

\section{7 \\ Conclusions}

In this chapter, I show that there are significant and persistent differences in firm growth over the life cycle between the manufacturing and service sectors. I take advantage of a detailed, firm-level panel database including the whole size distribution of Brazilian formal firms. I find that manufacturing firms, on average, grow faster as they age than service firms. This fact is robust to controlling for a set of factors that could lead to higher firm growth in manufacturing, such as industry characteristics and municipality-specific regulations.

My results suggest that slow life cycle growth in services is associated with weaker selection and a less intense relationship between firm productivity and employment. These results are consistent with low competition in the service sector, relative to manufacturing, due to some limitation that prevents the growth of productive firms. I find evidence that high monitoring costs in service industries could be an important dimension limiting firm employment, especially in an institutional environment typical of developing countries with strict labor regulation, weak law enforcement and lack of trust. In this context, 
managerial endowment, a firm-specific characteristic, strongly determines firm employment and growth in the service sector.

One limitation from this work is that our main data source provides limited information on firms' characteristics. Although I resort to a second database to obtain information on specific inputs and firm productivity, the sampling frame of this secondary database does now allow me to consistently describe firm behavior over the life cycle. For this reason, I provide some initial evidence on possible determinants of firm life cycle, but future work should focus on investigating more deeply the role of these determinants on preventing firm growth. My findings have important policy implications regarding the service sector. In the presence of high monitoring costs, the government should ensure firm growth by facilitating the hiring of outside managers. Measures such as improving the rule of law, reducing burdens associated with hiring and even investing in human capital would have positive effects on firm growth, selection and, consequently, aggregate productivity in the service sector. 


\section{Bibliography}

Akcigit, U., Alp, H., and Peters, M. (2016). Lack of selection and limits to delegation: Firm dynamics in developing countries. Working Paper 21905, National Bureau of Economic Research.

Albuquerque, R. and Hopenhayn, H. A. (2004). Optimal lending contracts and firm dynamics. The Review of Economic Studies, 71(2):285-315.

Allcott, H., Collard-Wexler, A., and O'Connell, S. D. (2016). How do electricity shortages affect industry? Evidence from India. American Economic Review, 106(3):587-624.

Allcott, H. and Greenstone, M. (2012). Is there an energy efficiency gap? Journal of Economic Perspectives, 26(1):3-28.

Amiti, M. and Freund, C. (2008). The anatomy of China's export growth. Washington, DC: The World Bank.

Andersen, D. C. (2017). Do credit constraints favor dirty production? Theory and plant-level evidence. Journal of Environmental Economics and Management, 84:189-208.

Anderson, S. T. and Newell, R. G. (2004). Information programs for technology adoption: The case of energy-efficiency audits. Resource and Energy Economics, 26(1):27-50.

Angrist, J. and Pischke, J.-S. (2009). Mostly harmless econometrics: An empiricist's companion. Princeton, NJ: Princeton University Press.

Arbache, J. (2015). Produtividade no setor de serviços. In Produtividade no Brasil: desempenho e determinantes, volume 2, pages 277-300. Brasília, DF: IPEA.

Assunção, J. J. and Braido, L. H. B. (2007). Testing household-specific explanations for the inverse productivity relationship. American Journal of Agricultural Economics, 89(4):980-990.

Assunção, J. J. and Schutze, A. M. (2017). Panorama da eficiencia energética no Brasil. Working paper, Climate Policy Initiative. 
Atkeson, A. and Kehoe, P. J. (2005). Modeling and measuring organization capital. Journal of Political Economy, 113(5):1026-1053.

Audretsch, D. B. (1995). Innovation, growth and survival. International Journal of Industrial Organization, 13(4):441-457.

Audretsch, D. B., Klomp, L., Santarelli, E., and Thurik, A. R. (2004). Gibrat's law: Are the services different? Review of Industrial Organization, 24(3):301-324.

Autor, D. H., Dorn, D., and Hanson, G. H. (2016). The China shock: Learning from labor-market adjustment to large changes in trade. Annual Review of Economics, 8(1):205-240.

Banerjee, A. V. and Duflo, E. (2005). Growth theory through the lens of development economics. In Handbook of Economic Growth, volume 1A, pages 473-552. New York, NY: Elsevier.

Bar-Isaac, H. and Tadelis, S. (2008). Seller reputation. Foundations and Trends in Microeconomics, 4(4):273-351.

Barrows, G. and Ollivier, H. (2018). Cleaner firms or cleaner products? How product mix shapes emission intensity from manufacturing. Journal of Environmental Economics and Management, 88:134 - 158.

Bartelsman, E., Haltiwanger, J., and Scarpetta, S. (2013). Cross-country differences in productivity: The role of allocation and selection. American Economic Review, 103(1):305-34.

Bartelsman, E., Scarpetta, S., and Schivardi, F. (2005). Comparative analysis of firm demographics and survival: Evidence from micro-level sources in OECD countries. Industrial and Corporate Change, 14(3):365-391.

Bas, M. (2012). Input-trade liberalization and firm export decisions: Evidence from Argentina. Journal of Development Economics, 97(2):481-493.

Bernard, A., Jensen, B., and Schott, P. (2004). Facing the dragon: Prospects for US manufacturers in the coming decade. Working paper, Dartmouth.

Bernard, A. B. and Jensen, J. B. (2002). The deaths of manufacturing plants. Working Paper 9026, National Bureau of Economic Research.

Bernard, A. B. and Jensen, J. B. (2004). Entry, expansion, and intensity in the US export boom, 1987 - 1992. Review of International Economics, 12(4):662-675. 
Bernard, A. B., Jensen, J. B., Redding, S. J., and Schott, P. K. (2012). The empirics of firm heterogeneity and international trade. Annual Review of Economics, 4(1):283-313.

Bernard, A. B., Jensen, J. B., and Schott, P. K. (2006a). Survival of the best fit: Exposure to low-wage countries and the (uneven) growth of US manufacturing plants. Journal of International Economics, 68(1):219-237.

Bernard, A. B., Jensen, J. B., and Schott, P. K. (2006b). Trade costs, firms and productivity. Journal of Monetary Economics, 53(5):917 - 937.

Bernard, A. B., Redding, S. J., and Schott, P. K. (2007). Comparative advantage and heterogeneous firms. The Review of Economic Studies, 74(1):31-66.

Bernard, A. B., Redding, S. J., and Schott, P. K. (2010). Multiple-product firms and product switching. American Economic Review, 100(1):70-97.

Bernard, A. B. and Wagner, J. (2001). Export entry and exit by German firms. Weltwirtschaftliches Archiv, 137(1):105-123.

Berry, R. A. and Cline, W. R. (1979). Agrarian structure and productivity in developing countries: A study prepared for the International Labour Office within the framework of the World Employment Programme. Baltimore, MD: Johns Hopkins University Press.

Blanchflower, D. G. (2000). Self-employment in OECD countries. Labour Economics, 7(5):471- 505.

Bloom, N., Draca, M., and Van Reenen, J. (2016). Trade induced technical change? The impact of Chinese imports on innovation, IT and productivity. The Review of Economic Studies, 83(1):87-117.

Bloom, N., Eifert, B., Mahajan, A., McKenzie, D., and Roberts, J. (2013). Does management matter? Evidence from India. The Quarterly Journal of Economics, 128(1):1-51.

Broda, C. and Romalis, J. (2009). The welfare implications of rising price dispersion. Working paper, University of Chicago.

Brummund, P. and Connolly, L. (2018). Who creates stable jobs? Evidence from Brazil. Working paper, University of Alabama.

Buera, F. J., Kaboski, J. P., and Shin, Y. (2011). Finance and development: A tale of two sectors. American Economic Review, 101(5):1964-2002. 
Busso, M., Madrigal, L., and Pagés, C. (2013). Productivity and resource misallocation in Latin America1. The BE Journal of Macroeconomics, 13(1):903-932.

Bustos, P. (2011). Trade liberalization, exports, and technology upgrading: Evidence on the impact of MERCOSUR on Argentinian firms. American Economic Review, 101(1):304-40.

Cabral, L. M. B. and Mata, J. (2003). On the evolution of the firm size distribution: Facts and theory. American Economic Review, 93(4):1075-1090.

Caminal, R. and Vives, X. (1999). Price dynamics and consumer learning. Journal of Economics \& Management Strategy, 8(1):95-131.

Cherniwchan, J., Copeland, B. R., and Taylor, M. S. (2017). Trade and the environment: New methods, measurements, and results. Annual Review of Economics, 9(1):59-85.

Clementi, G. L. and Hopenhayn, H. A. (2006). A theory of financing constraints and firm dynamics. The Quarterly Journal of Economics, 121(1):229-265.

Coad, A. (2007). Firm Growth: A survey. Working paper. Documents de travail du Centre d'Economie de la Sorbonne 2007.24 - ISSN : 1955-611X.

Cooley, T. F. and Quadrini, V. (2001). Financial markets and firm dynamics. American Economic Review, 91(5):1286-1310.

Copeland, B. R. and Taylor, M. S. (2013). Trade and the environment: Theory and evidence. Princeton, NJ: Princeton University Press.

Costa, F., Garred, J., and Pessoa, J. P. (2016). Winners and losers from a commodities-for-manufactures trade boom. Journal of International Economics, 102:50-69.

David, H., Dorn, D., and Hanson, G. H. (2013). The China syndrome: Local labor market effects of import competition in the United States. American Economic Review, 103(6):2121-68.

De Almeida, E. L. F. (1998). Energy efficiency and the limits of market forces: The example of the electric motor market in France. Energy Policy, 26(8):643-653.

De Paula, A. and Scheinkman, J. A. (2010). Value-added taxes, chain effects, and informality. American Economic Journal: Macroeconomics, 2(4):195-221.

DeCanio, S. J. (1993). Barriers within firms to energy-efficient investments. Energy policy, 21(9):906-914. 
Diederen, P., Van Tongeren, F., and Van Der Veen, H. (2003). Returns on investments in energy-saving technologies under energy price uncertainty in Dutch greenhouse horticulture. Environmental and Resource Economics, 24(4):379394.

Dunne, T., Roberts, M. J., and Samuelson, L. (1988). Patterns of firm entry and exit in U.S. manufacturing industries. The RAND Journal of Economics, 19(4):495-515.

Dunne, T., Roberts, M. J., and Samuelson, L. (1989). The growth and failure of U.S. manufacturing plants. The Quarterly Journal of Economics, 104(4):671698.

Empresa de Pesquisa Energética (2017). Balanço energético nacional 2017: Ano base 2016. Rio de Janeiro.

Eslava, M., Haltiwanger, J., Kugler, A., and Kugler, M. (2013). Trade and market selection: Evidence from manufacturing plants in Colombia. Review of Economic Dynamics, 16(1):135 - 158.

Evans, D. S. (1987). The relationship between firm growth, size, and age: Estimates for 100 manufacturing industries. The Journal of Industrial Economics, 35(4):567-581.

Feder, G. (1985). The relation between farm size and farm productivity: The role of family labor, supervision and credit constraints. Journal of Development Economics, 18(2-3):297-313.

Fisher-Vanden, K., Jefferson, G. H., Liu, H., and Tao, Q. (2004). What is driving China's decline in energy intensity? Resource and Energy Economics, 26(1):7797.

Fishman, A. and Rob, R. (2003). Consumer inertia, firm growth and industry dynamics. Journal of Economic Theory, 109(1):24 - 38.

Foster, L., Haltiwanger, J., and Krizan, C. J. (2006). Market selection, reallocation, and restructuring in the U.S. retail trade sector in the 1990s. The Review of Economics and Statistics, 88(4):748-758.

Foster, L., Haltiwanger, J., and Syverson, C. (2008). Reallocation, firm turnover, and efficiency: Selection on productivity or profitability? American Economic Review, 98(1):394-425.

Foster, L., Haltiwanger, J., and Syverson, C. (2016). The slow growth of new plants: Learning about demand? Economica, 83(329):91-129. 
Gervais, A. and Jensen, J. B. (2013). The tradability of services: Geographic concentration and trade costs. Working Paper 19759, National Bureau of Economic Research.

Hall, B. H. (1986). The relationship between firm size and firm growth in the US manufacturing sector. Working Paper 1965, National Bureau of Economic Research.

Haltiwanger, J., Kulick, R., and Syverson, C. (2018). Misallocation measures: The distortion that ate the residual. Working Paper 24199, National Bureau of Economic Research.

Head, K. and Ries, J. (1999). Rationalization effects of tariff reductions. Journal of International Economics, 47(2):295-320.

Hopenhayn, H. A. (1992). Entry, exit, and firm dynamics in long run equilibrium. Econometrica, 60(5):1127-1150.

Howarth, R. B., Haddad, B. M., and Paton, B. (2000). The economics of energy efficiency: Insights from voluntary participation programs. Energy Policy, 28(67):477-486.

Hsieh, C.-T. and Klenow, P. J. (2009). Misallocation and manufacturing TFP in China and India. The Quarterly Journal of Economics, 124(4):1403-1448.

Hsieh, C.-T. and Klenow, P. J. (2014). The life cycle of plants in India and Mexico. The Quarterly Journal of Economics, 129(3):1035-1084.

lacovone, L., Rauch, F., and Winters, L. A. (2013). Trade as an engine of creative destruction: Mexican experience with Chinese competition. Journal of International Economics, 89(2):379-392.

Jovanovic, B. (1982). Selection and the evolution of industry. Econometrica, 50(3):649-670.

Kim, M., Oh, J., and Shin, Y. (2017). Misallocation and manufacturing TFP in Korea, 1982-2007. Federal Reserve Bank of St. Louis Review, pages 233-44.

La Porta, R., Lopez-de Silanes, F., and Shleifer, A. (2008). The economic consequences of legal origins. Journal of Economic Literature, 46(2):285-332.

Levy, S. (2008). Good intentions, bad outcomes. Washington, DC: The Brookings Institute. 
Löfgren, Å., Millock, K., and Nauges, C. (2008). The effect of uncertainty on pollution abatement investments: Measuring hurdle rates for Swedish industry. Resource and Energy Economics, 30(4):475-491.

Lotti, F. (2007). Firm dynamics in manufacturing and services: A broken mirror? Industrial and Corporate Change, 16(3):347-369.

Luttmer, E. G. (2007). Selection, growth, and the size distribution of firms. The Quarterly Journal of Economics, 122(3):1103-1144.

Maloney, W. F. (2004). Informality revisited. World Development, 32(7):1159 1178.

Mata, J. (1994). Firm growth during infancy. Small Business Economics, 6(1):2739.

Melitz, M. J. (2003). The impact of trade on intra-industry reallocations and aggregate industry productivity. Econometrica, 71(6):1695-1725.

Muendler, M.-A. (2004). Trade, technology, and productivity: A study of Brazilian manufacturers, 1986-1998. Working Paper 1148, Center for Economic Studies and Ifo Institute (CESifo).

Olley, G. S. and Pakes, A. (1996). The dynamics of productivity in the telecommunications equipment industry. Econometrica, 64(6):1263-1297.

Ostertag, K. (2012). No-regret potentials in energy conservation: An analysis of their relevance, size and determinants. Heidelberg: Springer Science \& Business Media.

Pagés, C. (2010). The age of productivity. In The Age of Productivity: Transforming Economies from the Bottom Up. New York, NY: Palgrave Macmillan.

Pavcnik, N. (2002). Trade liberalization, exit, and productivity improvements: Evidence from Chilean plants. The Review of Economic Studies, 69(1):245276.

Radner, R. (2003). Viscous demand. Journal of Economic Theory, 112(2):189 231.

Restuccia, D. and Rogerson, R. (2008). Policy distortions and aggregate productivity with heterogeneous establishments. Review of Economic dynamics, 11(4):707-720.

Rodrik, D. (2013). Unconditional convergence in manufacturing. The Quarterly Journal of Economics, 128(1):165-204. 
Rohdin, P., Thollander, P., and Solding, P. (2007). Barriers to and drivers for energy efficiency in the Swedish foundry industry. Energy Policy, 35(1):672677.

Ryan, N. (2015). Is there an energy-efficiency gap? Experimental evidence from Indian manufacturing plants. Working Paper, Yale University.

Sen, A. K. (1962). An aspect of Indian agriculture. Economic Weekly, 14(46):243-246.

Teruel-Carrizosa, M. (2010). Gibrat's law and the learning process. Small Business Economics, 34(4):355-373.

Ulyssea, G. (2018). Firms, informality, and development: Theory and evidence from Brazil. American Economic Review, 108(8):2015-47.

Van Biema, M. and Greenwald, B. (1997). Managing our way to higher servicesector productivity. Harvard Business Review, 75(4):87-95. 


\section{A \\ Chapter 1 - Additional results}

Figure A.1: Value of Chinese imports and exports.

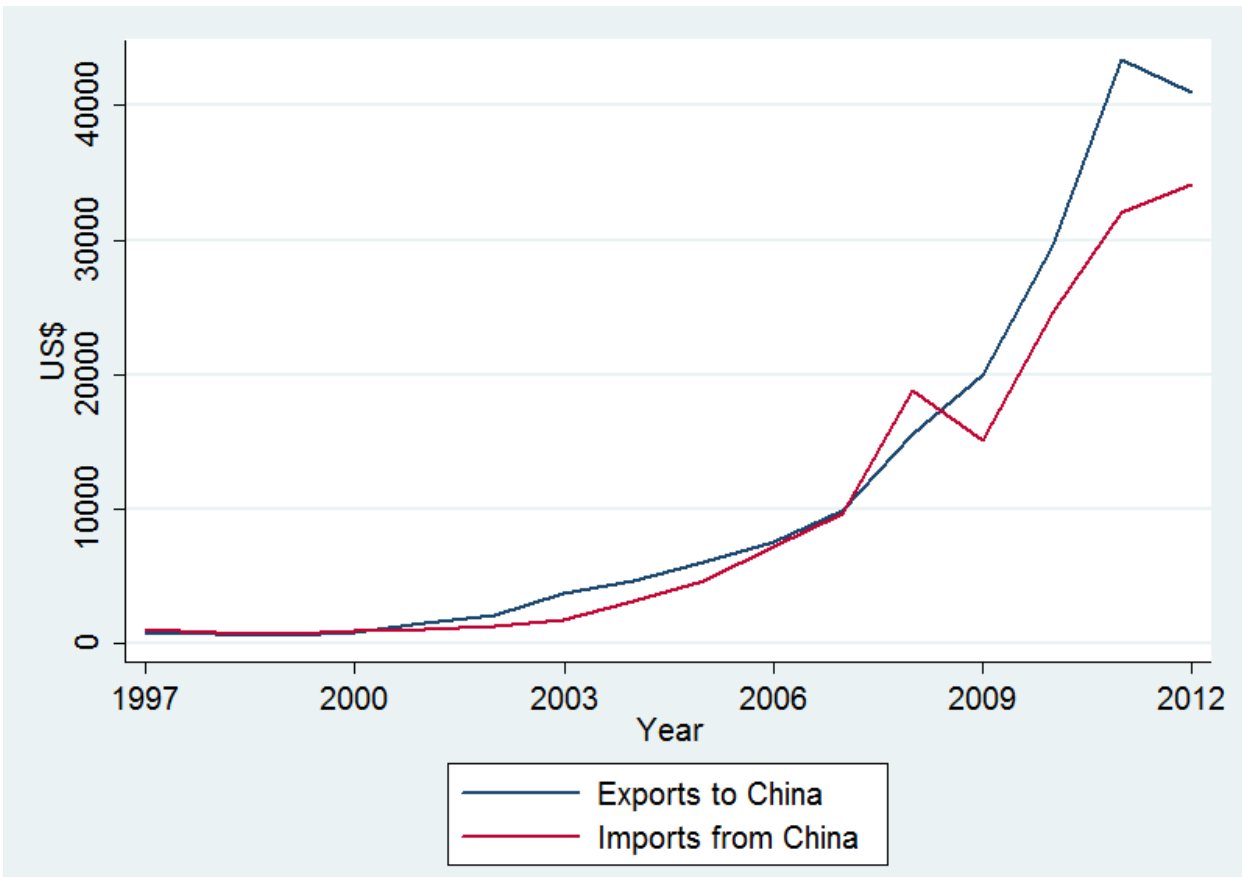

Notes: The Figure shows the evolution of the value of imports from China and the value of exports to China in Brazil, from 1997 to 2012. Trade data is from UN Comtrade. 
Table A.1: Employment - OLS.

\begin{tabular}{|c|c|c|c|c|c|c|}
\hline & \multicolumn{6}{|c|}{$\log \left(\right.$ Employment $\left._{\mathrm{i}, \mathrm{t}+1}\right)$} \\
\hline & $\begin{array}{l}(1) \\
\text { OLS }\end{array}$ & $\begin{array}{c}(2) \\
\text { OLS }\end{array}$ & $\begin{array}{l}(3) \\
\text { OLS }\end{array}$ & $\begin{array}{l}(4) \\
\text { OLS }\end{array}$ & $\begin{array}{l}(5) \\
\text { OLS }\end{array}$ & $\begin{array}{c}(6) \\
\text { OLS }\end{array}$ \\
\hline $\mathrm{IS}_{\mathrm{s}, \mathrm{t}-1}$ & $\begin{array}{l}-0.012 \\
(0.024)\end{array}$ & $\begin{array}{l}-0.012 \\
(0.024)\end{array}$ & $\begin{array}{c}-0.036^{*} \\
(0.020)\end{array}$ & $\begin{array}{c}-0.036^{*} \\
(0.020)\end{array}$ & $\begin{array}{l}-0.008 \\
(0.024)\end{array}$ & $\begin{array}{l}-0.008 \\
(0.024)\end{array}$ \\
\hline $\mathrm{IS}_{\mathrm{s}, \mathrm{t}-1} *$ Skill $_{\mathrm{pt}}$ & & & $\begin{array}{c}0.090^{* * *} \\
(0.032)\end{array}$ & $\begin{array}{c}0.090^{* * *} \\
(0.032)\end{array}$ & & \\
\hline $\mathrm{IS}_{\mathrm{s}, \mathrm{t}-1} *$ Exporting $_{\mathrm{pt}}$ & & & & & $\begin{array}{l}-0.081 \\
(0.050)\end{array}$ & $\begin{array}{l}-0.081 \\
(0.050)\end{array}$ \\
\hline $\mathrm{XS}_{\mathrm{s}, \mathrm{t}-1}$ & $\begin{array}{c}0.039 \\
(0.112)\end{array}$ & $\begin{array}{c}0.039 \\
(0.112)\end{array}$ & $\begin{array}{c}0.017 \\
(0.125)\end{array}$ & $\begin{array}{c}0.017 \\
(0.125)\end{array}$ & $\begin{array}{c}0.029 \\
(0.120)\end{array}$ & $\begin{array}{c}0.029 \\
(0.120)\end{array}$ \\
\hline $\mathrm{XS}_{\mathrm{s}, \mathrm{t}-1} * \mathrm{Skill}_{\mathrm{pt}}$ & & & $\begin{array}{c}0.060 \\
(0.048)\end{array}$ & $\begin{array}{c}0.060 \\
(0.048)\end{array}$ & & \\
\hline $\mathrm{XS}_{\mathrm{s}, \mathrm{t}-1} *$ Exporting $_{\mathrm{pt}}$ & & & & & $\begin{array}{c}0.202 \\
(0.228)\end{array}$ & $\begin{array}{c}0.202 \\
(0.228)\end{array}$ \\
\hline Age $_{i t}$ & & $\begin{array}{c}-137.6 \\
(712,259)\end{array}$ & & $\begin{array}{c}-459.0 \\
(718,358)\end{array}$ & & $\begin{array}{c}-126.0 \\
(707,046)\end{array}$ \\
\hline Skill $_{\text {it }}$ & & & $\begin{array}{c}0.037^{* * *} \\
(0.006)\end{array}$ & $\begin{array}{c}0.037^{* * *} \\
(0.006)\end{array}$ & & \\
\hline Exporting statusit & & & & & $\begin{array}{c}0.206^{* * *} \\
(0.016)\end{array}$ & $\begin{array}{c}0.206^{* * *} \\
(0.016)\end{array}$ \\
\hline Year fixed effects & Yes & Yes & Yes & Yes & Yes & Yes \\
\hline Plant fixed effects & Yes & Yes & Yes & Yes & Yes & Yes \\
\hline Industry trends & Yes & Yes & Yes & Yes & Yes & Yes \\
\hline Observations & $2,886,971$ & $2,886,961$ & $2,886,952$ & $2,886,942$ & $2,886,971$ & $2,886,961$ \\
\hline R-squared & 0.904 & 0.904 & 0.904 & 0.904 & 0.904 & 0.904 \\
\hline
\end{tabular}

Notes: Plant-level OLS and IV regressions. Dependent variable is plant employment. In IV regressions, I instrument IS and XS with import shares from China and export shares to China computed for 54 middle-income countries. Regressions cover data from 2002 to 2012. Robust standard errors clustered at industry level in parenthesis. Significance levels: * $10 \%, * * 5 \%, * * * 1 \%$. 
Table A.2: Employment - size groups OLS.

\begin{tabular}{|c|c|c|}
\hline & \multicolumn{2}{|c|}{$\log \left(\right.$ Employment $\left._{\mathrm{i}, \mathrm{t}+1}\right)$} \\
\hline & $\begin{array}{l}(1) \\
\text { OLS }\end{array}$ & $\begin{array}{c}(2) \\
\text { OLS }\end{array}$ \\
\hline $\mathrm{IS}_{\mathrm{s}, \mathrm{t}-1} *$ Small $_{\mathrm{it}}$ & $\begin{array}{l}-0.030 \\
(0.032)\end{array}$ & $\begin{array}{l}-0.030 \\
(0.032)\end{array}$ \\
\hline $\mathrm{IS}_{\mathrm{s}, \mathrm{t}-1} *$ Medium $_{\mathrm{it}}$ & $\begin{array}{c}0.024 \\
(0.026)\end{array}$ & $\begin{array}{c}0.024 \\
(0.026)\end{array}$ \\
\hline $\mathrm{IS}_{\mathrm{s}, \mathrm{t}-1} *$ Large $_{\mathrm{it}}$ & $\begin{array}{l}-0.031 \\
(0.039)\end{array}$ & $\begin{array}{l}-0.031 \\
(0.039)\end{array}$ \\
\hline $\mathrm{XS}_{\mathrm{s}, \mathrm{t}-1} *$ Small $_{\mathrm{it}}$ & $\begin{array}{c}0.094 \\
(0.147)\end{array}$ & $\begin{array}{c}0.094 \\
(0.147)\end{array}$ \\
\hline $\mathrm{XS}_{\mathrm{s}, \mathrm{t}-1} *$ Medium $_{\mathrm{it}}$ & $\begin{array}{l}-0.032 \\
(0.080)\end{array}$ & $\begin{array}{l}-0.032 \\
(0.080)\end{array}$ \\
\hline $\mathrm{XS}_{\mathrm{s}, \mathrm{t}-1} * \operatorname{Large}_{\mathrm{it}}$ & $\begin{array}{l}-0.071 \\
(0.084)\end{array}$ & $\begin{array}{l}-0.071 \\
(0.084)\end{array}$ \\
\hline Age $_{i t}$ & & $\begin{array}{c}-165.0 \\
(733,399)\end{array}$ \\
\hline Small $_{i t}$ & $\begin{array}{c}-1.169^{* * *} \\
(0.032)\end{array}$ & $\begin{array}{c}-1.169^{* * *} \\
(0.032)\end{array}$ \\
\hline Medium $_{\text {it }}$ & $\begin{array}{c}-0.658^{* * *} \\
(0.017)\end{array}$ & $\begin{array}{c}-0.658^{* * *} \\
(0.017)\end{array}$ \\
\hline Year fixed effec & Yes & Yes \\
\hline Plant fixed effects & Yes & Yes \\
\hline Industry trends & Yes & Yes \\
\hline Obs & $2,886,971$ & $2,886,961$ \\
\hline R-squared & 0.912 & 0.912 \\
\hline
\end{tabular}

Notes: Plant-level OLS and IV regressions. Dependent variable is plant employment. In IV regressions, I instrument IS and XS with import shares from China and export shares to China computed for 54 middle-income countries. Regressions cover data from 2002 to 2012. Robust standard errors clustered at industry level in parenthesis. Significance levels: $* 10 \%,{ }^{*} 5 \%, * * * 1 \%$. 
B

\section{Chapter 2 - Additional results}

Table B.1: Three-digit CNAE industries

\begin{tabular}{|c|c|}
\hline CNAE & Activity description \\
\hline 05.0 & Mining of coal and lignite \\
\hline 06.0 & Extraction of crude petroleum and natural gas \\
\hline 07.1 & Mining of iron ores \\
\hline 07.2 & Mining of non-ferrous metal ores \\
\hline 08.1 & Quarrying of stone, sand and clay \\
\hline 08.9 & Mining and quarrying n.e.c. \\
\hline 09.1 & Support activities for petroleum and natural gas extraction \\
\hline 09.9 & Support activities for other mining and quarrying \\
\hline 10.1 & Processing and preserving of meat \\
\hline 10.2 & Processing and preserving of fish, crustaceans and molluscs \\
\hline 10.3 & Processing and preserving of fruit and vegetables \\
\hline 10.4 & Manufacture of vegetable and animal oils and fats \\
\hline 10.5 & Manufacture of dairy products \\
\hline 10.6 & Manufacture of grain mill products, starches and starch products \\
\hline 10.7 & Manufacture of sugar \\
\hline 10.8 & Manufacture of coffee products \\
\hline 10.9 & Manufacture of other food products \\
\hline 11.1 & Manufacture of alcoholic beverages \\
\hline 11.2 & Manufacture of non-alcoholic beverages \\
\hline 12.1 & Processing of tobacco \\
\hline 12.2 & Manufacture of tobacco products \\
\hline 13.1 & Spinning, weaving of textiles \\
\hline 13.2 & Manufacture of other textiles, except crocheted and knitted \\
\hline 13.3 & Manufacture of knitted and crocheted textiles \\
\hline 13.4 & Finishing of textiles \\
\hline 13.5 & Manufacture of made-up textile articles, except apparel \\
\hline 14.1 & Manufacture of wearing apparel \\
\hline 14.2 & Manufacture of knitted and crocheted apparel \\
\hline 15.1 & Tanning and dressing of leather \\
\hline 15.2 & Manufacture of leather luggage, handbags, saddlery and harness \\
\hline 15.3 & Manufacture of footwear \\
\hline 15.4 & Manufacture of footwear parts \\
\hline 16.1 & Sawmilling and planing of wood \\
\hline 16.2 & Manufacture of products of wood, cork, straw and plaiting materials \\
\hline 17.1 & Manufacture of pulp \\
\hline 17.2 & Manufacture of paper and paperboard \\
\hline 17.3 & Manufacture of containers of paper and paperboard \\
\hline 17.4 & Manufacture of other articles of paper and paperboard \\
\hline 18.1 & Printing \\
\hline 18.2 & Service activities related to printing \\
\hline 18.3 & Reproduction of recorded media \\
\hline 19.1 & Manufacture of coke oven products \\
\hline 19.2 & Manufacture of refined petroleum products \\
\hline 19.3 & Manufacture of biofuels \\
\hline
\end{tabular}


Table B.1 - Continued from previous page

\begin{tabular}{|c|c|}
\hline CNAE & Activity description \\
\hline 20.1 & Manufacture of organic chemicals \\
\hline 20.2 & Manufacture of inorganic chemicals \\
\hline 20.3 & Manufacture of plastics and synthetic rubber in primary forms \\
\hline 20.4 & Manufacture of man-made fibres \\
\hline 20.5 & Manufacture of pesticides and other agrochemical products \\
\hline 20.6 & $\begin{array}{l}\text { Manufacture of soap and detergents, cleaning and polishing preparations, } \\
\text { perfumes and toilet preparations }\end{array}$ \\
\hline 20.7 & $\begin{array}{l}\text { Manufacture of paints, varnishes and similar coatings, printing } \\
\text { ink and mastics }\end{array}$ \\
\hline 20.9 & Manufacture of other chemical products \\
\hline 21.1 & Manufacture of medicinal chemical products \\
\hline 21.2 & Manufacture of pharmaceuticals \\
\hline 22.1 & Manufacture of rubber products \\
\hline 22.2 & Manufacture of plastics products \\
\hline 23.1 & Manufacture of glass and glass products \\
\hline 23.2 & Manufacture of cement \\
\hline 23.3 & Manufacture of articles of concrete, cement and plaster \\
\hline 23.4 & Manufacture of ceramic products \\
\hline 23.9 & Manufacture of other non-metallic mineral products n.e.c \\
\hline 24.1 & Manufacture of pig iron and iron alloys \\
\hline 24.2 & Manufacture of steel \\
\hline 24.3 & Manufacture of steel tubes \\
\hline 24.4 & Manufacture of basic precious and other non-ferrous metals \\
\hline 24.5 & Casting of metals \\
\hline 25.1 & Manufacture of structural metal products \\
\hline 25.2 & Manufacture of tanks, reservoirs and containers of metal \\
\hline 25.3 & Forging, pressing, stamping and roll-forming of metal; powder metallurgy \\
\hline 25.4 & Manufacture of cutlery, hand tools and general hardware \\
\hline 25.5 & Manufacture of weapons and ammunition \\
\hline 25.9 & Manufacture of other fabricated metal products n.e.c. \\
\hline 26.1 & Manufacture of electronic components and boards \\
\hline 26.2 & Manufacture of computers and peripheral equipment \\
\hline 26.3 & Manufacture of communication equipment \\
\hline 26.4 & $\begin{array}{l}\text { Manufacture of equipment for reproducing, recording } \\
\text { and amplifying audio and video }\end{array}$ \\
\hline 26.5 & $\begin{array}{l}\text { Manufacture of measuring, testing, navigating and control equipment; } \\
\text { watches and clocks }\end{array}$ \\
\hline 26.6 & Manufacture of irradiation, electromedical and electrotherapeutic equipment \\
\hline 26.7 & Manufacture of optical instruments and photographic equipment \\
\hline 26.8 & Manufacture of magnetic and optical media \\
\hline 27.1 & Manufacture of electric motors, generators, transformers and \\
\hline 27.2 & Manufacture of batteries and accumulators \\
\hline 27.3 & Manufacture of electricity distribution and control apparatus \\
\hline 27.4 & Manufacture of electric lighting equipment \\
\hline 27.5 & Manufacture of domestic appliances \\
\hline 27.9 & Manufacture of other electrical equipment \\
\hline 28.1 & Manufacture of engines, pumps, compressors, gears, taps and valves \\
\hline 28.2 & Manufacture of general-purpose machinery \\
\hline 28.3 & Manufacture of agricultural and forestry machinery \\
\hline 28.4 & Manufacture of machine tools \\
\hline 28.5 & Manufacture of machinery for mining, quarrying and construction \\
\hline 28.6 & Manufacture of special-purpose machinery \\
\hline 29.1 & Manufacture of cars \\
\hline 29.2 & Manufacture of trucks and buses \\
\hline 29.3 & $\begin{array}{l}\text { Manufacture of bodies (coachwork) for motor vehicles; } \\
\text { manufacture of trailers and semi-trailers }\end{array}$ \\
\hline 29.4 & Manufacture of parts and accessories for motor vehicles \\
\hline
\end{tabular}


Table B.1 - Continued from previous page

\begin{tabular}{ll}
\hline CNAE & Activity description \\
\hline 29.5 & Engine restauration and rebuilding for motor vehicles \\
30.1 & Building of ships and boats \\
30.3 & Manufacture of railway locomotives and rolling stock \\
30.4 & Manufacture of aircrafts \\
30.5 & Manufacture of military fighting vehicles \\
30.9 & Manufacture of other transport equipment n.e.c. \\
31.0 & Manufacture of furniture \\
32.1 & Manufacture of jewellery, bijouterie and related articles \\
32.2 & Manufacture of musical instruments \\
32.3 & Manufacture of sports goods \\
32.4 & Manufacture of games and toys \\
32.5 & Manufacture of medical and dental instruments and supplies \\
32.9 & Other manufacturing n.e.c. \\
33.1 & Repair of fabricated metal products, machinery and equipment \\
33.2 & Installation of industrial machinery and equipment \\
\hline
\end{tabular}

Figure B.1: Resource and energy misallocation (TFP)

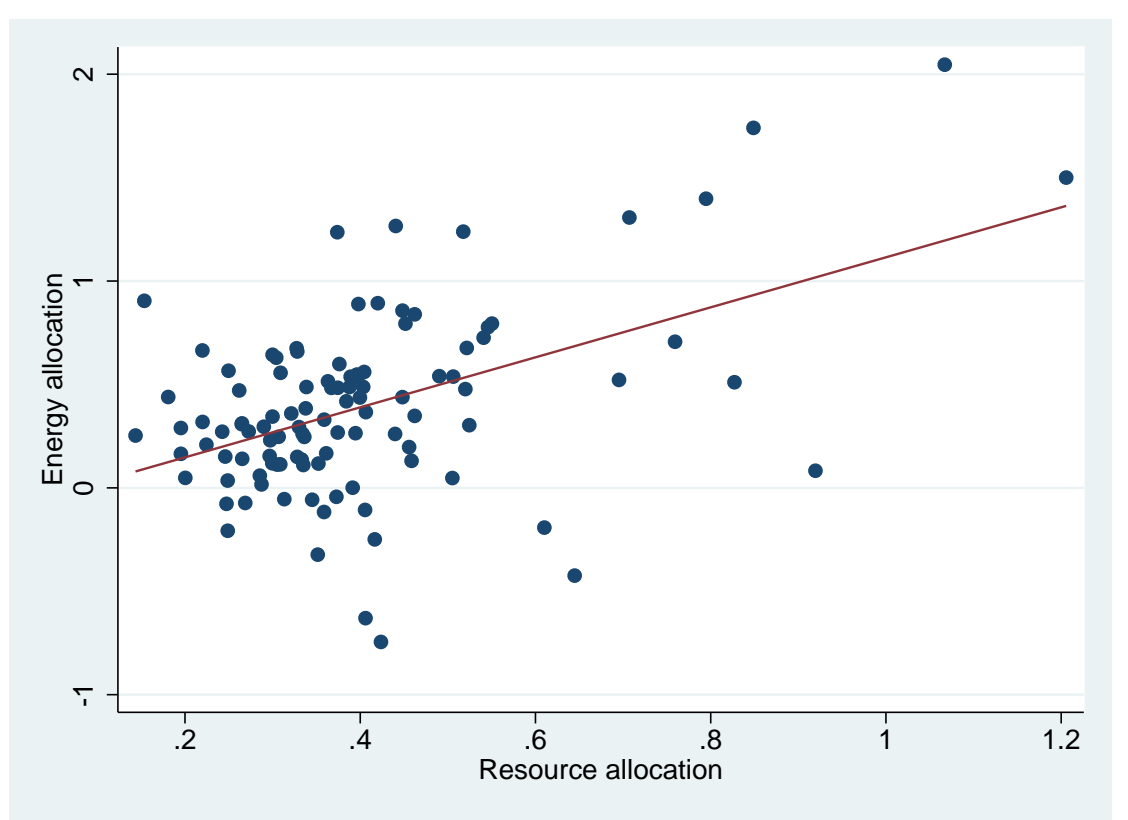

Notes: Measures of energy allocation, $\delta_{s}^{e}$, and resource allocation, $\delta_{s}^{\theta}$, plotted for each of the 106 three-digit industries in our database. Productivity of firm $i$ in sector $s, \theta_{s i}$, is total factor productivity estimates assuming a production function with capital, labor and electricity inputs. Data from PIA and RAIS. 
Figure B.2: Resource and energy misallocation (TFPQ)

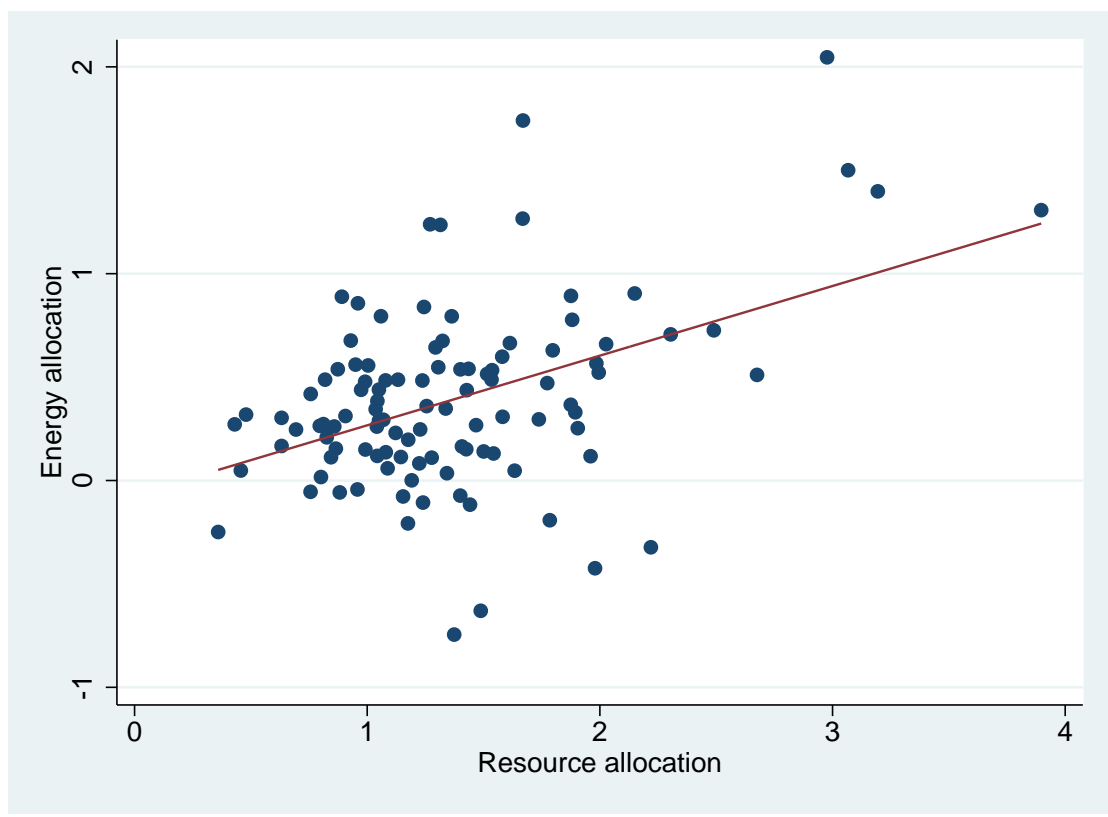

Notes: Measures of energy allocation, $\delta_{s}^{e}$, and resource allocation, $\delta_{s}^{\theta}$, plotted for each of the 106 three-digit industries in our database. Productivity of firm $i$ in sector $s, \theta_{s i}$, is computed as value added per worker. Data from PIA and RAIS.

Figure B.3: Resource and energy misallocation (2015)

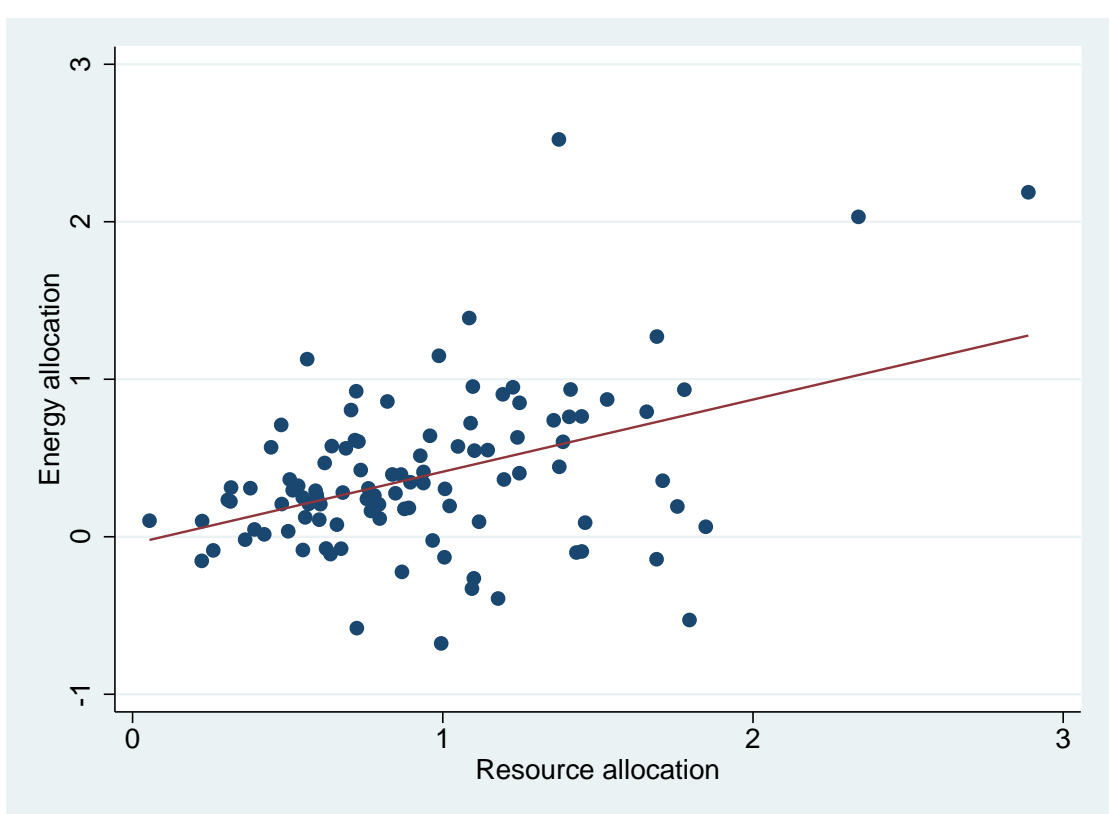

Notes: Measures of energy allocation, $\delta_{s}^{e}$, and resource allocation, $\delta_{s}^{e}$, plotted for each of the 106 three-digit industries in our database. Data from PIA and RAIS. 
C

\section{Chapter 3 - Additional results}

Table C.1: Number of observations (RAIS)

\begin{tabular}{cccccc}
\hline & \multicolumn{2}{c}{ Manufacturing } & & \multicolumn{2}{c}{ Services } \\
\cline { 2 - 3 } \cline { 5 - 6 } Year & Establishments & Employment & & Establishments & Employment \\
\hline 2002 & 62,095 & $1,377,927$ & & 151,164 & $2,093,377$ \\
2003 & 63,257 & $1,406,768$ & & 158,650 & $2,209,318$ \\
2004 & 65,968 & $1,550,068$ & & 166,571 & $2,336,808$ \\
2005 & 68,042 & $1,584,009$ & & 174,110 & $2,490,901$ \\
2006 & 71,836 & $1,697,512$ & & 182,896 & $2,730,434$ \\
2007 & 73,423 & $1,807,778$ & & 189,842 & $2,922,212$ \\
2008 & 76,961 & $1,863,065$ & & 200,798 & $2,992,257$ \\
2009 & 79,388 & $1,882,279$ & & 214,755 & $3,167,903$ \\
2010 & 80,964 & $2,025,097$ & & 232,761 & $3,447,734$ \\
2011 & 84,520 & $2,050,814$ & & 249,205 & $3,704,401$ \\
2012 & 87,053 & $2,073,507$ & & 264,776 & $3,920,867$ \\
\hline Notes: & Number of firms and total employment by year. Data from RAIS.
\end{tabular}

Table C.2: Service sector composition

\begin{tabular}{lcc}
\hline Subsectors & Firms (\%) & Employment (\%) \\
\hline Accommodation and food & 18.33 & 10.52 \\
Transportation, storage and communication & 13.90 & 16.59 \\
Financial intermediation & 03.94 & 04.73 \\
Real estate, renting and business & 35.40 & 36.30 \\
Education & 06.13 & 10.53 \\
Health and social work & 07.84 & 10.41 \\
Other community, social and personal & 14.42 & 10.88 \\
\hline
\end{tabular}


Table C.3: Number of observations (PIA and PAS)

\begin{tabular}{|c|c|c|c|c|}
\hline \multicolumn{5}{|c|}{ Panel A: Deterministic Sample } \\
\hline \multirow[b]{2}{*}{ Year } & \multicolumn{2}{|c|}{ Manufacturing } & \multicolumn{2}{|c|}{ Services } \\
\hline & Establishments & Employment & Establishments & Employment \\
\hline 2002 & 24,435 & $3,918,585$ & 28,740 & $3,534,325$ \\
\hline 2003 & 25,745 & $4,053,298$ & 31,198 & $3,670,284$ \\
\hline 2004 & 26,812 & $4,563,825$ & 36,036 & $4,100,992$ \\
\hline 2005 & 28,724 & $4,759,092$ & 37,732 & $4,454,615$ \\
\hline 2006 & 29,993 & $5,000,251$ & 40,316 & $4,694,310$ \\
\hline 2007 & 29,684 & $5,304,702$ & 48,194 & $5,145,470$ \\
\hline 2008 & 31,629 & $5,507,843$ & 46,182 & $5,521,609$ \\
\hline 2009 & 32,538 & $5,581,634$ & 48,924 & $5,852,770$ \\
\hline 2010 & 33,169 & $6,005,154$ & 53,276 & $6,497,878$ \\
\hline 2011 & 35,715 & $6,225,842$ & 57,896 & $7,033,875$ \\
\hline 2012 & 36,451 & $6,393,529$ & 64,733 & $7,411,164$ \\
\hline \multicolumn{5}{|c|}{ Panel B: Surveyed Sample } \\
\hline \multirow[b]{2}{*}{ Year } & \multicolumn{2}{|c|}{ Manufacturing } & \multicolumn{2}{|c|}{ Services } \\
\hline & Establishments & Employment & Establishments & Employment \\
\hline 2002 & 7,864 & 97,608 & 11,247 & 57,701 \\
\hline 2003 & 8,346 & 102,700 & 10,405 & 75,902 \\
\hline 2004 & 8,515 & 106,114 & 10,141 & 50,749 \\
\hline 2005 & 8,451 & 123,145 & 16,597 & 130,157 \\
\hline 2006 & 8,406 & 122,109 & 16,746 & 129,731 \\
\hline 2007 & 11,167 & 164,782 & 16,321 & 131,665 \\
\hline 2008 & 10,679 & 153,340 & 15,866 & 127,218 \\
\hline 2009 & 10,577 & 151,895 & 16,177 & 126,473 \\
\hline 2010 & 11,004 & 155,218 & 17,057 & 135,412 \\
\hline 2011 & 11,027 & 153,674 & 17,270 & 135,124 \\
\hline 2012 & 11,147 & 148,790 & 17,381 & 131,005 \\
\hline
\end{tabular}

Notes: Number of firms and total employment by year. Data from PIA and PAS.

Figure C.1: Employment over the life cycle

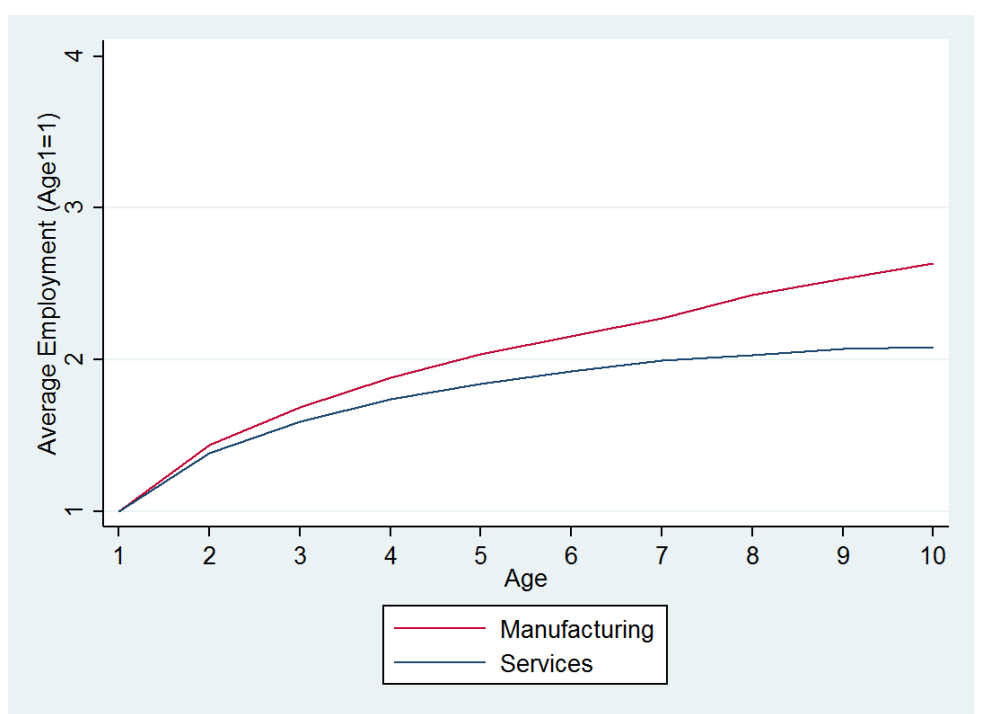

Notes: This figure plots average firm employment by age, for manufacturing and service firms. Firm entry is inferred from when the firm is first observed in the data. Data from RAIS, from 2002 to 2012. 